\title{
Pet Ownership, Attachment, and Well-Being
}

by

Maria Pranschke

A thesis submitted to the Faculty of Graduate and Postdoctoral Affairs in partial fulfillment of the requirements for the degree of

Master of Science

in

Neuroscience

Carleton University

Ottawa, Ontario

(C) 2019

Maria Pranschke 


\begin{abstract}
The present research examined links between attachment to pets and psychological well-being in different populations. Key factors among pet owners that were expected to moderate the relationship between attachment and well-being, notably social connectedness and genetic polymorphisms relating to oxytocinergic functioning, were also explored. Survey responses and saliva samples were gathered from attendees at a pet exhibition (Study 1), members of the public (pet owners and nonowners) at a mall and museum (Study 2), and low-income, marginally housed pet owners (Study 3). Pet owners reported greater quality of life and were more likely to have a polymorphism of the oxytocin receptor gene (rs225429). However, across all three studies, greater attachment to pets was associated with negative psychological wellbeing and the presence of physical health conditions. Overall, findings suggest that pet attachment and its relation to human well-being can differ depending on psychosocial characteristics of pet owners.
\end{abstract}




\section{Acknowledgements}

Over the two years it took to complete this thesis, I relied on the knowledge, guidance, and support of so many members of the Carleton community. First and foremost, I want to thank my supervisor, Dr. Kim Matheson, for taking me on as a master's student and offering her wisdom and encouragement at every stage of the process. Her mentorship was vital in helping me to grow into my own as a researcher. A big thanks also goes to Dr. Hymie Anisman for providing humour and advice in equal measure and being an indispensable resource for the biological aspects of this research. As a member of my advisory committee, Dr. Alfonso Abizaid contributed much appreciated insight and enthusiasm. The support of my lab mates was also crucial, and here I would especially like to thank Dr. Angela Paric for her lab expertise and my fellow master's comrade Mathew Kent for acting as a sounding board and consistent source of

encouragement. The backing of the CHAIM Centre and the Neuroscience department has also been important to my success as a student and the completion of this research. I also want to express my appreciation for the collaboration of Community Vet Outreach, who provided me with both guidance and practical support to gather data with their clientele. Finally, a huge thanks goes out to my friends, my family, and especially my husband Eric for his endless patience and support over the last two years. 


\section{Table of Contents}

Title Page

Abstract .ii

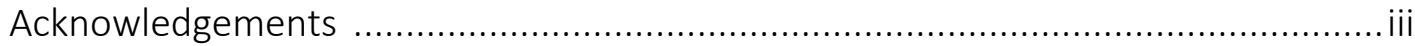

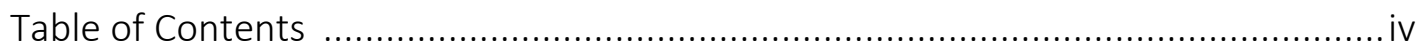

List of Tables and Figures ........................................................................... vi

List of Appendices ............................................................................

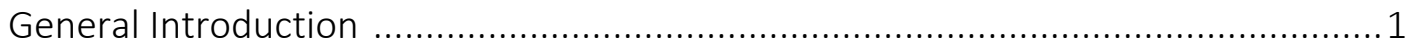

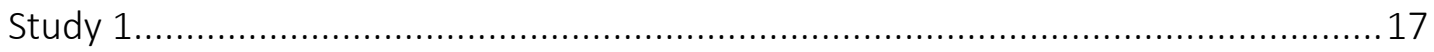

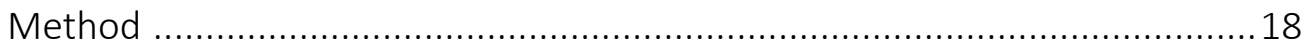

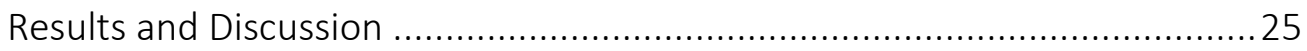

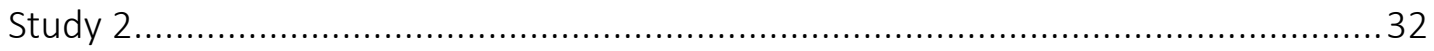

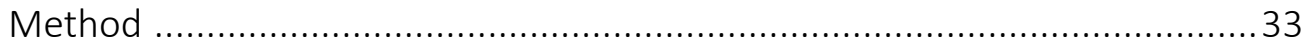

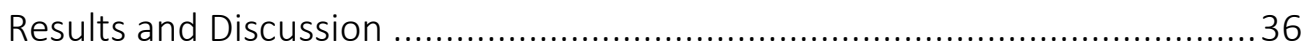

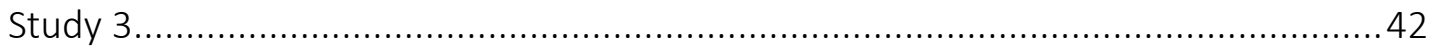

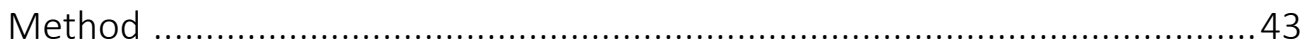

Quantitative Results and Discussion ............................................ 48

Qualitative Results and Discussion ......................................................... 51 


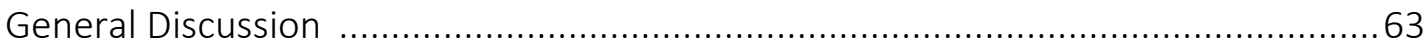

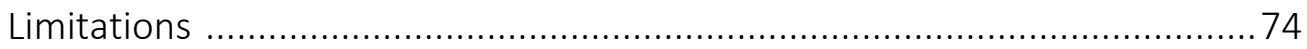

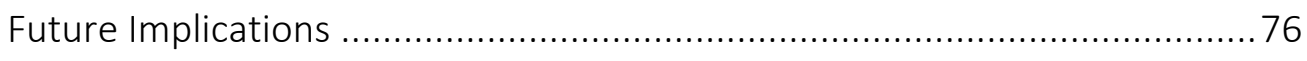

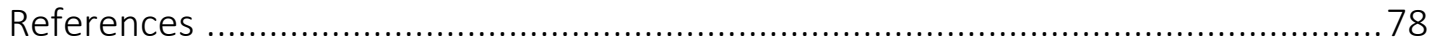

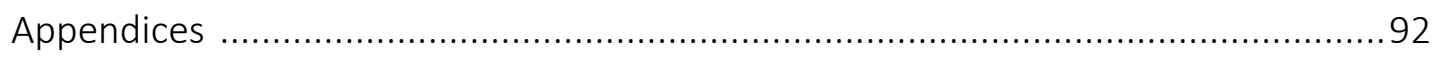




\section{List of Tables and Figures}

\section{Study 1}

Table 1: Participant Demographic Information

Table 2: 2-Tailed Pearson Correlation Coefficients for Demographic, Moderator,

Predictor, and Outcome Variables 26

Table 3: Interaction Term Coefficients \& P-Values for Moderation Analyses

27

Figure 1: Relation Between LAPS GA Subscale and Quality of Life as a Function of the Presence of a Physical Health Condition 29

Figure 2: Relation Between LAPS PS Subscale and Quality of Life as a Function of a Physical Health Condition 29

Table 4: Valid for Oxytocin-Related Genotype Analyses 30

Table 5: Results of Independent T-Tests for Effects of Genotype on Pet Attachment 31

\section{Study 2}

Table 6: Participant Demographic Information 34

Table 7: 2-Tailed Pearson Correlation Coefficients for Demographic, Moderator,

Predictor, and Outcome Variables Among Pet Owners 38

Table 8: Interaction Term Coefficients \& P-Values for Moderation 39 
Figure 3: Relation Between LAPS PS Subscale and Quality of Life as a Function of rs1042778 Genotype

Table 9: Valid for Oxytocin-Related Genotype Analyses

Table 10: Results of Independent T-Tests for Effects of Genotype on Pet Attachment

\section{Study 3}

Table 11: Participant Demographic Information 45

Table 12: 2-Tailed Pearson Correlation Coefficients for Demographic, Moderator,

Predictor, and Outcome Variables Among Pet Owners

Table 13: Mean LAPS Subscale Scores for Studies 1, 2, and 3 50

Table 14: Interaction Term Coefficients \& P-Values for Moderation 51

Table 15: Results of Thematic Analysis of Participant Responses to Qualitative Questions 51 


\section{List of Appendices}

Appendix A: Materials for Study 1

Appendix C: Materials for Study 3 


\section{General Introduction}

The impact of companion animals on human health and well-being has become something of a hot topic over the past decade. At first glance, a substantial body of anecdotal, qualitative, and correlational evidence seems to vindicate the popular belief that pets have a positive influence on our lives, providing considerable benefits to physical and mental health and more than justifying the cost in time and money spent caring for them (Wells, 2009). However, the empirical data evaluating these assertions reveals inconsistent and sometimes contrary results, suggesting a much less straightforward relationship between pet ownership and well-being. Some have cautioned that our understanding of the so-called "pet effect" remains hindered by a wide diversity of study designs and a general lack of scientific rigour (Herzog, 2011). Others have proposed that the degree to which pets impact well-being may vary as a function of key moderating and mediating characteristics of owners (Amiot, Bastian, and Martens, 2016). Variables such as attachment to pets, social connections, and marginalization have been hypothesized to influence the significance and nature of human relationships with companion animals, and the resulting implications for wellbeing. It was the goal of the present research to explore whether bonds with pets promote mental health benefits, and whether these effects vary based on psychosocial characteristics of pet owners.

It was also considered that biological factors might contribute to variations in attachment to animal companions, which in turn might be associated with well-being. 
Investigation into the neurobiological mechanisms behind human-animal interactions has prompted a focus on the role of the neuropeptide oxytocin, whose well-studied impact on human social relationships and stress processes-as well as its apparent overlap with the documented effects of human-animal interaction-make it a promising candidate for granting insight into how bonds with pets may come to impact human well-being (Beetz, Uvnäs-Moberg, Julius, and Kotrschal, 2012). This raises the possibility that genotypes based on well-known mutations of the oxytocin receptor and other genes linked to social behaviours could moderate the relationship between pets and human well-being. Building on existing findings in the areas of human-animal interaction and the neurobiology of human social behaviour, the present research explored the role of pet attachment, social connections, and oxytocinergic processes across different populations (including a group of marginalized pet owners) in order to address the question of how and when relationships with pets might contribute to human well-being.

\section{Pets and Well-being}

Pet ownership (and in particular dog ownership) has been linked to myriad physical health benefits, including lower risk of cardiovascular disease and death (Mubanga et al., 2017), fewer visits to the doctor (Headey and Grabka, 2007), and positive health behaviours such as better sleep and more frequent exercise (Headey, $\mathrm{Na}$, and Zheng, 2008). Pet ownership has also been empirically implicated in positive mental health outcomes in some populations, including improved mood (Turner, Rieger, and Gygax, 2003), lower perceptions of stress (Kertes, Liu, Hall, Hadad, Wynne, and Bhat, 
2017), lower levels of depression (Cheung and Kam, 2017), and less loneliness (Black, 2012; Stanley, Conwell, Bowen, and Van Orden, 2013). In her detailed review of research on pets' impact on health, Wells (2009) suggested several possible mechanisms for how animals might confer benefits to their owners, including the provision of significant attachment bonds and social support, stress reduction, the facilitation of social contact, and an encouragement towards physical activity (this last one again being largely specific to dogs).

Despite these promising relations, not all research has supported a positive link between pets and well-being. Some large-scale studies have failed to replicate significant associations between pet ownership and key aspects of mental and physical health (Wright, Kritz-Silverstein, Morton, Wingard, and Barrett-Connor, 2007; Winefield, Black, and Chur-Hansen, 2008), while other research has suggested that pet owners may actually be less healthy than non-owners in some ways. For example, a study of older adults found that pet owners reported poorer self-rated health status than those who did not own pets (Koivusilta and Ojanlatva, 2006). One proposed explanation for the mixed results is that the samples of pet owners and non-pet owners appear to differ across several health-relevant sociodemographic factors, raising the possibility that researchers may either be over- or under-estimating the impact of pets in some cases based on who is included in their samples (Saunders, Parast, Babey, and Miles, 2017). Further differences may stem from inconsistencies in the way pet ownership is operationalized across studies. For example, some researchers may collect data from owners of all types 
of pets, whereas others focus specifically on the impact of dogs or cats. Similarly, inconsistent conceptions of pet ownership may lead to conflation of experiences between those who actively choose to own and care for animals versus those who merely live with them incidentally.

Nonetheless, the preponderance of positive correlational findings and evident importance of pets in contemporary life indicates that the potential well-being effects of pet ownership are a phenomenon worth investigating, particularly if benefits can be derived for individuals who might otherwise be vulnerable to mental or physical health challenges. However, the inconsistencies in the literature underline a need to be mindful of correlational designs and confounding variables, and the need to provide clear descriptors of populations when reporting results.

While such methodological issues likely account for some of the conflicting results between studies (e.g. Utz, 2014), evidence also points to key moderating factors (such as feelings towards pets and general social functioning) that may be relevant in determining the extent and nature of the impact of pet ownership on well-being. These too may account for some variation of findings (Amiot and Bastien, 2015). The identification and analysis of such interactive factors, rather than broad attempts to determine whether pets are a general panacea for human health, will hopefully lead to a more nuanced understanding of the impact of companion animals. In the following sections, we will explore some of the factors proposed to influence the link between pet ownership and human well-being. 


\section{Attachment to Pets}

Some researchers have suggested that the strength of owners' attachment to their companion animals, rather than merely owning or living with a pet, may be a more relevant determinant of the impact of pets on human well-being (Garrity, Stallones, Marx, and Johnson, 1989; Peacock, Chur-Hansen, and Winefield, 2012). Beyond providing a source of companionship for their owners, pets are perceived by many to be a unique, significant, and nonjudgmental form of social support (Wells, 2009). Researchers have proposed that, as is the case within human relationships, emotional closeness to animals may mediate the degree to which availability of this support impacts health and wellbeing (Johnson, Garrity, and Stallones, 1992). Consistent with this view, pet owners who report being highly attached to their animals perceive them as greater sources of support than those reporting low levels of attachment (Meehan, Massavelli, and Pachana, 2017; Stammbach and Turner, 1999). Measures of attachment may also reflect the general importance that pets have in the lives of their owners, as research on experiences of pet death suggest that the strength of attachment to an animal is linked to the severity of grief among owners (Adams, Bonnett, and Meek, 2000; Field, Orsini, Gavish, and Packman, 2009).

In contrast to the field of human attachment theory, which is generally concerned with qualitatively characterizing attachment styles, standardized animal attachment measures have typically focused on quantifying the level or strength of the self-reported emotional bond (Crawford, Worsham, and Swinehart, 2006). For example, one commonly 
used measure is the Lexington Attachment to Pets Scale (LAPS), which consists of 23 items intended to generate a score representing feelings of affection and emotional closeness to a companion animal. Pet attachment as measured by the LAPS is considered to be multidimensional, with three factors representing General Attachment, People Substituting, and Animals Rights/Welfare (Johnson et al., 1992). Another popular measure, the Pet Attachment Survey (Holcomb, Williams, and Richards, 1985) takes a similar approach to quantifying attachment, with two scales that represent intimacy and relationship maintenance within the owner-pet bond. Research into the role of pet attachment has generally confirmed its importance as a predictor of well-being. However, the relationship between self-reported attachment and well-being has not always been consistent. In two early studies, Ory and Goldberg (1983) found an association between attachment to companion animals and increased happiness among older women, while Garrity et al. (1989) found that greater attachment correlated with reduced symptoms of depression in an elderly population. George, Jones, Spicer, and Budge (1998) similarly found links between attachment to pets and increased mental well-being, but also with increased physical health symptoms. More recent work has found associations between high levels of pet attachment and greater psychological distress (Peacock, Chur-Hansen, and Winefield, 2012). Virtually all this research is correlational, and so in addition to the mixed results, it is unclear whether attachment led to differences in distress, or whether those who were experiencing distress (or not) were more likely to bond more closely with pets. 
Taken together, these results suggest that emotional attachment to companion animals may play a role in mediating the link between pet ownership and certain aspects of well-being, but that the strength and nature of that link may not be consistent across individuals or groups. Such variations may in part reflect the differential effects of moderating factors such as social connectedness and support.

\section{The Role of Social Connections}

As pet owners commonly report that their pets provide benefits in terms of social support and companionship (Wells, 2009), the role of social variables both within and outside of the pet-owner bond has frequently been examined, often in relation to pet attachment. For example, many dog owners report seeking support from their pets in times of emotional distress (Kurdek, 2009). Similar results have been found with cat owners in that many cat-owning participants reported using their pets as sources of emotional support, particularly if their level of attachment to the animal was high (Stammback and Turner, 1999).

Pet ownership and attachment may impact perceptions of loneliness and social connectedness more generally. Research with older adult pet owners found that high pet attachment was associated with lower levels of loneliness (Krause-Parello and Giluck, 2013). Other studies have linked dog ownership in particular with greater frequency of positive social interactions, facilitating contact with neighbours and increasing civic engagement (McNicholas and Collis, 2000; Wood, Giles-Corti, and Bulsara, 2005; Wood et al., 2015). It might be the tendency for pets to promote social connections with other 
humans that accounts for the relationship between pet attachment and lower loneliness, rather than being a direct result of 'pet support' per se.

However, once again, the patterns of relations across studies are mixed.

Moreover, social variables might not only be viewed as potential outcomes of pet ownership, but as factors that may influence attachment to pets and the associated effects on well-being. In the development of the LAPS, higher attachment scores were found among pet owners who reported having fewer social ties (Johnson et al., 1992). These findings were in line with an earlier study involving elderly participants that found that stronger pet attachment was linked to lower levels of illness, but only among those with low availability of human social support. In contrast, among those with high availability of social support, stronger pet attachment was weakly associated with greater levels of illness, suggesting that attachment to pets acts differentially on health outcomes depending on the availability of social support (Garrity et al., 1989).

A more recent investigation of Canadian dog owners living alone similarly suggested that the impact of attachment may differ depending on the availability of human social support. Among respondents with low levels of social support, high attachment predicted greater loneliness and severity of depression, whereas among dog owners with high levels of social support, high attachment predicted less loneliness (Antonacopoulos and Pychyl, 2010). Thus, the findings that social variables such as connectedness to peers and the availability of support appear to moderate associations 
between pet ownership, attachment, and well-being may help to explain some of the inconsistent results among studies probing for a link between pets and health effects.

\section{Experiences of Marginalized and Vulnerable Pet Owners}

Although there is little research directly assessing the implications of pet ownership in marginalized versus non-marginalized populations, a wealth of qualitative evidence attests to the degree of emotional significance and therapeutic benefits that marginalized pet owners attribute to their animals. These findings raise the possibility that experiences of pet ownership among members of marginalized groups may be especially pronounced compared to those of the general population, and that the corresponding links between pet ownership, pet attachment, and well-being, as well as the factors that moderate these links, may differ.

Analysis of interviews with adults diagnosed with Borderline Personality Disorder (BPD) revealed several themes regarding the benefits conferred by pets, including the promotion of social interaction and community engagement, participation in meaningful activities, and the ability to cope with mental illness (Hayden-Evans, Milbourn, and Netto, 2018). Others have suggested that some individuals living with long-term mental illness consider their pets to be primary sources of support for symptom management (particularly when other avenues for support are lacking), providing both distraction from negative experiences and an impetus to keep a routine and stay active (Brooks, Rushton, Walker, Lovell, and Rogers, 2016). Adults living with serious mental illness indicated that pets strengthened feelings of self-efficacy and empowerment while providing 
companionship, empathy, and a conduit for social connection with other people (Wisdom, Saedi, and Green, 2009). Research with pet owners diagnosed with physical illnesses have yielded similar findings. For example, women living with HIV considered their dogs to provide both a sense of purpose and unconditional support in the face of a highly stigmatizing diagnosis (Kabel, Khosla, and Teti, 2015).

While the reported effects on social contact, emotional support, and companionship are in line with findings from research among pet owners in general, the apparent therapeutic and meaning-making effects of pets in marginalized populations may bring about unique outcomes on well-being. A systematic review of research regarding pet ownership among people living with mental illness proposed that bonds with companion animals and associated benefits may be especially salient in this group due to the high rates of isolation and stigmatization that often co-occur with psychiatric diagnoses (Brooks et al., 2018). This hypothesis fits well with the finding that an impoverished support network has been linked to stronger bonds with pets (Johnson et al., 1992).

As a group, people who are homeless or living in marginal/unsafe housing are known to experience both high levels of physical and mental illness and significant stigmatization, isolation, and social exclusion (Schanzer, Dominguez, Shrout, and Caton, 2007; Watson, Crawley, and Kane, 2016). Though limited, evidence suggests that bonds between people and their pets in this population are particularly strong and meaningful, even in the face of considerable stigma and judgment from members of the public 
(Irvine, Kahl, and Smith, 2012). For example, homeless adolescents reported that caring for a dog was a way of reducing feelings of loneliness and experiencing unconditional love, in addition to having practical benefits relating to increased exercise and warmth (Rew, 2000; Rhoades, Winetrobe, and Rice, 2015). At the same time, there are significant barriers relating to pet ownership among this population with the potential to negatively impact well-being; for example, pets may limit housing options and use of other services (Rhoades et al., 2015). Indeed, homeless individuals in Australia raised themes of grief and loss in relation to having to give up pets due to housing issues (Slatter, Lloyd, and King, 2012), while street-involved youth in Canada described significant negative emotional outcomes after losing pets via death, theft, or incarceration (Lem, Coe, Haley, Stone, and O'Grady, 2013).

Despite the apparent challenges associated with pet ownership among those who are homeless or precariously housed, several studies have found higher levels of attachment to pets among such individuals in comparison to the general population (Labrecque and Walsh, 2011), and pet ownership has been found to predict lower symptoms of depression among street-involved youth (Rhoades et al., 2015; Lem, Coe, Haley, Stone, and O'Grady, 2016). It seems that companion animals are perceived to be highly important to members of vulnerable and marginalized groups and may provide unique benefits. However, difficulties associated with caring for pets can also present significant hardship. In this way, the experience of pet owning appears to be multifaceted and qualitatively different for marginalized pet owners. 


\section{The Oxytocin Hypothesis and Stress Reduction}

Close bonds with animals are perceived by many pet owners as a significant basis for social and emotional support, the relevance of which has sometimes been compared to human social connections (Kurdek, 2008). Affiliative behaviours and supportive relations between humans are associated with numerous benefits to physical health and mental well-being, many of which may stem from a protective effect against life stress (Cohen and Wills, 1985; Feder, Nestler, and Charney, 2009). For social mammals, affiliative behaviour and bonding involve the activation of the oxytocinergic system. First popularized as the "love hormone", the neuropeptide oxytocin has since been implicated in a wide variety of human social behaviours, including the creation and maintenance of social connections, social reward, and especially affiliative behaviours, such as intimate physical contact (Light, Grewen, and Amico, 2005) and the provision of social support (Grewen, Girdler, Amico, and Light, 2005). Oxytocin also appears to play a role in reducing anxiety and protecting against the effects of psychosocial stressors through modulation of the hypothalamic-pituitary-adrenal (HPA) axis (Bartz, Zaki, Bolger, and Ochsner, 2011; Brown, Cardoso, and Ellenbogen, 2016). This association between oxytocin signalling and the physiological stress response may be directly relevant to the benefits associated with social support and attachment bonds, as levels of oxytocin appears to interact with social support to diminish stress reactivity (Heinrichs, Baumgartner, Kirschbaum, and Ehlert, 2003). 
The social support role that pets seem to play for some owners has prompted researchers to extend what is known about oxytocin from research on human relationships (i.e., promoting affiliative behaviour and buffering against stress) to understanding bonds with animals. In this regard, it has been proposed that at least some of the positive effects associated with pet ownership may be mediated through oxytocinergic processes (Beetz et al., 2012). A number of studies have demonstrated that positive interactions with dogs can lead to short-term rises in peripheral oxytocin, reduced heart rate, and lowered cortisol levels (Handlin et al., 2011; Odendaal and Meintjes, 2003). One study comparing the effects of interacting with dogs to a quiet reading period found that among female participants, oxytocin levels rose more in the former group than the latter. Interestingly, men in both conditions displayed a decrease in oxytocin over the course of measurement, although this decrease was less pronounced in the dog interaction condition (Miller et al., 2009). Though preliminary, these results suggest that interacting with a pet can affect both oxytocin levels and stress parameters in humans, thus presenting a plausible mechanism by which pets could influence aspects of health and well-being in their owners.

This hypothesis is further bolstered by positive findings from research exploring the impact of animals on both subjective and biological measures of stress in experimental settings. An assessment of the effects of interacting with animals on stress parameters during the Trier Social Stress Test (TSST), a robust social stressor, found that adult participants paired with a novel dog demonstrated an attenuated cortisol response 
and lower heart rate than those paired with a human friend for social support (Polheber and Matchock, 2013). In children, a study using an adapted version of the TSST found that the presence of a family dog significantly reduced reported stress compared to the presence of a parent (Kertes et al., 2017). Similarly, a positron-emission tomography (PET) study demonstrated that having a pet dog present during scanning led to reduced activity in regions associated with stress perceptions and autonomic arousal in healthy adults (Sugawara et al., 2012).

It should be noted that although it might provide valuable insights into neurobiological processes, directly measuring oxytocin levels in human participants can present considerable practical and ethical challenges to the research process. Analysis of extracted plasma samples using radioimmunoassay (RAI) is generally considered to be a valid method of measurement, but blood sampling may be overly intrusive and impractical for use with certain populations, particularly those considered to be vulnerable. Less intrusive methods such as saliva analysis appear to correspond only weakly with plasma measurements, and urinary analysis is even less promising (McCullough, Churchland, and Mendez, 2013). Further, the degree to which peripheral oxytocin correlates meaningfully with central oxytocin levels remains unclear, limiting interpretation of peripheral results (Valstad et al., 2017). For this reason, alternative approaches to investigating the roles of oxytocin within the context of the owner-pet relationship were considered. 
One promising avenue to explore the impact of oxytocin and other chemical transmitters involves genetic analysis, specifically the examination of single-nucleotide polymorphisms (SNPs). The oxytocin receptor gene (OXTR) has several well characterized SNPs that have been studied in detail in relation to social behaviour (Tops, Habel, and Radke, 2018), empathy (Wu, Li, and Su, 2012), and stress reactivity (Rodrigues, Saslow, Garcia, John, and Keltner, 2009). Research has linked the rs53576 SNP, a silent G to A substitution located on the third intron of OXTR, to differences in emotional stability (Massey-Abernathy, 2017) and general sociality (Li, Zhao, Li, Broster, Zhou, and Yang, 2015). Experimental evidence suggests that carriers of the major $\mathrm{G}$ allele may be more likely to benefit from social support (Chen et al., 2011); this is in line with data showing that $\mathrm{G}$ allele carriers reported a greater tendency to seek out support from others when distressed (Kim et al., 2010). Among married individuals, those with the GG genotype reported greater satisfaction with their relationships, a link that appeared to be mediated by greater attachment security (Molin, Goktas, Kershaw, \& DeWan, 2019). At the same time, it has been suggested that the G allele may confer an overall heightened sensitivity to social cues, resulting in greater vulnerability to the negative impacts of social ostracism and rejection by peers (McQuaid, Mclnnis, Matheson, and Anisman, 2015).

Given the intimate nature of relationships with companion animals and their purported roles as providers of nonjudgmental emotional support, the possible relevance of these and other socially linked SNPs to the human-animal bond presents a new and potentially illuminating area of research. A recent study conducted with dog owners 
found significant associations between SNPS of the OXTR gene in humans, including rs53576, rs1042778, and rs2254298, and the animals' performance on several behavioural measures intended to assess attachment to their owners (Kovacs et al., 2018). The authors suggested that genetic variation in the oxytocinergic system might influence individuals' behaviour towards their pets, thereby making the dogs more responsive. At time of writing, the possible role of these and other SNPs relevant to the oxytocin system as moderators of the relationship between pets and well-being had yet to be investigated.

To explore the effects of pet ownership and attachment to pets with a view to assessing the moderating roles of social connectedness and oxytocin-related genotype, three separate studies were conducted with distinct populations. In the first study, data were collected from attendees at a pet-related event in order to test predictions in a large, highly motivated pet-owning sample. In the second study, data were collected from pet owning and non-owning individuals at two public locations (a shopping mall and a museum) to bolster sample size for genetic analyses, access a more varied group of pet owners, and allow for comparisons with non-owners on measures of well-being. Finally, Study 3 replicated the research protocol with a sample of marginalized (low-income and precariously housed) individuals, with the addition of qualitative measures to provide further insight into results with this unique group. 


\section{Study 1}

The objective of Study 1 was to assess the relationship between attachment to pets and well-being, and to explore the moderating role of social connectedness and polymorphisms related to oxytocinergic functioning. The sample surveyed consisted of members of the public attending a weekend pet exhibition, thus attracting individuals who likely hold a strong identity as pet enthusiasts. Because of this, it was expected that participants would be relatively homogenous, with high levels of motivation for participating in pet-related research and high levels of attachment to their animals. The following hypotheses were tested:

- Strength of attachment to pets would be associated with positive well-being (lower depressive symptomology, less loneliness, and greater quality of life)

- Self-reported social connectedness would moderate the relationship between attachment to pets and well-being. At lower levels of social connectedness, more negative associations between attachment and well-being would be evident, whereas more positive associations between attachment and well-being would exist at higher levels of social connectedness

- Carriers of alleles thought to confer more effective/sensitive oxytocinergic functioning (i.e., GG carriers of the rs53576 OXTR polymorphism) would report higher levels of overall pet attachment. In addition to this main effect, it was expected that GG carriers would demonstrate stronger positive relationships between attachment and the indices of well-being, relative to AA/AG carriers. 


\section{Method}

Procedure. To recruit participants, the research team rented a booth at the Ottawa Pet Expo for 2 days in November of 2017. Signage advertising the study was displayed at the booth. Participants were recruited based on voluntary interest while circulating at the exhibition. Participation criteria required that individuals be over 18 , able to speak and understand English, and be a current pet owner. Those who expressed interest were given an informational handout with a brief description of the study and listened to a verbal recruitment script with added details about the research protocol.

Participants were assigned a unique numeric code and completed the questionnaire portion of the study on a laptop computer using the Qualtrics online platform. An informed consent document was presented at the start of the Qualtrics process, and after agreeing to proceed, participants were administered a series of questionnaires. The questionnaires consisted of a background information section as well as measures of pet attachment, social connectedness, quality of life, loneliness, and depressive symptoms. Two other measures were also included (rumination: Matheson \& Anisman, 2003; resilience: Campbell-Sills \& Stein, 2007), but as no consistent significant associations were found with these variables and there were no specific hypotheses regarding their role with respect to pet attachment, analyses involving them were not reported.

Following completion of the questionnaires, participants were asked to provide a saliva sample for SNP genotyping. Saliva samples were collected using individual DNA 
Collection and Preservation Devices from Norgen Biotek Corp. Tubes were labelled with each participant's numeric code in order to match genetic data to questionnaire responses for analysis. Upon completion of the study, participants received a written debriefing document and a treat bag for their dog or cat (valued at \$5) as a thank-you for participating.

DNA was isolated from saliva samples using a spin column procedure and reagents from Norgen Biotek Saliva DNA Isolation Kits. Following isolation, samples were plated and shipped to Génome Québec for SNP determination using Sequenom ${ }^{\circledR}$ iPLEX ${ }^{\circledR}$ Gold technology. The procedures for this study were approved by the Carleton University Research Ethics Board B (CUREB-B Clearance \#: 107984) and the Carleton Biohazards Committee. See Appendix A for materials used in Study 1.

Participants. The sample comprised 103 adult pet-owning participants who were primarily Euro-Caucasian non-single females (Table 1). Income levels were relatively high. Cross-tabulation of reported health conditions revealed that $42(40.8 \%)$ individuals reported no current health condition, whereas 33 (32.0\%) reported having either a physical or mental health condition, and 23 (22.3\%) reported having both. Levels of depressive symptoms were relatively high, with $36.9 \%(n=38)$ of individuals meeting diagnostic threshold for depression using the 10-item short-form of the CES-Depression Scale (i.e., scored higher than 10 on the 0 to 30 range). Over two-thirds of participants indicated having a dog (69.9\%), whereas just over half of the sample had a cat (56.3\%). 
Table 1

Participant Demographic Information for Study 1

\begin{tabular}{|c|c|}
\hline Variable & Mean (SD) or Count (\%) \\
\hline & Total $\mathrm{N}=103$ \\
\hline Age & $38.07(S D=13.982)$ \\
\hline \multicolumn{2}{|l|}{ Gender } \\
\hline Female & $75(72.8 \%)$ \\
\hline Male & $25(24.3 \%)$ \\
\hline Other & $3(2.9 \%)$ \\
\hline \multicolumn{2}{|l|}{ Ethnicity } \\
\hline Caucasian & $88(85.4 \%)$ \\
\hline Asian & $4(3.9 \%)$ \\
\hline Indigenous & $4(3.9 \%)$ \\
\hline Latin American & $1(0.97 \%)$ \\
\hline Mixed or other & $6(5.8 \%)$ \\
\hline \multicolumn{2}{|l|}{ Income Level } \\
\hline$<\$ 15,000-\$ 29,999$ & $17(16.5 \%)$ \\
\hline$\$ 30,000-\$ 59,999$ & $19(18.4 \%)$ \\
\hline$\$ 60,000-\$ 89,999$ & $17(16.5 \%)$ \\
\hline$\$ 90,000-\$ 105,000+$ & $32(31.1 \%)$ \\
\hline \multicolumn{2}{|l|}{ Relationship Status } \\
\hline Dating/in a relationship & $82(79.6 \%)$ \\
\hline Single & $21(20.4 \%)$ \\
\hline \multicolumn{2}{|l|}{ Physical Health (PH) Status } \\
\hline $\mathrm{PH}$ condition & $43(41.7 \%)$ \\
\hline No PH condition & $55(53.4 \%)$ \\
\hline \multicolumn{2}{|l|}{ Mental Health (MH) Status } \\
\hline MH condition & $38(36.9 \%)$ \\
\hline No MH condition & $62(60.2 \%)$ \\
\hline \multicolumn{2}{|l|}{ Type of Pet } \\
\hline Dog & $43(41.7 \%)$ \\
\hline Cat & $29(28.2 \%)$ \\
\hline Both dog and cat & $29(28.2 \%)$ \\
\hline Other type of pet only & $2(1.9 \%)$ \\
\hline
\end{tabular}

\section{Measures.}

Background information. Participants answered questions about their ethnicity, age, gender, relationship status, income, and general health status, including whether they currently had a physical or mental health condition. Questions about number and type of pets currently owned were also included in this section. 
Attachment to pets. Strength of attachment to pets was measured using the Lexington Attachment to Pets Scale (LAPS; Johnson, Garrity, and Stallones, 1992). Respondents used a 4-point Likert scale ranging from 0 'Strongly Disagree' to 3 'Strongly Agree' to rate their agreement with 23 statements measuring emotional closeness and affection towards their favourite pet; a Don't Know/Refuse to Answer option was also offered, and was coded as missing.

The LAPS contains 3 subscales representing factors of General Attachment, People Substituting, and Animals Rights/Welfare. The General Attachment subscale contains 11 items (e.g., "My pet and I have a very close relationship") while the People Substituting subscale contains 7 items (e.g., "Quite often I confide in my pet") and the Animal Rights/Welfare subscale contains 5 (e.g., "Pets deserve as much respect as humans do"). Mean scores for each dimension were calculated, reverse scoring where appropriate.

The General Attachment and People Substituting subscales were selected for analysis in the present study due to high reliability ( $\alpha=.82$ for both) and their theoretical relevance to the research question; the Animal Rights/Welfare subscale displayed lower reliability, particularly given the number of items included $(\alpha=.72)$ and was less relevant to hypotheses, and so was not included in analyses.

Depressive symptoms. Depressive symptoms were measured using the CESD-R-10 (Andresen, 1994). Respondents rated the frequency of experiencing a given behaviour or emotion over the past week (e.g., "I felt everything I did was an effort") on a 4-point scale 
from 0 'Rarely or None of the Time' to 3 'All of the Time'. Total scores were calculated by summing (reverse scoring where appropriate) across all items, and missing data were replaced by participant's mean response $(\alpha=.88)$. Scores could range from 0 to 30 . When used for diagnostic purposes, a score of 10 or higher indicates that the individual merits further diagnostic consideration for depression.

Social connectedness. Social connectedness was measured using a short form of the Social Connectedness Scale (SCS-15) developed by Lee, Draper, and Lee (2001). Using a 6-point Likert scale ranging from 1 'Strongly Disagree' to 6 'Strongly Agree,' respondents rated their agreement with 15 statements intended to measure feelings of psychological belonging and connectedness to peers (e.g., "I feel understood by the people I know"). Mean item responses were calculated (reverse scoring where appropriate), with higher scores reflecting greater perceived social connectedness ( $\alpha=$ .93).

Quality of life. A single-item quality of life measure was drawn from a larger battery developed by Revicki, Turner, Brown, and Martindale (1992) originally designed to assess the effectiveness of depression treatment on outpatients' quality of life. Respondents selected a number from 1 'Completely Dissatisfied' to 10 'Completely Satisfied' to represent their overall life satisfaction.

Loneliness. Feelings of loneliness were assessed using a 3-item scale developed by Hughes, Waite, Hawkley, and Cacioppo (2004). Respondents used a 3-point scale ranging from 1 'Hardly Ever' to 3 'Often' to rate the frequency with which each question applied 
(e.g., "How often do you feel that you lack companionship?"). Total scores were calculated by summing across the three items and missing data were replaced by participant's mean response $(\alpha=.86)$. Scores could range from 3 to 9.

Genotype. Following DNA isolation and plating, participant saliva samples were assayed for the determination of three polymorphisms of the oxytocin receptor gene (OXTR; rs1042778, rs2254298, and rs53576) and one polymorphism of the CD38 gene, which codes for a transmembrane protein known to regulate oxytocin release in the central nervous system (rs3796863). Distributions of genetic polymorphisms are known to vary significantly across ethnic groups (Risch, 2000), and the role oxytocin-related SNPs play in determining behavioural and psychological tendencies also appear to differ as a function of culture, with particularly marked differences emerging in Asian populations. For example, the $\mathrm{G}$ allele of the rs53576 SNP has been implicated in support-seeking behaviour in Caucasian, but not Korean individuals (Kim et al., 2010). To control for this expected variation while preserving sample size, genetic analyses in the present investigation were restricted to participants of non-Asian backgrounds. Results of any genotype-related analyses should be considered strictly exploratory given the limited number of samples collected.

Statistical Analysis. Statistical analyses were performed using IBM SPSS Statistics 25 (SPSS Science, Chicago, IL, USA). Significance was determined at the $p<.05$ level for all analyses. Bivariate correlations were undertaken to detect associations between wellbeing measures (CESD-R-10 depression, loneliness, and quality of life) and LAPS 
dimensions of General Attachment and People Substituting. In order to check for the presence of confounding variables, the relationships between attachment and certain demographic factors (gender, age, income, and the presence of physical or mental health conditions) were assessed by means of t-tests or correlations, as appropriate; any variables with significant links to both attachment and well-being indices were controlled via linear regression when testing for associations between attachment and well-being. T-tests were also conducted to detect direct relations between genotype and pet attachment. Finally, the PROCESS macro for SPSS (Model 1, Hayes \& Preacher, 2013) was used to assess the moderating roles of social connectedness and genotype on the associations between pet attachment and well-being measures, followed by simple slopes analyses when the interactions were significant. Due to their associations with attachment scores in the present study and their reported significance in the humananimal interaction literature, gender and the presence of physical or mental illness were also explored as potential moderators alongside social connectedness and oxytocinrelated genotype.

Prior to conducting statistical analyses, standardized scores for all measures of interest were generated to detect the presence of outlying data points (determined at a threshold of +/-3.29 SD). To ensure they did not exert undue influence in our analyses while preserving sample size, the raw scores of any observations flagged as outliers were adjusted to bring them into the $+/-3.29$ SD range. 


\section{Results and Discussion}

\section{Associations between demographic variables, pet attachment, and well-being. To}

determine whether demographic variables should be included as covariates, their relations to the predictor and outcome variables of interest were assessed. As seen in

Table 2, while age and income level did not predict General Attachment scores, endorsement of the People Substituting dimension was more likely among younger and lower income participants. Females $(M=2.71, S D=0.30)$ reported somewhat higher levels of General Attachment than their male counterparts $(M=2.55, S D=0.41), t(97)=$ 2.09, $p=.039, \eta^{2}=.043$, as well as higher levels of People Substituting $(M=2.27, S D=$ 0.58 for females, $M=1.93, S D=0.70$ for males) $, t(97)=2.40, p=.018, \eta^{2}=.056$. In addition, higher General Attachment was found among those participants who indicated a physical health condition $(M=2.74, S D=0.31)$ than among those who reported no such conditions $(M=2.60, S D=0.34), t(95)=-2.13, p=.036, \eta^{2}=.045 ;$ a similar pattern approached significance for the People Substituting dimension of the LAPS $\left(p=.079, \eta^{2}=\right.$ .032). By contrast, there was no significant difference in either pet attachment subscale as a function of having a mental health condition. Having a physical or mental health condition was also associated with well-being measures, and was explored further in later analyses.

Income level was also significantly and positively related to quality of life, and as such represented a potential confounding factor in the relationship between the People Substituting subscale and this particular well-being outcome. 
Table 2

2-Tailed Pearson Correlation Coefficients for Demographic, Moderator, Predictor, and Outcome Variables (Study 1)

\begin{tabular}{l|ccccccc} 
& Age & Income level & CESD-R-10 & QoL & Loneliness & SCS-15 & LAPS GA \\
\hline Age & - & - & - & - & - & - & - \\
Income level & $.32 * *$ & - & - & - & - & - & - \\
CESD-R-10 & -.16 & -.16 & - & - & - & - & - \\
QoL & -.02 & $.29 * *$ & $-.70^{* *}$ & - & - & - & - \\
Loneliness & -.05 & -.11 & $.63^{* *}$ & $-.53^{* *}$ & - & & - \\
SCS-15 & .07 & .14 & $-.52^{* *}$ & $.54^{* *}$ & $-.61^{* *}$ & - & - \\
LAPS GA & -.10 & -.11 & .17 & -.16 & -.00 & .04 & - \\
LAPS PS & $-.21^{*}$ & $-.26^{*}$ & $.20^{*}$ & -.18 & .16 & -.11 & $.55^{* *}$ \\
\hline
\end{tabular}

Contrary to hypotheses, higher scores on the People Substituting dimension of the LAPS were associated with higher levels of depression. No significant associations were found between either attachment subscale and quality of life (even when controlling income, partial $r=-.09, p=.430)$, loneliness, or social connectedness. Although we had predicted that pet attachment would promote well-being, links between higher attachment and psychological distress have been reported in other research (Peacock et al., 2012). While the correlational nature of this study did not allow us to test the directionality of these associations, it is possible that depressed individuals were more likely to turn to their pets (rather than people) for comfort.

Moderation analyses. Analyses were undertaken to assess the potential moderating roles of social connectedness, the presence of physical or mental health conditions, gender, and genotype on the relationship between dimensions of pet attachment and the well-being measures. Continuous variables were mean centred prior to calculating the cross-products (interactions). Given the direct associations were 
reported in the correlational analyses, results for the interaction terms only are displayed in Table 3.

Table 3

Interaction Term Coefficients and P-Values for Moderation Analyses (Study 1)

\begin{tabular}{|c|c|c|c|c|c|c|c|c|c|}
\hline \multirow[b]{3}{*}{ Interaction term: } & \multicolumn{9}{|c|}{ Outcome Variable: } \\
\hline & \multicolumn{3}{|c|}{ CESD-R-10 } & \multicolumn{3}{|c|}{ Quality of Life } & \multicolumn{3}{|c|}{ Loneliness } \\
\hline & $N$ & $B$ & Sig. & $N$ & $B$ & Sig. & $N$ & $b$ & Sig. \\
\hline \multicolumn{10}{|l|}{ General Attachment } \\
\hline *SCS-15 & 100 & 0.20 & .195 & 100 & -0.03 & .542 & 100 & 0.05 & .238 \\
\hline *PH cond. & 95 & -0.43 & .209 & 96 & 0.26 & $.022^{*}$ & 95 & -0.08 & .453 \\
\hline *MH cond. & 97 & -0.38 & .234 & 98 & 0.17 & .145 & 97 & -0.06 & .554 \\
\hline *Gender & 97 & -0.01 & .972 & 97 & -0.01 & .942 & 97 & 0.16 & .127 \\
\hline *rs53576 & 73 & 0.24 & .525 & 74 & 0.07 & .555 & 73 & -0.14 & .266 \\
\hline *rs1042778 & 74 & 0.13 & .736 & 75 & -0.20 & .130 & 74 & 0.21 & .096 \\
\hline *rs2254298 & 67 & -0.66 & .208 & 68 & 0.16 & .373 & 67 & -0.16 & .345 \\
\hline \multirow[t]{3}{*}{ *rs3796863 } & 73 & 0.17 & .660 & 74 & -0.02 & .868 & 73 & 0.05 & .685 \\
\hline & \multicolumn{3}{|c|}{ CESD-R-10 } & \multicolumn{3}{|c|}{ Quality of Life } & \multicolumn{3}{|c|}{ Loneliness } \\
\hline & $N$ & $B$ & Sig. & $N$ & B & Sig. & $N$ & $B$ & Sig. \\
\hline \multicolumn{10}{|l|}{ People Substituting } \\
\hline$*$ SCS-15 & 101 & 0.12 & .375 & 101 & -0.04 & .338 & 101 & 0.04 & .365 \\
\hline *PH cond. & 96 & -0.46 & .098 & 97 & 0.26 & $.004 * *$ & 96 & -0.09 & .314 \\
\hline *MH cond. & 98 & -0.51 & .053 & 99 & 0.15 & .109 & 98 & -0.02 & .850 \\
\hline *Gender & 98 & 0.14 & .653 & 98 & 0.01 & .914 & 98 & 0.16 & .088 \\
\hline *rs53576 & 73 & -0.13 & .696 & 74 & -0.05 & 649 & 73 & -0.08 & .439 \\
\hline *rs1042778 & 74 & -0.11 & .753 & 75 & -0.05 & .674 & 74 & -0.07 & .539 \\
\hline *rs2254298 & 67 & 0.60 & .199 & 68 & -0.05 & .782 & 67 & 0.15 & .322 \\
\hline *rs3796863 & 73 & -0.02 & .952 & 74 & -0.05 & .656 & 73 & 0.05 & .662 \\
\hline
\end{tabular}

As seen in Table 3, of the moderators explored, only physical health condition interacted significantly with dimensions of attachment to predict well-being, specifically quality of life. Simple slopes analysis (see Figure 1) indicated that when no physical health condition was present, greater General Attachment to pets was associated with lower quality of life $(b=-0.16, p=.028)$, whereas this negative association was not evident 
among those who did report having a physical health condition $(b=0.10, p=.241)$.

Similarly, as seen in Figure 2, greater levels of People Substituting predicted lower quality of life for those without physical health conditions $(b=-0.17, p=.005)$, while there was no significant association with quality of life when a physical health condition was present $(b=0.09, p=.183)$. In both instances, at lower levels of pet attachment, the presence of a physical condition predicted lower quality of life $(b=-2.00, p=.001$ for General Attachment, $b=-2.22, p<.001$ for People Substituting) whereas when attachment was high, the presence of a physical condition did not appear to affect quality of life $(b=$ 0.09, $p=.872$ for General Attachment, $b=0.08, p=.888$ for People Substituting).

The interaction between People Substituting and the presence of a mental health condition in predicting CESD-R-10 score also approached significance. When no mental health condition was reported, People Substituting predicted higher depression scores ( $b$ $=0.36, p=.016)$ whereas for those reporting a mental health condition, no such significant link existed $(b=-0.14, p=.503)$. Given the number of analyses conducted, this effect (and others) could well be due to chance. 
Figure 1

Relation Between LAPS GA Subscale and Quality of Life as a Function of the Presence of a Physical Health (PH) Condition

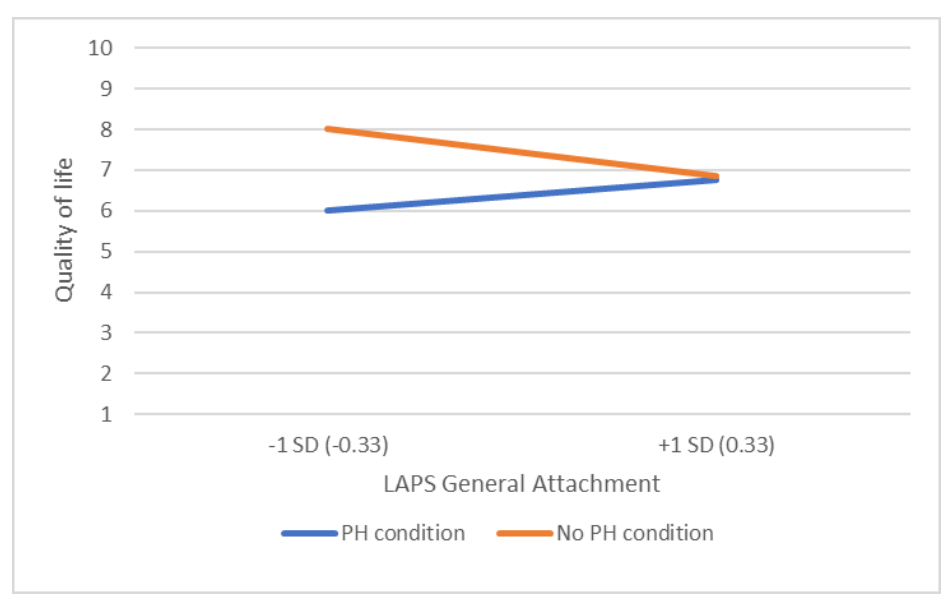

Figure 2

Relation Between LAPS PS Subscale and Quality of Life as a Function of the Presence of a Physical Health (PH) Condition

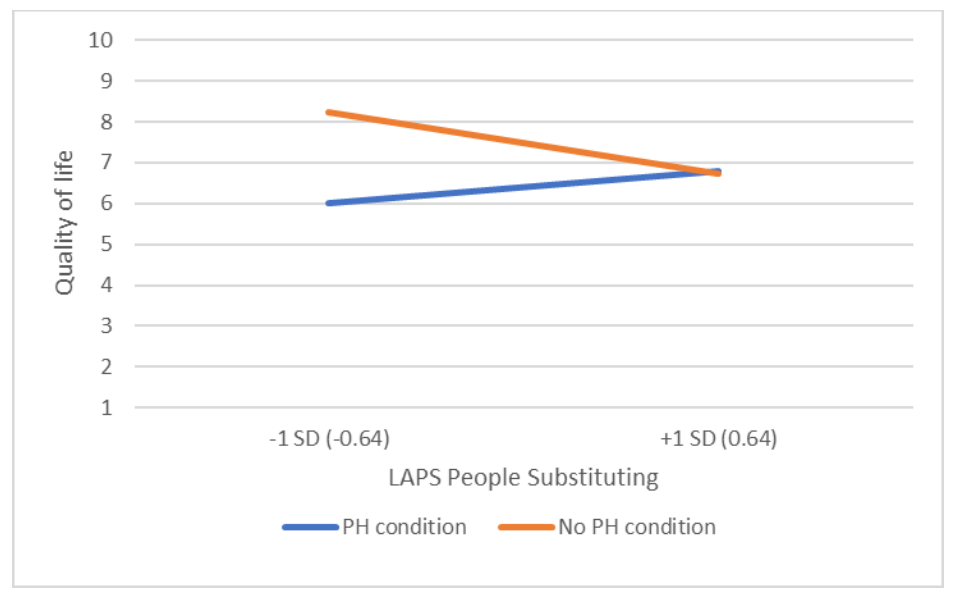

Thus, it appeared that the link between pet attachment and certain aspects of well-being varied as a function of some characteristics of the owner, but surprisingly, not others, such as gender and level of social connectedness. In particular, the link between physical health issues and quality of life in the present study varied as a function of strength of attachment, suggesting that strong bonds with pets may provide some protective well-being-related effects for individuals with physical conditions. However, 
bearing in mind the large number of analyses conducted, this finding should be viewed as preliminary and requiring replication.

Direct effects of genotype on attachment. Due to the limited number of participants with homozygous minor alleles for each of the four SNPs under study, the decision was made to group them with heterozygous participants for the purposes of statistical analysis, an approach that is consistent with previous research involving polymorphisms of the oxytocin receptor gene (McQuaid et al., 2015). Distributions of allelic variations for the four SNPs are presented in Table 4. Note that assays for certain polymorphisms failed for some samples, resulting in a lower $n$ for some SNPs.

Table 4

Valid for Oxytocin-Related Genotype Analyses (Study 1)

\begin{tabular}{l|ccccc} 
SNP: & Homo (major) & Hetero & Homo (minor) & $\boldsymbol{N}$ & Split in file \\
\hline rs53576 (OXTR) & GG: 36 & AG: 30 & AA: 8 & 74 & GG vs AG/AA \\
rs1042778 (OXTR) & GG: 30 & GT: 39 & TT: 6 & 75 & GG vs GT/TT \\
rs2254298 (OXTR) & GG: 51 & AG: 16 & AA: 1 & 68 & GG vs AG/AA \\
rs3796863 (CD38) & CC: 37 & AC: 26 & AA: 11 & 74 & CC vs AC/AA
\end{tabular}

Contrary to expectations, independent samples t-tests did not reveal any significant differences in pet attachment as a function genotype (see Table 5). 
Table 5

Results of Independent T-Tests for Effects of Genotype on Pet Attachment (Study 1)

\begin{tabular}{|c|c|c|c|c|c|}
\hline \multicolumn{6}{|c|}{ rs53576 (OXTR) } \\
\hline & GG Mean $(S D)$ & AG/AA Mean $(S D)$ & $T$ & Sig. & $\eta^{2}$ \\
\hline LAPS GA & $29.86(3.50)$ & 28.94 (3.99) & 1.05 & .300 & .015 \\
\hline LAPS PS & $15.33(4.46)$ & $15.32(4.07)$ & 0.01 & .995 & .000 \\
\hline \multicolumn{6}{|c|}{ rs1042778 (OXTR) } \\
\hline & GG Mean $(S D)$ & GT/TT Mean (SD) & $T$ & Sig. & $\eta^{2}$ \\
\hline LAPS GA & $28.99(3.63)$ & $29.61(3.84)$ & -0.69 & .491 & .007 \\
\hline LAPS PS & 14.85 (3.72) & $15.74(4.55)$ & -0.89 & .375 & .011 \\
\hline \multicolumn{6}{|c|}{ rs2254298 (OXTR) } \\
\hline & GG Mean $(S D)$ & AG/AA Mean $(S D)$ & $T$ & Sig. & $\eta^{2}$ \\
\hline LAPS GA & 28.95 (3.98) & $29.51(3.11)$ & -0.52 & .603 & .004 \\
\hline LAPS PS & $15.02(4.49)$ & $14.92(3.43)$ & 0.08 & .931 & .000 \\
\hline \multicolumn{6}{|c|}{ rs3796863 (CD38) } \\
\hline & CC Mean $(S D)$ & AC/AA Mean $(S D)$ & $T$ & Sig. & $\eta^{2}$ \\
\hline LAPS GA & $29.45(3.45)$ & $29.17(4.05)$ & 0.32 & .747 & .001 \\
\hline LAPS PS & $15.56(4.22)$ & $15.09(4.29)$ & 0.47 & .639 & .003 \\
\hline
\end{tabular}

None of the four polymorphisms were significantly related to indices of well-being (depression, loneliness, or quality of life). However, the CD38 SNP was predictive of mental health status such that carriers of the A allele were more likely to report a current mental health condition, $X^{2}(1, N=79)=5.79, p=.016, \phi=.27$.

Recent research has provided preliminary evidence that the rs2254298

polymorphism may play a role in determining affective reactions to animals, with carriers of the $\mathrm{G}$ allele reporting greater levels of empathy towards animals (Connor, Lawrence, and Brown, 2018; Daly and Morton, 2006). It may be that the limited sample size 
hindered the detection of any such effects, although effect sizes for genotype in the present study were also small ${ }^{1}$.

\section{Study 2}

In Study 2, our intention was to replicate the results of Study 1 with a more diverse sample of pet owners (i.e., compared to those who attend pet expos), to increase the sample size of pet owners to allow for greater statistical power for combined genetic analysis, and to gather data from non-pet owners as a comparison group on questions of well-being. Given that the data collection locations (a mall and a museum) were not specific to individuals with an interest in pets, it was expected that the sample in Study 2 would be somewhat more heterogeneous than in Study 1, with greater variation of attachment among pet owners.

The same hypotheses reported in Study 1 were tested in Study 2, with two additions:

- Pet ownership would be associated with greater well-being; specifically, pet owners would report lower levels of depressive symptoms, less loneliness, and higher quality of life than those who do not own pets.

- Oxytocin-related genotype would predict pet ownership; specifically, individuals with genotypes thought to confer more sensitive oxytocinergic functioning, such

\footnotetext{
${ }^{1}$ Direct effects of oxytocin-related genotypes on pet attachment were also analyzed in a combined file containing data from pet-owning participants across all three studies $(N=161)$; despite increased statistical power, no significant associations were found.
} 
as the GG genotype of the rs53576 polymorphism, would be more likely to own pets.

\section{Method}

Procedure. The research team was provided with table space at a local mall in order to recruit and gather data from members of the public over two 3-day periods, as well as at a local museum for a 2-day period. The same questionnaire and biological data collection protocol was followed as in Study 1, with informed consent and questionnaires being administered online for most participants. Following the first series of data collection days, the option of completing the informed consent and questionnaires by hand was added to encourage the participation of older members of the public and those not familiar with computer use. Non-pet owners were routed past pet-related questions. Instead of treat bags for animals, chocolate bars were provided to non-pet owners as thanks for their participation. The procedures for this study were approved by the Carleton University Research Ethics Board B (CUREB-B Clearance \#: 107984) and the Carleton Biohazards Committee. See Appendix B for materials used in Study 2.

Participants. A total of 164 adult participants were recruited, with most of the data collected at the mall location. As shown in Table 6, participants were predominantly Euro-Caucasian, female, and in a relationship; however, the average age of participants was 47.14 years $(S D=18.39)$, notably higher than in the pet expo study. Once again, the majority indicated having a physical or mental illness; 69 (42.1\%) participants reported no health conditions, whereas $52(31.7 \%)$ reported having either a physical or health 
condition and $32(19.5 \%)$ reported both. Levels of depressive symptoms were relatively high, with 74 (45.1\%) individuals meeting the CESD-R-10 diagnostic threshold. Most pet owners reported dog and/or cat ownership, with equal numbers of each in the combined sample.

Table 6

Participant Demographic Information for Study 2

\begin{tabular}{|c|c|c|c|c|}
\hline \multirow[t]{4}{*}{ Demographic variable } & \multicolumn{4}{|c|}{ Mean (SD) or count (\%) } \\
\hline & \multicolumn{2}{|c|}{ Mall location $(N=119)$} & \multicolumn{2}{|c|}{ Museum location $(N=45)$} \\
\hline & $\begin{array}{c}\text { Pet owners } \\
n=59\end{array}$ & $\begin{array}{c}\text { Non-pet owners } \\
n=60\end{array}$ & $\begin{array}{c}\text { Pet owners } \\
n=26\end{array}$ & $\begin{array}{c}\text { Non-pet owners } \\
n=19\end{array}$ \\
\hline & $45.92(19.86)$ & $54.03(18.79)$ & 40.38 (11.69) & $38.79(12.07)$ \\
\hline $\begin{array}{l}\text { Gender } \\
\text { Female } \\
\text { Male } \\
\text { Other } \\
\end{array}$ & $\begin{array}{c}37(62.7) \\
21(35.6) \\
1(1.7)\end{array}$ & $\begin{array}{c}33(55) \\
26(43.3) \\
1(1.7) \\
\end{array}$ & $\begin{array}{c}17(65.4) \\
9(34.6) \\
-\end{array}$ & $\begin{array}{c}12(63.2) \\
7(36.9) \\
-\end{array}$ \\
\hline $\begin{array}{l}\text { Ethnicity } \\
\text { Caucasian } \\
\text { Indigenous } \\
\text { Latin American } \\
\text { Asian } \\
\text { Arab } \\
\text { Black } \\
\text { South Asian } \\
\text { South East Asian } \\
\text { Mixed or other }\end{array}$ & $\begin{array}{c}47(79.7) \\
3(5.1) \\
- \\
- \\
2(3.4) \\
2(3.4) \\
- \\
1(1.7) \\
4(6.7)\end{array}$ & $\begin{array}{l}44(73.3) \\
2(3.3) \\
3(5.0) \\
1(1.7) \\
1(1.7) \\
2(3.3) \\
2(3.3) \\
1(1.7) \\
3(5.0)\end{array}$ & $\begin{array}{c}23(88.5) \\
1(3.8) \\
1(3.8) \\
1(3.8) \\
- \\
- \\
- \\
- \\
-\end{array}$ & $\begin{array}{c}13(68.4) \\
1(5.3) \\
1(5.3) \\
2(10.5) \\
1(5.3) \\
- \\
1(5.3) \\
- \\
-\end{array}$ \\
\hline $\begin{array}{l}\text { Income level } \\
\quad<\$ 15,000-\$ 29,999 \\
\$ 30,000-\$ 59,999 \\
\$ 60,000-\$ 89,999 \\
\$ 90,000-\$ 105,000+\end{array}$ & $\begin{array}{l}14(23.7) \\
12(20.3) \\
11(18.6) \\
12(20.3)\end{array}$ & $\begin{array}{l}19(31.6) \\
15(25.0) \\
10(16.6) \\
7(11.6)\end{array}$ & $\begin{array}{c}1(3.8) \\
3(11.5) \\
3(11.5) \\
17(65.3)\end{array}$ & $\begin{array}{c}- \\
4(21.1) \\
3(15.8) \\
11(57.9)\end{array}$ \\
\hline $\begin{array}{l}\text { Relationship status } \\
\text { Dating/in a relationship } \\
\text { Single }\end{array}$ & $\begin{array}{l}29(49.2) \\
30(50.8)\end{array}$ & $\begin{array}{c}25(41.7) \\
33(55) \\
\end{array}$ & $\begin{array}{c}24(92.3) \\
2(7.7) \\
\end{array}$ & $\begin{array}{c}16(84.2) \\
3(15.8) \\
\end{array}$ \\
\hline $\begin{array}{l}\text { Physical health }(\mathrm{PH}) \text { status } \\
\mathrm{PH} \text { condition } \\
\text { No PH condition }\end{array}$ & $\begin{array}{l}28(47.5) \\
28(47.5)\end{array}$ & $\begin{array}{l}29(48.3) \\
28(46.7)\end{array}$ & $\begin{array}{c}9(34.6) \\
17(65.4)\end{array}$ & $\begin{array}{c}7(36.8) \\
11(57.9)\end{array}$ \\
\hline $\begin{array}{l}\text { Mental health }(\mathrm{MH}) \text { status } \\
\text { MH condition } \\
\text { No MH condition }\end{array}$ & $\begin{array}{l}24(40.7) \\
32(54.2)\end{array}$ & $\begin{array}{l}14(23.3) \\
40(66.7)\end{array}$ & $\begin{array}{c}7(26.9) \\
19(73.1)\end{array}$ & $\begin{array}{c}1(5.3) \\
18(94.7)\end{array}$ \\
\hline $\begin{array}{l}\text { Type of pet } \\
\text { Dog } \\
\text { Cat } \\
\text { Both dog and cat } \\
\text { Other type of pet only }\end{array}$ & $\begin{array}{c}22(37.3) \\
25(42.4) \\
8(13.6) \\
3(5.1) \\
\end{array}$ & $\begin{array}{l}- \\
- \\
-\end{array}$ & $\begin{array}{l}9(34.6) \\
6(23.1) \\
3(11.5) \\
6(23.1)\end{array}$ & $\begin{array}{l}- \\
- \\
-\end{array}$ \\
\hline
\end{tabular}


Note. A "Prefer not to say" option was offered on questions considered to be sensitive, resulting in missing data for some variables.

Measures. The measures described in Study 1 were administered in the present investigation, with the addition of a question assessing current pet ownership. Reliability scores for all measures in this sample were high: $\alpha=.90$ for the LAPS General Attachment subscale, $\alpha=.85$ for the LAPS People Substituting subscale, $\alpha=.87$ for the CESD-R-10, $\alpha=$ .85 for the loneliness scale, and $\alpha=.91$ for the measure of social connectedness.

Statistical Analysis. The same statistical procedures reported in Study 1 were followed in the present investigation for within-pet owner analyses. Independent samples t-tests and chi-square tests of independence (as appropriate) were used to characterize sample variation based on data collection location.

Bivariate correlations, independent samples t-tests, and chi-square tests of independence (as appropriate) were used to make comparisons between pet owners and non-pet owners. In order to check for the presence of confounding variables, links between pet ownership and key demographic factors (gender, age, income, and the presence of physical or mental health conditions) were examined; those variables that were significantly linked to both pet ownership and well-being indices were controlled via linear regression when testing for effects of pet ownership on well-being. Chi-square tests were also conducted to assess the role of genotype in predicting pet ownership. As before, outliers were determined at a threshold of +/-3.29 SD for standardized scores and adjusted accordingly prior to analysis. 


\section{Results and Discussion}

Comparisons by data collection location. As seen in Table 5, mall participants

were significantly older than museum participants, $t(161)=3.28, p=.001, \eta^{2}=.063$, and reported lower income levels, $t(140)=-6.36, p<.001, \eta^{2}=.224$. Mall participants were also more likely to indicate being single, $X^{2}(1, N=155)=24.37, p<.001, \phi=.388$, and to be living with a mental health condition, $X^{2}(1, N=155)=4.30, p=.038, \phi=-.167$. Mall participants also reported higher CESD-R-10 scores $(M=10.41, S D=6.56)$ than museum participants $(M=7.40, S D=4.89), t(159)=2.79, p=.006, \eta^{2}=0.47$, but did not differ significantly in terms of loneliness or quality of life. Interestingly, mall participants who owned pets scored higher on both LAPS subscales: $M=2.46, S D=0.58$ vs. $M=2.15, S D=$ 0.57 for General Attachment, $t(81)=2.27, p=.026, \eta^{2}=.060 ; M=1.86, S D=0.83$ vs. $M$ $=1.48, S D=0.74$ for People Substituting, $t(81)=2.01, p=.048, \eta^{2}=.047$. There were no significant differences between participants at the two data collection locations in terms of ethnicity, gender, the presence of physical health conditions, or current pet ownership. Subsequent analyses were collapsed across location to provide a more varied and larger sample of participants.

Comparisons between pet owners and non-pet owners. As seen in Table 6, pet owners in the present study were significantly younger $(M=44.22, S D=17.88$ years) than those who did not own pets $(M=50.32, S D=18.53), t(161)=-2.14, p=.034, \eta^{2}=$ .028 , and pet owners were more likely to report living with a mental health condition, $X^{2}$ $(1, N=155)=5.51, p=.019, \phi=.189$. No further significant demographic differences 
between pet owners and non-pet owners were detected. As both age and mental health condition were related to well-being indices in the present study, their influence was controlled to isolate the effect of pet ownership on well-being.

Although no differences were seen in the variables of depression score or loneliness as a function of pet ownership, when age and mental health condition were controlled, being a current pet owner predicted greater quality of life (partial $r^{2}=.19, n=$ $147, p=.021)$. This result suggests some support for the hypothesis that pet owners would experience enhanced well-being compared to those who did not own pets.

\section{Associations between demographic variables, pet attachment, and well-being}

among pet owners. To determine whether demographic variables should be included as covariates, their relations to the predictor and outcome variables of interest were assessed. As seen in Table 7, income level was not significantly associated with either LAPS subscale in Study 2, although it did predict several indices of well-being. Similarly, gender did not predict attachment in the present study. However, as in Study 1, age was associated with People Substituting such that younger pet owners reported higher subscale scores.

The correlation found in Study 1 between General Attachment and the presence of a physical health condition was also replicated. Those who reported a physical health condition indicated higher levels of pet attachment for the both the General Attachment subscale $(M=2.50, S D=0.46$ for those with physical conditions vs $M=2.21, S D=0.65$ for those without), $t(78)=-2.26, p=.027, \eta^{2}=.061$, and the People Substituting subscale $(M$ 
$=2.06, S D=0.72$ for those with physical conditions vs. $M=1.44, S D=0.78$ for those without), $t(78)=-3.65, p<.001, \eta^{2}=.146$. Additionally, there was a significant effect of mental health status, in that participants with a current mental health condition $(M=$ $2.12, S D=0.70)$ displayed higher People Substituting scores than did those with no such condition $(M=1.50, S D=0.80), t(78)=-3.53, p=.001, \eta^{2}=.137$. This relation to mental health conditions was not evident for the General Attachment subscale.

Table 7

2-Tailed Pearson Correlation Coefficients for Demographic, Moderator, Predictor, and Outcome Variables Among Pet Owners (Study 2)

\begin{tabular}{l|ccccccc} 
& Age & Income level & CESD-R-10 & QoL & Loneliness & SCS-15 & LAPS GA \\
\hline Age & - & - & - & - & - & - & - \\
Incomelevel & .04 & - & - & - & - & - & - \\
CESD-R-10 & -.14 & $-.27^{*}$ & - & - & - & - & - \\
QoL & .18 & .16 & $-.59^{* *}$ & - & - & - & - \\
Loneliness & -.02 & $-.30^{*}$ & $.56^{* *}$ & $-.45^{* *}$ & - & & - \\
SCS-15 & .17 & $.26^{*}$ & $-.65^{* *}$ & $.45^{* *}$ & $-.61^{* *}$ & - & - \\
LAPS GA & .11 & .00 & .13 & .01 & .11 & -.09 & - \\
LAPS PS & $-.23^{*}$ & -.16 & $.31^{* *}$ & -.01 & .20 & $-.31^{* *}$ & $.75^{* *}$ \\
\hline Note. ${ }^{*}=p<.05, * *$ & $=p<.01 ;$ GA & $=$ &
\end{tabular}

Once again, on the whole, the expected links between attachment and positive mental well-being were not evident. Instead, as in Study 1, greater People Substituting was significantly related to higher levels of depressive symptoms $(p=.004)$ as well as decreased social connectedness $(p=.004)$, and was mildly related to greater loneliness ( $p$ $=.071$ ). As before, given the correlational nature of the data, although substituting human relationships with pets might render individuals more vulnerable to depressive symptoms and feelings of disconnection, it is also possible that these psychological states were motivating such connections to pets. 
Moderation analyses. Analyses were undertaken to assess the potential

moderating roles of social connectedness, the presence of physical or mental health conditions, gender, and genotype on the relationship between pet attachment and wellbeing. Continuous variables were mean centred prior to calculating the cross-products (interactions). The significance of the interaction terms between the pet attachment subscales and these moderators are presented in Table 8, and indicate that the relationships between attachment and the well-being variables were minimally altered by the various moderators considered.

Table 8

Interaction Term Coefficients and P-Values for Moderation Analyses (Study 2)

\begin{tabular}{|c|c|c|c|c|c|c|c|c|c|}
\hline \multirow[b]{3}{*}{ Interaction term: } & \multicolumn{9}{|c|}{ Outcome Variable: } \\
\hline & \multicolumn{3}{|c|}{ CESD-R-10 } & \multicolumn{3}{|c|}{ QoL } & \multicolumn{3}{|c|}{ Loneliness } \\
\hline & $N$ & $B$ & Sig. & $N$ & $B$ & Sig. & $N$ & B & Sig. \\
\hline \multicolumn{10}{|l|}{ General Attachment } \\
\hline *SCS-15 & 83 & 0.11 & .268 & 82 & -0.06 & .065 & 82 & 0.03 & .367 \\
\hline *PH cond. & 80 & 0.09 & .689 & 79 & 0.08 & .283 & 79 & -0.01 & .835 \\
\hline *MH cond. & 80 & -0.24 & .207 & 79 & 0.03 & .602 & 79 & -0.01 & .847 \\
\hline *Gender & 82 & 0.07 & .752 & 81 & 0.09 & .204 & 81 & -0.06 & .333 \\
\hline *rs53576 & 56 & -0.15 & .601 & 56 & 0.15 & .096 & 56 & -0.00 & .963 \\
\hline *rs1042778 & 56 & -0.11 & .682 & 56 & -0.09 & .276 & 56 & -0.06 & .415 \\
\hline *rs2254298 & 53 & 0.15 & .599 & 53 & -0.00 & .989 & 53 & 0.05 & .467 \\
\hline \multirow[t]{3}{*}{ *rs3796863 } & 56 & -0.16 & .531 & 56 & 0.10 & .206 & 56 & -0.02 & .787 \\
\hline & \multicolumn{3}{|c|}{ CESD-R-10 } & \multicolumn{3}{|c|}{ QoL } & \multicolumn{3}{|c|}{ Loneliness } \\
\hline & $N$ & B & Sig. & $n$ & $B$ & Sig. & $N$ & $b$ & Sig. \\
\hline \multicolumn{10}{|l|}{ People Substituting } \\
\hline *SCS-15 & 83 & -0.01 & .918 & 82 & -0.03 & .395 & 82 & 0.05 & .124 \\
\hline *PH cond. & 80 & 0.22 & .387 & 79 & 0.09 & .277 & 79 & -0.04 & .592 \\
\hline *MH cond. & 80 & -0.02 & .926 & 79 & 0.01 & .922 & 79 & 0.10 & .217 \\
\hline *Gender & 82 & 0.36 & .137 & 81 & 0.10 & .195 & 81 & -0.10 & .171 \\
\hline *rs53576 & 56 & 0.00 & .989 & 56 & 0.08 & .423 & 56 & 0.03 & .737 \\
\hline *rs1042778 & 56 & 0.19 & .535 & 56 & -0.20 & $.032 *$ & 56 & -0.05 & .540 \\
\hline *rs2254298 & 53 & -0.26 & .400 & 53 & 0.10 & .301 & 53 & -0.06 & .502 \\
\hline *rs3796863 & 56 & -0.32 & .282 & 56 & 0.12 & .202 & 56 & -0.03 & .742 \\
\hline
\end{tabular}


Note. ${ }^{*}=p<.05, * *=p<.01$

A significant interaction between pet attachment and the OXTR gene polymorphism rs1042778 in predicting quality of life was found. As seen in Figure 3, among carriers of the T allele, greater endorsement of the People Substituting dimension of the LAPS was mildly related to lower quality of life $(b=-0.14, p=.053)$, whereas no such association was evident for homozygous $\mathrm{G}$ allele carriers $(b=0.07, p=.275)$. Given the weak significance of the effect, low sample size, and the number of analyses being carried out, this result should be viewed as highly preliminary and requiring replication²; it should also be noted that this same interaction did not approach significance in Study 1 $(p=.674)$.

Figure 3

Relation Between LAPS PS Subscale and Quality of Life as a Function of rs1042778 Genotype (Study 2)

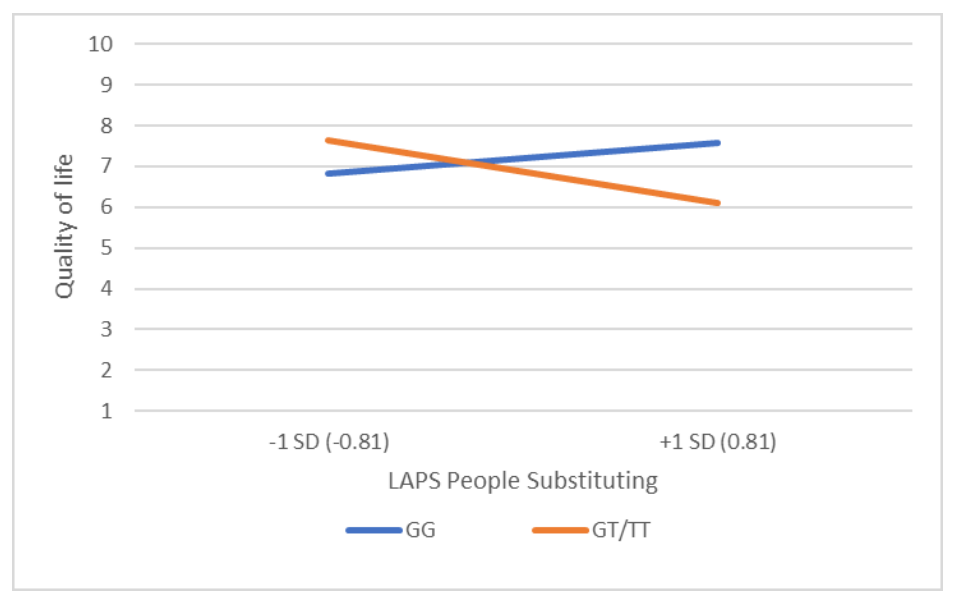

\footnotetext{
${ }^{2}$ Interaction of oxytocin-related genotypes with pet attachment subscales were also analyzed in a combined file containing data from pet-owning participants across all three studies $(N=161)$; however, with increased statistical power, no significant moderating effects were found.
} 
Direct effects of genotype on attachment and pet ownership. Distributions of

allelic variations for the four oxytocin-related SNPs in the present study are presented in

Table 9:

Table 9

Valid for Oxytocin-Related Genotype Analyses (Study 2)

\begin{tabular}{l|ccccc} 
SNP: & Homo (major) & Hetero & Homo (minor) & $\mathbf{N}$ & Split in file \\
\hline rs53576 (OXTR) & GG: 56 & AG: 44 & AA: 10 & 110 & GG vs AG/AA \\
rs1042778 (OXTR) & GG: 41 & GT: 52 & TT: 17 & 110 & GG vs GT/TT \\
rs2254298 (OXTR) & GG: 72 & AG: 28 & AA: 3 & 103 & GG vs AG/AA \\
rs3796863 (CD38) & CC: 55 & AC: 44 & AA: 11 & 110 & CC vs AC/AA
\end{tabular}

Consistent with our findings from Study 1, independent samples t-tests once again revealed no direct effects of genotype on pet attachment (Table 10):

Table 10

Results of Independent T-Tests for Effects of Genotype on Pet Attachment (Study 2)

rs53576

\begin{tabular}{|c|c|c|c|c|c|}
\hline & GG Mean $(S D)$ & AG/AA Mean (SD) & $T$ & Sig. & $\eta^{2}$ \\
\hline LAPS GA & $25.61(5.48)$ & $24.90(7.75)$ & 0.39 & .700 & .003 \\
\hline \multirow[t]{3}{*}{ LAPS PS } & $11.90(5.61)$ & $11.95(5.77)$ & -0.04 & .971 & .000 \\
\hline & \multicolumn{5}{|c|}{ rs1042778 } \\
\hline & GG Mean $(S D)$ & GT/TT Mean (SD) & $T$ & Sig. & $\eta^{2}$ \\
\hline LAPS GA & $25.03(8.07)$ & $25.37(5.67)$ & -0.19 & .853 & .001 \\
\hline \multirow[t]{3}{*}{ LAPS PS } & $11.93(6.30)$ & $11.92(5.16)$ & 0.00 & .998 & .000 \\
\hline & \multicolumn{5}{|c|}{ rs2254298 } \\
\hline & GG Mean $(S D)$ & AG/AA Mean $(S D)$ & $T$ & Sig. & $\eta^{2}$ \\
\hline LAPS GA & $26.10(5.47)$ & $23.59(8.58)$ & 1.30 & .199 & .032 \\
\hline LAPS PS & $12.64(4.72)$ & 10.31 (6.77) & 1.47 & .147 & .041 \\
\hline
\end{tabular}

\begin{tabular}{cccccc}
\multicolumn{7}{c}{ rs3796863 } \\
& CC Mean (SD) & AC/AA Mean (SD) & $T$ & Sig. & $\eta^{2}$ \\
\hline LAPS GA & $25.48(7.23)$ & $24.98(6.46)$ & 0.28 & .783 & .001 \\
LAPS PS & $11.90(5.64)$ & $11.95(5.74)$ & -0.03 & .974 & .000 \\
\hline
\end{tabular}

Note. ${ }^{*}=p<.05,{ }^{* *}=p<.01 ; \mathrm{GA}=$ General Attachment; PS = People Substituting 
There were no significant associations between any of the four SNPs and indices of well-being or any of the proposed moderating variables in the present study. However, a significant link between pet ownership and the rs2254298 polymorphism was found such that A allele carriers were more likely than homozygous $\mathrm{G}$ carriers to report current pet ownership, $X^{2}(1, N=103)=4.17, p=.041, \phi=.201$. While this result is intriguingparticularly in light of recent findings from a large-scale twin study suggesting that a propensity toward dog ownership may be a heritable trait (Fall, Kuja-Halkola, Dobney, Westgarth, and Magnusson, 2019) - it should again be emphasized that the sample size for analyses using genotype in this study were quite low. As such, this finding should be viewed as preliminary and requiring replication.

\section{Study 3}

The objective in Study 3 was to assess the relations between pet attachment and well-being among precariously housed, low-income pet owners. Research with similarly vulnerable groups suggests that bonds with pets may be particularly strong (Labrecque and Walsh, 2011) and experiences of pet ownership qualitatively different, comprising both positive and negative implications (Rew, 2000; Rhoades et al., 2015; Slatter et al., 2012). It was expected that rates of physical and mental illness would be significantly higher than in the previous two studies, and that pet attachment would also be comparatively high.

The same hypotheses regarding pet attachment and our non-biological moderators were tested in Study 3. Due to the challenges associated with recruiting this population, a relatively small sample size was anticipated and so no genotype-related 
analyses were performed for the present study. Qualitative data regarding the meaning of pets in the lives of the precariously housed were collected in order to provide additional insight into the role pets might play in the well-being of vulnerable populations.

\section{Method}

Procedure. The research team collaborated with Community Vet Outreach (CVO), an organization providing pro-bono veterinary care to low-income, precariously housed individuals in Ottawa, Ontario, to gather data with their client group. CVO hosted the research team at several events from summer 2018 to winter 2019, including preventative pet health clinics and community pet fairs. Caseworkers were notified of the opportunity for clients to take part in the research through an email sent out by CVO prior to the events.

The verbal recruitment script, informed consent document, and debriefing document for this study were developed in cooperation with CVO organizers, who suggested the language be made simple and concise in order to aid in client understanding. Given the vulnerable nature of the participant group, some demographic questions in the questionnaires were removed or altered to be less intrusive, more relevant, and simpler to complete; for example, the question about income level was replaced by a question about income source. In lieu of using Qualtrics, paper or verbal administration of the informed consent, questionnaires, and debriefing processes was offered due to concerns about low literacy and familiarity with computers among 
participants. Following completion of the questionnaires, participants responded orally to three open-ended questions regarding their experiences with pet ownership. These responses were audio recorded. Participants were provided with $15 \$$ gift cards for Shoppers Drug Mart as well as small treat bags for their pets as a thank you for participating.

Data for each participant received a common numeric code allowing for the matching up of qualitative and quantitative data. Questionnaire data were entered manually into an SPSS file for analysis. Audio data was transcribed verbatim with any identifying information redacted, then imported into the qualitative data analysis program NVivo. The procedures for this study were approved by the Carleton University Research Ethics Board B (\# 109013). See Appendix C for Study 3 materials.

Participants. A total of 52 adult participants were initially recruited. Two were non-pet owners; as there were not enough non-pet owners to allow for meaningful comparisons, these data were discarded leaving an $N$ of 50 pet-owning participants. As seen in Table 11, the sample consisted predominantly of Euro-Caucasian females, and a majority of participants identified social assistance as their primary source of income. As expected, most participants indicated living with a physical and/or mental health condition, with only $8(16 \%)$ reporting no such conditions; $12(24 \%)$ individuals reported having either a physical or mental health issue and the remaining 26 (52\%), just over half the sample, reported both. The presence of depressive symptoms in this sample was very high, with 39 (78\%) individuals meeting the CESD-R-10 diagnostic threshold. All 
participants owned either a cat, a dog, or both, with cat ownership being slightly more common than dog ownership.

Table 11

Participant Demographic Information for Study

\begin{tabular}{|c|c|}
\hline Variable & Mean (SD) or Count (\%) \\
\hline & Total $\mathrm{N}=50$ \\
\hline Age & $41.54(S D=15.95)$ \\
\hline \multicolumn{2}{|l|}{ Gender } \\
\hline Female & $30(60 \%)$ \\
\hline Male & $20(40 \%)$ \\
\hline \multicolumn{2}{|l|}{ Ethnicity } \\
\hline Caucasian & $43(86 \%)$ \\
\hline Indigenous & $4(8 \%)$ \\
\hline Latin American & $1(2 \%)$ \\
\hline Mixed or other & $2(4 \%)$ \\
\hline \multicolumn{2}{|l|}{ Primary Income Source } \\
\hline Social Assistance & $41(72 \%)$ \\
\hline Employed & $4(8 \%)$ \\
\hline Retired/pension & $3(6 \%)$ \\
\hline Other & $1(2 \%)$ \\
\hline \multicolumn{2}{|l|}{ Relationship Status } \\
\hline Dating/in a relationship & $21(42 \%)$ \\
\hline Single & $29(58 \%)$ \\
\hline \multicolumn{2}{|l|}{ Physical health (PH) status } \\
\hline PH condition & $33(66 \%)$ \\
\hline No PH condition & $13(26 \%)$ \\
\hline \multicolumn{2}{|l|}{ Mental health (MH) status } \\
\hline MH condition & $34(68 \%)$ \\
\hline No MH condition & $16(32 \%)$ \\
\hline \multicolumn{2}{|l|}{ Type of pet } \\
\hline Dog & $17(34 \%)$ \\
\hline Cat & $21(42 \%)$ \\
\hline Both dog \& cat & $12(24 \%)$ \\
\hline $\begin{array}{l}\text { Note. A "Prefer not to say" } \\
\text { considered to be sensitive, } r \\
\text { variables. }\end{array}$ & $\begin{array}{l}\text { was offered on questions } \\
\text { g in missing data for some }\end{array}$ \\
\hline
\end{tabular}

It should be noted that while most of the data collection events were exclusive to

CVO clients and/or held internally at local service agencies with vulnerably housed

clientele, one of the pet fairs was held in an outdoor park and was thus accessible to all

members of the surrounding community, introducing the possibility that some

participants might not meet the criteria of precariously housed or low income. No 
question formally assessing precariously housed status was included in the questionnaires, but the variable of primary income source was examined as a means of addressing this concern (as CVO clientele must be in receipt of social assistance/income supports in order to qualify for services). It was found that only a small number of individuals ( $n=2$ ) who took part in the research at this event reported full-time employment as their primary source of income; all other participants $(n=7)$ were either retirees or in receipt of social assistance. However, given the nature of the event and the neighbourhood it was held in, even employed attendees were likely be low-income, and hence the decision was made not to discard data based on employment status.

Quantitative measures and analyses. The same quantitative measures administered in Studies 1 and 2 were used in the present study, with some adjustments made to the background information section in accordance with considerations for the marginalized status of the participant group. Reliability scores for all scales in this sample were high: $\alpha=.92$ for the LAPS General Attachment subscale, $\alpha=.78$ for the LAPS People Substituting subscale, $\alpha=.87$ for the CESD-R-10, $\alpha=.84$ for the loneliness scale, and $\alpha=$ .90 for the social connectedness measure.

The same statistical procedures reported in Study 1 for assessing links between demographic variables, pet attachment, well-being indices, and proposed moderators were followed. Outliers were once again determined at a threshold of +/-3.29 SD for standardized scores and adjusted accordingly prior to analysis. 
Qualitative measures and analysis. In addition to the questionnaires, qualitative questions were posed to participants with the goal of providing context to their experiences with their pets:

1. Does your pet ever help you when you are lonely, stressed out, or going through a difficult time? (If yes) How?

2. Are there times when caring for your pet can be difficult or stressful? (If yes) How?

3. What is the biggest source of joy you get from your pet?

Once transcribed, thematic analysis of participants' responses was conducted using NVivo Version 12. An informal reflexivity journal was kept by the primary coder (MP) for the purpose of recording reactions to these data throughout the process of reading participant responses and identifying themes (see Appendix D). Initial readings and re-readings of the transcripts were performed in order for the author to familiarize herself with the data and to make note of any themes that were observed. Themes were then refined and revised through successive readings of the data. Following this, the author undertook a process of axial coding in which similar themes were grouped and combined into superordinate themes within each question. Finally, responses were read and themes identified by a second member of the research team in order to ensure interjudge reliability of the coding schema; any differences in identified themes were discussed and resolved among both coders, together with a third member of the research team. 
As themes frequently overlapped, a single response could be coded under multiple categories; for example, the following response would be coded as both "Empathy and Intuiting Emotions" and "Physical Touch":

Well, one of my cats knows when I'm upset and will actually come over to me and cuddle with me, and then the other 2 just kind of like, do this kneading thing on my body. It relaxes me. I don't know why but it just does.

Note that one participant's audio responses were lost and another participant declined to participate in this portion of the study, resulting in a reduced $N$ of 48 .

\section{Quantitative Results and Discussion}

\section{Associations between demographic variables, pet attachment, and well-being.}

Correlational analyses presented in Table 12 revealed no significant associations between either of the LAPS subscales and the demographic variables of age, gender, or presence of a mental health condition. However, strong significant relationships were found with physical health condition, echoing results from Studies 1 and 2. Once again, individuals reporting the presence of a physical health condition reported greater General Attachment to pets than those who did not report any such conditions $(M=2.82, S D=$ 0.20 versus $M=2.48, S D=0.49), t(42)=-3.34, p=.002, \eta^{2}=.210$; the same pattern was evident for the People Substituting subscale of the LAPS $(M=2.53, S D=0.50$ versus $M=$ 1.91, $S D=0.60), t(43)=-3.58, p=.001, \eta^{2}=.230$. As in the previous two studies, mental and physical health conditions were also related to indices of well-being. 
Table 12

2-Tailed Pearson Correlation Coefficients for Demographic, Moderator, Predictor, and Outcome Variables Among Pet Owners (Study 3)

\begin{tabular}{l|cccccc} 
& Age & CESD-R-10 & QoL & Loneliness & SCS-15 & LAPS GA \\
\hline Age & - & - & - & - & - & - \\
CESD-R-10 & -.22 & - & - & - & - & - \\
QoL & $.37^{* *}$ & $-.53^{* *}$ & - & - & - & - \\
Loneliness & -.19 & $-.55^{* *}$ & $-.29^{*}$ & - & - & - \\
SCS-15 & .21 & $-.61^{* *}$ & $.48^{* *}$ & $-.61^{* *}$ & - & - \\
LAPS GA & .17 & -.02 & .13 & .09 & -.04 & - \\
LAPS PS & -.14 & .20 & -.08 & $.31^{*}$ & $-.42^{* *}$ & $.55^{* *}$ \\
\hline
\end{tabular}

Contrary to predictions (but consistent with results from the previous two studies), neither attachment subscale was associated with higher levels of well-being. No significant links were found between attachment and CESD-R-10 score or quality of life rating. However, as in Study 2, higher levels of attachment comprising People Substituting were associated with greater loneliness $(p=.029)$ and less social connectedness $(p=.002)$.

Comparisons of attachment levels with participants in Studies 1 and 2 . When pet attachment data from pet owners across all three studies were combined and compared in a one-way analysis of variance (ANOVA), scores on both LAPS subscales differed significantly across the studies, $F(2,233)=15.09, p<.001, \eta^{2}=.116$ for the General Attachment factor, $F(2,235)=15.78, p<.001, \eta^{2}=.120$ for the People Substituting factor. Mean attachment subscales scores for each study are presented in Table 13: 
Table 13

Mean LAPS Subscale Scores for Studies 1, 2, and 3

\begin{tabular}{lcc} 
& LAPS GA Mean (SD) & LAPS PS Mean (SD) \\
\hline Study 1: & $2.67(0.33)$ & $2.18(0.63)$ \\
Study 2: & $2.36(0.59)$ & $1.74(0.82)$ \\
Study 3: & $2.74(0.34)$ & $2.39(0.59)$ \\
\hline
\end{tabular}

GA = General Attachment; PS = People Substituting

Tukey's HSD post-hoc analyses indicated that while pet attachment subscale scores were significantly higher among vulnerable participants in the present study than in the more general pet-owning group assessed in Study $2(p<.001$ for both General Attachment and People Substituting), they did not differ significantly from those of Pet Expo participants in Study 1, where individuals were also anticipated to be highly motivated and engaged with pet ownership ( $p=.569$ for General Attachment, $p=.184$ for People Substituting).

Moderation analyses. Potential moderators of the relationship between LAPS subscale scores and indices of well-being were examined (see the interactions terms assessing moderating roles in Table 14). Continuous variables were mean centred prior to calculating the cross-products. Contrary to predictions (but in line with results of Study 2), no interaction effects between pet attachment and any of the proposed moderators were found to be significant. 
Table 14

Interaction Term Coefficients and P-Values for Moderation Analyses (Study 3)

\begin{tabular}{|c|c|c|c|c|c|c|c|c|c|}
\hline \multirow[b]{3}{*}{ Interaction term: } & \multicolumn{9}{|c|}{ Outcome Variable: } \\
\hline & \multicolumn{3}{|c|}{ CESD-R-10 } & \multicolumn{3}{|c|}{ QoL } & \multicolumn{3}{|c|}{ Loneliness } \\
\hline & $N$ & $B$ & Sig. & $N$ & $B$ & Sig. & $n$ & $B$ & Sig. \\
\hline \multicolumn{10}{|l|}{ General Attachment } \\
\hline$* S C S$ & 48 & 0.35 & .367 & 47 & -0.23 & .092 & 48 & -0.02 & .871 \\
\hline *PH con & 44 & 0.01 & .992 & 43 & -0.08 & .712 & 44 & -0.13 & .489 \\
\hline$* \mathrm{MH}$ con & 48 & 0.17 & .701 & 47 & -.13 & .463 & 48 & -0.01 & .945 \\
\hline \multirow[t]{3}{*}{ *Gender } & 48 & -0.29 & .615 & 47 & 0.10 & .614 & 48 & -0.07 & .623 \\
\hline & \multicolumn{3}{|c|}{ CESD-R-10 } & \multicolumn{3}{|c|}{ QoL } & \multicolumn{3}{|c|}{ Loneliness } \\
\hline & $N$ & B & Sig. & $N$ & $B$ & Sig. & $n$ & B & Sig. \\
\hline \multicolumn{10}{|l|}{ People Substituting } \\
\hline$* S C S$ & 49 & 0.03 & .878 & 48 & -0.08 & .279 & 49 & 0.06 & .301 \\
\hline *PH con & 45 & -0.18 & .751 & 44 & 0.13 & .530 & 45 & -0.12 & .475 \\
\hline *MH con & 49 & -0.14 & .729 & 48 & -0.15 & .347 & 49 & -0.11 & .375 \\
\hline *Gender & 49 & -0.70 & .187 & 48 & 0.14 & .450 & 49 & 0.04 & .757 \\
\hline
\end{tabular}

\section{Qualitative Results and Discussion}

An overview of the results of thematic analysis is displayed in Table 15. Themes and their relations to each other will be presented and discussed separately for each question.

Table 15

Results of Thematic Analysis of Participant Responses to Qualitative Questions

\begin{tabular}{|c|c|c|c|c|c|}
\hline \multicolumn{2}{|c|}{$\begin{array}{l}\text { Does your pet help you when } \\
\text { you are lonely, stressed out, or } \\
\text { going through a difficult time? }\end{array}$} & \multicolumn{2}{|c|}{$\begin{array}{l}\text { Are there times when caring } \\
\text { for your pet is difficult or } \\
\text { stressful? }\end{array}$} & \multicolumn{2}{|c|}{$\begin{array}{c}\text { What is the biggest source of joy } \\
\text { you get from your pet? }\end{array}$} \\
\hline Theme: & $\begin{array}{l}\text { Frequency } \\
\text { (\%): }\end{array}$ & Theme: & $\begin{array}{l}\text { Frequency } \\
\text { (\%): }\end{array}$ & Theme: & $\begin{array}{l}\text { Frequency } \\
\text { (\%): }\end{array}$ \\
\hline Companionship & $21(43.8 \%)$ & Not Stressful & 17 (35.4\%) & Companionship & $10(20.8 \%)$ \\
\hline Physical Touch & 22 (45.8\%) & $\begin{array}{l}\text { Stressful, but } \\
\text { Worthwhile }\end{array}$ & $2(4.2 \%)$ & Physical Touch & $8(16.7 \%)$ \\
\hline $\begin{array}{l}\text { Empathy and } \\
\text { Intuiting } \\
\text { Emotions }\end{array}$ & $16(33.3 \%)$ & $\begin{array}{l}\text { Behavioural } \\
\text { Issues }\end{array}$ & $13(27.1 \%)$ & $\begin{array}{l}\text { Enjoyment and } \\
\text { Positive } \\
\text { Emotion }\end{array}$ & $12(25.0 \%)$ \\
\hline
\end{tabular}




\begin{tabular}{|c|c|c|c|c|c|}
\hline $\begin{array}{l}\text { Comfort and } \\
\text { Distraction }\end{array}$ & 15 (31.2\%) & $\begin{array}{l}\text { Chores and } \\
\text { General Care }\end{array}$ & $6(12.5 \%)$ & $\begin{array}{l}\text { Love and } \\
\text { Connection }\end{array}$ & $12(25.0 \%)$ \\
\hline Lifting Mood & $5(10.4 \%)$ & $\begin{array}{l}\text { Lack of } \\
\text { Resources }\end{array}$ & $8(16.7 \%)$ & Pet's Presence & $12(25.0 \%)$ \\
\hline $\begin{array}{l}\text { Motivation and } \\
\text { Dependence }\end{array}$ & $4(8.3 \%)$ & $\begin{array}{l}\text { Worries } \\
\text { About Pet's } \\
\text { Health } \\
\text { Poor Health } \\
\text { (Owner's) }\end{array}$ & $5(10.4 \%)$ & Pet's Happiness & $5(10.4 \%)$ \\
\hline
\end{tabular}

\section{Question 1: Does your pet help you when you are lonely, stressed out, or going}

through a difficult time? All 48 participants answered in the affirmative when asked if pets were helpful in addressing stress, loneliness, or other difficulties. The consistency of descriptions across the themes suggests that nearly all viewed their pets as important sources of support. As indicated in Table 12, analyses of how pets were perceived to benefit mental well-being revealed six main themes.

The notion that pets provided companionship was raised by almost half of participants, with responses covering a wide spectrum in terms of the magnitude of that companionship. Some responses indicated that pets alleviated loneliness by simply being there, while others described their animals fulfilling a more active social role in the person's life, such as providing supportive listening or acting as a friend to get out of the house with. One participant said of their pet that "He's my best friend, I can pretty much confide in him about anything and everything. I can talk to him and he doesn't judge, he doesn't nothing, he just listens." While companionship is an obvious and expected benefit of pet ownership regardless of marginalized status, this range of intensity reflected in the responses suggests that for some, pets were viewed as taking on a social 
and emotional support role comparable to that of a human friend, while for others, pets may have simply been seen as good company.

Reference to physical interaction with their animal was also a frequently raised theme in responses to how pets help alleviate stress. Specific behaviours included cuddling, petting, holding, being licked or kissed, and sleeping with pets. As one participant described, "He's fun to cuddle with and he'll generally lick my face if he sees that I'm crying. Maybe it's just the salt, I don't know." The prominence of both this theme and references to companionship is consistent with our quantitative results suggesting that lower social connectedness with others might drive stronger bonds with pets in a way that substitutes for the lack of relationships with people, leading marginalized individuals to view their animals as more human-like support figures.

There also seemed to be a strong link between perceiving pets as empathetic and appreciating the physical contact, for example by their pets jumping into their lap when they were upset. Some participants seemed to ascribe an almost psychic quality to their pet's empathetic abilities, as illustrated in the following response:

He just knows what mood I'm having at a given time and he responds accordingly. If he thinks I'm down, he doesn't want me to be down so he snuggles up to me and takes me out of the mood I'm in. That's the way it works.

One participant even explained how they were teaching their pet to respond appropriately when they were in distress: 
I feel like he's getting there, he's still really young so I find he doesn't really know what to do yet, so we're trying to teach him when like someone's crying or screams or gets hurt he should go comfort them so, so he's getting there. From these responses, it seems clear that many participants felt their pets had the capacity to not only understand their emotional state, but to actively respond in a supportive manner.

Related to pets being perceived as able to detect emotions, they were also regarded as providing relief from negative mood states through comfort and distraction. Specifically, pets were perceived to sense their owner's distress and distract them by initiating physical affection. One participant described their pet helping them in the following manner:

He gives my face kisses when I'm crying, so he licks away my tears...he stays in my lap, like you know for the entire time that I'm upset. He doesn't leave my sight. And he'll get me to give him pets, ways to not focus on what's going on. Focus on him.

Another participant viewed their pet's ability to distract them as less intentional, but still effective: "Your brain just runs in circles when you're alone, and just having a cat roll up and bother you even for food or something is just a distraction, you know? A good distraction." Thus, pets were often viewed as active or passive helpers in managing negative emotions among participants. 
Though less frequent, several participants described interacting with their pets as having direct positive effects on mood and motivation. This included making them feel happier, making them smile, or providing entertainment value with their antics. One participant described their pet's ability to improve their mood quite simply: "She relaxes me, she makes me laugh, she makes me smile, she snuggles with me, she gives me kisses, oh yeah." Likewise, a minority of participants described their pet as a significant source of strength or a motivator to get things done or to 'get out of the house':

She gives me the strength to do what I need to do in my day, because if it wasn't for me caring for her, she wouldn't, you know, she wouldn't be able to live. And knowing that I have someone that depends on me is what gives me the energy to do it, you know?

\section{Question 2: Are there times when caring for your pet is difficult or stressful?}

Given some of the difficulties and challenges associated with pet ownership in similarly vulnerable groups, it was anticipated that this question might contextualize any negative links between attachment and well-being. Overall, responses about pet-related stress were less definite than responses about their pet's positive impact. In addition to many participants refuting the idea of pets causing stress, some of those who did identify stressors also minimized their seriousness, suggesting that individuals generally perceived their relationships with their pets as more helpful than challenging. However, some of the themes raised in response to this question (particularly those dealing with worries 
about pet health or the ability to provide appropriate care) could negatively impact wellbeing. Thematic analysis suggested seven distinct themes.

The most frequent response to this question was to state that caring for their pets was not challenging or stressful. Most participants who responded in this way simply answered in the negative ("No" or "Never"), but a few elaborated, emphasizing their commitment to their pet's care. One participant summed up their feelings quite succinctly as "Animals never get me stressed." Even among those who indicated that caring for pets could be stressful, some participants qualified the statement, indicating they were happy to do it and considered their animals to be worth the trouble:

I always get out of bed and I always make sure they're taken care of. If they're low on food, I'll go out in snowstorms to get them food. I will climb mountains to get them food. I will even go hungry so that they have food and stuff.

The most frequently identified stressors involved pets behaving badly or not cooperating. Examples included aggression with other animals, hyperactivity, damage to furniture, and behaviours related to pets being unsterilized (such as spraying in unneutered cats). Two participants identified their pets' young ages as a factor in the bad behaviour, "Yes, because she's a puppy, uh, sometimes things don't go how you want them to and sometimes she doesn't listen but, uh, just roll with it." Interestingly, there was significant variation in the level of stress related to pet misbehaviour. While many seemed to consider behavioural issues to be minor or manageable, one described their experience as a more challenging: 
Yes, very much so. Just trying to train him right now is really difficult, he's really bad on walks and tends to be hyperactive at home when we're trying to eat or relax and just constantly needs attention. So these are moments when it can be really frustrating and stressful.

About a quarter of participants expressed that pet-related chores and regular pet care were a source of stress. Chore-related responses included descriptions of cleaning up after pets, scooping the litterbox, and keeping animals groomed. Other participants expressed that caring for pets sometimes interfered with sleep (as when taking a dog out to urinate in the middle of the night) or other important activities (as when pets sought attention while the owner was busy). One participant described a need to balance their pet's needs with their own schedule:

So I guess sometimes just the balance of being able to take care of her while also doing your everyday life can be difficult sometimes, or if I just need to do like, sometimes I have to do like internet banking or just do random things on the computer, but she's always there right there in your face.

As with behavioural issues, some participant responses expressed mild annoyance while others were more definitive about stress relating to pet care. Some of this may be attributable to differences in pet type and personality, but some may be related to the owner's own health status (a separate theme), as evidenced in this response: "I live with chronic pain syndrome and at times I find it hard to take care of myself." 
Unsurprisingly given the population, several participants described financial strain relating to pet care, either in terms of affording food or being able to take their pet to a vet if medical needs arose. Some individuals described inadequate finances as their only source of pet-related stress:

Sometimes it can be difficult, because everything is going up, like price-wise and the money that we receive isn't going up. All the prices for food go up and we don't receive the exact same increase in our cheques as we do for food and everything else. Other than that no, no I don't have an issue besides like, the money.

Another participant made specific reference to their appreciation of the pro-bono services offered at the CVO clinic they were attending:

It is stressful when you don't have the money to take your pets to...like if your pet really needs to be seen by a doctor and you can't afford it, that's very stressful. And thank god for this place, it relieves a lot of stress off of me today 'cause of this place. It's perfect. I love it.

Despite the pro-bono veterinary clinics, some participants expressed anxiety about the pet's health and well-being or difficulties dealing with a pet's illness. This theme was sometimes raised alongside a lack of financial resources, with concerns about being able to afford medical care. In some instances, worries were specifically related to pets getting older and moving towards end of life. However, owners of younger pets also cited 
concern for their animal's well-being as a stressor, with one participant likening her anxiety to that of a new parent:

He's only 3 and half months old and he's a kitten so he gets into a lot of stuff. I'm always like if you can think about those, those women who just had a baby and they're so terrified that something's going to happen to this child or whatever, that's me. I'm so scared that like when I'm out or something he's going to end up knocking something over onto himself or like, I don't know, other than like him being a kitten it's not really like, it's not really that stressful.

Finally, consistent with the higher reported rates of health conditions in the present study, a minority of participants made reference to their own health issues interfering with their ability to care for their pet. Responses touched on addiction, mental health, and physical limitations that contributed to difficulty attending to their pet's needs:

When I can't like, when I'm feeling depressed sometimes I forget about my animals. But when I feel better it's like 'Oh shit, I forgot about them.' I have to go home and I have to change their litter box.

Responses under this theme seemed to suggest that individuals felt a responsibility to care for their pet, and in some cases the associated stress was partly in response to struggling to fulfill that obligation.

\section{Question 3: What is the biggest source of joy you get from your pet? To give}

participants the opportunity to share a positive thought or story about their pet at the end of the research process, they were asked about the joys of owning a pet. Six themes 
emerged, many of which were similar to those expressed in response to question 1 , with some slight differences in terms of nuances.

Once again, a spectrum of statements describing the companionship derived from pets was evident. Some participants described their pet playing a much more significant, human-like role: "Just having him, him being mine, my best friend. My confidant, you know? He's like a soul mate, he's just a part of me, you know?" Others were less sentimental about pets, but nevertheless described their importance for reducing loneliness during a difficult life transition:

So I'm a single parent and when my daughter went to university I really struggled in the beginning, like just being alone and being motivated to do anything or to look after myself, and it's like, for some reason, having the cats in the house I don't feel alone. Like, there are times when I wake up and I have this moment of being really afraid of being alone and then it's like "Oh wait a minute, the cats are here, it's okay, I'm not actually alone". And it's a little weird cause l'm not one of these crazy pet lovers, I don't think my pets are human or anything like that, but there is something in having another living being around you, that you know, to a little extent needs you and loves you and all of that. There is something in just the fact that it's another living being around you.

Thus, some of the variation in experiences of companionship may stem not just from characteristics of the pet or owner, but the presence of challenging situations in an individual's life. 
Though less prominent than when considering the stress reduction benefits, several responses cited physical interactions with pets as a source of joy. Some participants did connect these experiences to comfort, while others referred to small, routine actions that seemed to communicate tenderness and affection:

He does this funny thing when he sleeps with me on the bed, when we first lay down he comes over and he'll put his head on my chest but then he'll turn it sideways, and really kind of like lean into my chest, and it's just really cute. Unsurprisingly, references to feelings of love, trust, and connection with pets were also raised. The love provided by pets was often described as unconditional, and sometimes as surpassing experiences with human relationships:

Honestly, just the company, being able to touch him and love him and the fact that I'm his person. I am his world, so it kind of fits in a way no one else would in a way right? So he just, he gives me a form of happiness I can't get from other people.

Similar to this theme, several participants raised positive emotions associated with pet ownership, enjoying their pets' cute appearance or watching them play, the funny things their pets did, and their ability able to make them smile when things were difficult: "Just the way they can change my day from bad to good, just with a little purr or a little, acting a little goofy. They're just totally wonderful that way." Even a pet's mere presence was a source of happiness, with several participants describing the joy associated with waking up to their pet or coming home to have their pet greet them at the door. The relative 
frequency with which this theme was raised suggested its importance, but its overall meaning was challenging to decipher. For example, one participant described their pets' presence as routine and expected, perhaps suggesting that there was value in the pet's consistency: "You become dependent on them. Because I wake up and I expect to see my dog and my cat you know?" For another, the value seemed to lie more in the pet's excitement and positive reaction to them, "When I get home and he gets really excited to see me, that part's really like 'Oh you know like I feel loved' coming \{home\} to something that's really excited to see me." It may be that this theme comprises a diversity of positive emotions and experiences relating to pet ownership.

In a twist on the joy derived from the mere presence of their pets, a small number of participants raised their pets' non-judgmental nature and positive regard for them as a source of joy, "Being able to be myself and not have to worry about them judging me for like, if I wanna dance around in my underwear in the house, I can."

An appreciation of their pet was also reflected in the comments of a minority of participants who emphasized the importance of their pet's happiness and well-being rather than their own, suggesting that they found enjoyment and meaning in caring for them. One participant described the satisfaction they felt at providing for their pet: ...like seeing her happy you know? When I give her treats that she likes, or when I play with the \{toys and stuff, she gets excited, because she's still just a kitten, and then you know, when she's all wiped out, she'll go and drink her water, have a 
snack, and then she'll come and nudge me and snuggle up to me, it's nice to be appreciated.

\section{General Discussion}

Companion animals are considered by many to be beneficial to human health and well-being. In the present research, current pet owners did indeed appear to experience higher quality of life compared to those who did not own pets, with differences in age and presence of mental illness controlled. However, pet owners did not report fewer depressive symptoms or less loneliness. Prior research into the physical and mental health effects of pet ownership has returned mixed results. While many studies report myriad short- and long-term benefits to health, including stress reduction, improved social functioning, and the prevention of illness (Wells, 2009), other investigations have failed to replicate such effects, calling the existence of a generalized "pet effect" into question (Herzog, 2011). Indeed, pet owners in the current study were more likely to report the presence of a mental health condition than those who did not own pets. In line with this, results from a large, representative sample from Sweden found that while pet owners were generally healthier than their non-pet owning counterparts, they also had higher rates of mental health complaints (Müllersdorf et al., 2010). These seeming inconsistencies underline the importance of looking more deeply at how pet ownership is experienced among different individuals (such as through the examination of attachment bonds). 
When differences in emotional bonds with pets were assessed in the present research, links between strength of attachment and indicators of well-being were not consistent. Analyses in studies 1 and 2 both revealed small associations between attachment and depression scores, but contrary to expectations, greater attachment was related to greater rather than lower depressive symptomology. Similarly, participants with high levels of pet attachment in studies 2 and 3 reported higher loneliness and less connectedness to other people. These variations across the populations sampled in the three studies may suggest that emotional bonds with pets are, at best, inconsistent mediators of health outcomes among owners. The negative relations to well-being might further imply that strong emotional bonds with pets increase susceptibility to stress rather than conferring protective effects for some individuals. In a study that also linked greater pet attachment with increased symptoms of depression in a sample of older adults, Militades \& Shearer noted that for those individuals who are highly attached to their animals, pets may act as substitutes for human support and connection (2010). It may be that support gleaned from companion animals is comparatively less effective as a buffer against stress, thus leading to increased vulnerability. In line with this, Rynearson suggested that an overreliance on animals as attachment figures could lead to negative psychological outcomes in clinical populations, particularly if those bonds were disrupted (1978).

However, mixed results regarding the direction and strength of the relationship between pet attachment and well-being have been found in previous investigations 
(Garrity et al., 1989; George et al., 1998; Ory \& Goldberg, 1983; Peacock et al., 2012).

Several alternative explanations could account for such variation of findings. For example, it could be that stress and poor well-being lead individuals to bond more closely with companion animals, increasing their level of emotional attachment. This interpretation could also account for the consistent association between the presence of physical health conditions and strength of attachment to pets in the present research, a result that was found across all three participant groups. Other investigations have also found links between attachment to pets and mental distress (Brooks et al., 2016; Peacock, ChurHansen, \& Winefield, 2012) as well as physical health symptoms (George et al., 1998). As our measures did not include questions ascertaining the timing of acquiring a pet or being diagnosed with a health condition, we were not able to assess the directionality of the relationship. Longitudinal study designs in which changes in health status are tracked over time in individuals who acquire pets could be useful to address this question. Speculatively, however, it seems unlikely that the impact of pet ownership and/or attachment on health would favour higher overall rates of diagnosed illness-although this possibility is admittedly more plausible among vulnerable individuals and older populations, for whom caring for pets may represent a more substantial strain on resources, or affect willingness to address health symptoms if treatment might interfere with keeping a beloved pet (McNicholas, Gilbey, Rennie, Ahmedzai, Dono, \& Ormerod, 2005). In light of these results, it might also be valuable to stratify analyses based on 
health status in order to assess the relationship between attachment and well-being in healthy and less healthy owners separately.

This interpretation of illness and stress driving closer bonds with pets was also consistent with the results of our qualitative analysis of the experiences of precariously housed participants in Study 3, many of whom described the importance of their animals as sources of support and comfort. If this is the case, then the question of pets' effectiveness at helping individuals to address and manage health complaints, especially among vulnerable populations, is highly relevant and should be a focus of future research. A systematic review of the existing literature on pet ownership among individuals living with mental illness (largely comprising qualitative studies) concluded that despite some mixed evidence, connections with pets appeared to provide benefits to this group in the areas of emotional support and symptom management (Brooks et al., 2018). Examining the use of animal-assisted health interventions, which have gained traction in recent years as adjunct or standalone approaches to the treatment of many physical and psychiatric conditions, may provide further insights. In this regard, a meta analysis of animal-assisted interventions concluded that there exist moderate positive impacts on a range of health issues, including medical difficulties, behavioural issues, and emotional well-being (Nimer \& Lundahl, 2007). It has been suggested that some of these effects might be mediated through animals' ability to promote relaxation and provide distraction from negative states, thereby reducing anxiety or pain (Beetz, 2017). Although caution should be exercized in applying such findings to non-clinical populations, they 
nonetheless suggest that interactions with animals can meaningfully impact how individuals experience illness.

While social connectedness did not appear to moderate the relations between pet attachment and well-being in the present research, those reporting lower levels of social connectedness indicated greater attachment to their animals in Studies 2 and 3, a finding that is consistent with previous research linking greater attachment and anthropomorphizing behaviours to impoverished social networks (Antonacopoulos \& Pychyl, 2008; Johnson et al., 1992). Once again, this suggests that in some instances, pets may be "filling in" for an absence of human support and connection, bolstering the theory that bonds with pets might be especially profound in the lives of socially marginalized individuals. Likewise, the association between attachment and physical illness may be accounted for by this social isolation, as many individuals living with serious health conditions experience exclusion on the basis of their illness (Brooks et al., 2018). Intriguingly, physical health status did interact with attachment to predict quality of life for participants in Study 1, wherein higher levels of attachment appeared to provide some protection against the impact of illness on well-being. However, analyses in the other two participant groups failed to replicate this finding, suggesting that it may have only limited generalizability (or represents a statistical artefact).

Considering the inconsistencies in the relations found between attachment and indices of well-being across the three studies, it appears plausible that bonds with pets are subject to the effects of other moderating variables that were not explored in the 
present research. Although the measure of social connectedness was chosen to capture a general sense of participants' feelings of belonging and interpersonal functioning, selecting a different social variable might have been more insightful. For example, other investigations have focused on perceived peer support among pet owners and found that links between attachment and health varied on that basis (Antonacopoulos \& Pychyl, 2010; Garrity et al., 1989). While connectedness and support are likely to be related, they are nonetheless distinct concepts; a person with a wide network of friends and acquaintances (high social connections) could still perceive a lack of close, reliable interpersonal support. The one-on-one nature of most human-animal relationships, and the comfort derived from supportive interactions with pets that was described by marginalized individuals, suggest that support availability may be the more relevant factor in influencing the way people relate to their pets. Thus, different results might have been found if social support had been measured rather than social connectedness.

While pet attachment is often interpreted as a singular construct, the attachment measure in the present research was multidimensional, reflecting a general feeling of emotional closeness, but also the extent to which people center pets in their lives and view them as fulfilling a human-like role. How attachment is experienced had implications for its relationship to well-being, as all significant direct links between wellbeing and attachment involved the People Substituting subscale of the LAPS rather than the General Attachment subscale. Consistent with this, grief following the death of a pet was especially profound among those who scored highly on the People Substituting 
factor, in that it was uniquely related to depressive symptoms among bereaved owners (Testoni, De Cataldo, Ronconi, \& Zamperini, 2017). The importance of this form of attachment in relation to well-being seems consistent with the view that those who regard their pets as possessing more anthropomorphic qualities would experience more pronounced links between attachment and well-being, and perhaps be especially vulnerable to negative effects when bonds with pets are disrupted. Interestingly, the results of the present research suggested that this kind of attachment is more evident among owners who are younger and at a lower income level, a finding which may lend further support to the idea of bonds with pets being especially important to more vulnerable individuals.

\section{Pets and Marginalized Groups}

The population sampled in Study 3 comprised a unique subset of pet owners with significant challenges to health and social functioning. Given previous research, it was expected that bonds and interactions with pets would be experienced differently (and perhaps more intensely) than among pet owners in the general population. Although attachment levels were higher in this group than in the more generalized sample from Study 2, links with well-being were fairly similar, with both groups displaying associations between attachment and greater social isolation (higher loneliness, lower social connectedness). However, in sharing their experiences of pet ownership, the precariously housed respondents described the impact of their pets as highly significant and 
multifaceted, emphasizing positive effects on stress and coping while also identifying areas where pets could create frustration and worry.

While the potential negative impacts of pet ownership were less evident in their descriptions in that many participants expressly did not view their responsibilities as pet owners as stressful, some individuals nonetheless raised themes of worry about their pet's health, behaviour, and daily care, particularly in relation to financial strain. A small number also touched on difficulties associated with caring for their pet while living with addiction, mental illness, and physical challenges. All of these aspects could contribute to negative outcomes for pet owners from marginalized populations, particularly in the context of stressors relating to income and housing issues. Indeed, previous research has linked the inability to adequately care for a pet with increased presence of depressive symptoms (Militades \& Shearer, 2010).

At the same time, participants clearly and consistently expressed the belief that their pets provided significant value to their lives, whether in the form of giving physical comfort, elevating mood, or just being a constant and reliable presence. Support provided by pets was presented as very similar to (and sometimes as surpassing) interactions with people. The fact that this perceived importance of bonds with pets to health did not translate into more positive associations between attachment and wellbeing indicators could be interpreted in several ways. It may be that the construct of pet attachment as assessed by the LAPS does not predict well-being benefits as we proposed, and another variable might be more appropriate for capturing connections to companion 
animals. Alternatively, as most pet owners in this group were uniformly highly attached to their animals, then examining variations of well-being differences among them may be less insightful. Instead, comparisons with similarly vulnerable non-pet owners may have been more illuminating, and perhaps would have revealed positive mental health impacts (Rhoades et al., 2015). Indeed, in Study 2, pet attachment was more variable, and was associated with negative well-being effects, whereas pet ownership in this same study was associated with enhanced well-being. Given the health and social challenges inherent to being precariously housed, it is also possible that any stress buffering or health-promotion effects of pet attachment were masked by the presence of other, more compelling factors influencing well-being.

It could also be that despite their perceived importance, participants simply overestimated the benefits that their pets conferred. Most research assessing the role of pet ownership in marginalized groups has been qualitative in nature, with little opportunity to quantitatively or behaviourally assess the accuracy of participants' impressions of their pet's impact. The emotional importance of companion animals to vulnerable individuals is striking, but it may also represent a source of bias when relying on self-report to explore links with well-being, particularly when participants are aware of the research question and passionate about the subject matter. Thus, it is possible that the health-promoting effects of pets in marginalized groups have been overstated. However, whatever their effects, the results of qualitative analyses as well as the replicated association between attachment and physical health status provide some 
backing for the supposition that vulnerable individuals feel able to turn to their pets for support when dealing with challenges to health and well-being.

\section{Genotype Analyses and the Oxytocin Hypothesis}

Oxytocinergic processes have been identified as potential mediators of some of the apparent benefits of pet ownership, particularly in relation to stress and mental wellbeing. Although none of the genotypes we examined appeared to consistently interact with (or directly predict) attachment to pets, there was a significant relationship between the oxytocin receptor gene polymorphism rs2254298 and pet ownership, with A allele carriers being more likely to report currently owning a companion animal. If replicable, this result could indicate that while not directly related to feelings towards pets or wellbeing in our investigation, oxytocinergic mechanisms might nonetheless be at play in human interactions with companion animals. It is difficult to say whether either allele confers more sensitive overall oxytocinergic functioning for this particular SNP. However, some research has found an association between the A allele and increased volume of the amygdala, a limbic structure where significant oxytocin binding occurs and that is thought to regulate multiple aspects of social behaviour (Inoue, 2010). This said, a recent study found that the rs2254298 polymorphism appears to play a role in determining affective reactions to pets, with carriers of the $\mathrm{G}$ allele reporting greater levels of empathy towards animals (Connor, Lawrence, \& Brown, 2006). This result might lead one to expect that participants with the $G / G$ genotype (rather than $A / G$ or $A / A$ carriers) would be more likely to seek out pet ownership, which is opposite to our own findings. Thus, 
particularly as the sample for genotype analyses in Study 2 was relatively small, this association between a SNP of the oxytocin receptor gene and current pet ownership should be viewed as preliminary and requiring replication.

Although hypotheses regarding oxytocin-related genotype were not tested among the precariously housed participants in Study 3, the frequency and recurrence of physical touch with pets as a theme within qualitative analyses may have some relevance to the oxytocin hypothesis of human-animal interaction. In this regard, warm contact between humans is thought to raise oxytocin levels and reduce stress parameters (Light et al., 2005). If physical touch with bonded animals has similar effects as some evidence suggests (e.g. Odendaal \& Meintjes, 2003), this may in part explain both the prominence of this theme and its connection to participants being comforted by their animals (although whether this result is generalizable to other groups of pet owners is unclear). Relatedly, oxytocin levels have been found to predict how frequently owners touched their dogs, with individuals with lower oxytocin levels before and during short-term interactions engaging in more frequent touching behaviour (Petersson et al., 2017). The authors of this study speculated that this pattern may be driven by a higher need for interaction among those with low levels of oxytocin in order to experience oxytocinmediated effects, such as stress reduction.

Although oxytocin has gained recognition for its role in promoting prosocial behaviour and reducing stress, it has been suggested that it is more appropriately understood as a hormone that increases the salience of social cues, heightening 
sensitivity to both positive and negative impacts on mental health (McQuaid, Mclnnis, Stead, Matheson, \& Anisman, 2014; McQuaid et al, 2015). Viewed in this manner, the question of whether oxytocinergic processes are involved in bonds and interactions with animals should perhaps be treated as distinct from the question of whether they mediate any of the proposed positive health effects associated with owning companion animals. While our results were inconclusive with respect to the latter hypothesis, they might suggest some very preliminary support for the former.

\section{Limitations}

As discussed, the correlational nature of the present research meant that we could only speculate on the causality of links between key variables. Additionally, although their use has been validated in prior research, the self-reported nature of the measures we used to assess attachment and well-being make it possible that our results were influenced by biased responding. This limitation may be particularly important to consider for a subject like pet ownership, which many people are passionate about. Although efforts were made to avoid biasing participants throughout the research process, it is conceivable that some responses were affected by a pre-existing belief that pets promote good health.

Small sample sizes were also a significant limitation of this research, particularly with respect to genetic analyses. Our choice to collapse the heterogenous and minor homogenous genotypes for each of the four oxytocin-related polymorphisms was dictated by the low number of participants who contributed biological samples, and thus 
different results might have been evident in a larger dataset. Further, while efforts were made to gather a less specialized, more varied sample of pet owners in Study 2, each of our participant groups was accessed through convenience sampling and as a result, findings should not be viewed as generalizable to all pet owners; notably, all three samples consisted primarily of Caucasian females.

The measure of attachment used in the present investigation was originally developed as a tool for measuring attachment in cat and dog owners, and although the large majority of our participants identified themselves as such, many also reported owning multiple types of animals - and a small number of participants reported only owning another type of pet, ranging from fish to turtles to ferrets. The measure contains items that might be inapplicable to pets that are not as interactive; for example "I play with my pet quite often" may be a good measure of emotional closeness with dogs, but less appropriate for assessing feelings towards fish or reptiles. Pet type has been found to affect bonds with pets in previous studies, with dog and cat owners reporting the highest levels of attachment (Hawkins, Williams, \& the Scottish SPCA, 2017). Especially considering the emphasis participants placed on physical interaction with pets in their qualitative responses in Study 3, both the way in which individuals relate to their animals and any resulting implications for well-being might very well differ as a function of pet species.

Further, our choice of measure for pet attachment was grounded in previous research, but it may be that another variable would have better captured emotional 
bonds with companion animals for the purposes of assessing links with well-being. In their original report on the development of the attachment measure, the authors of the LAPS noted that the majority of its items appeared to be indicators of above-average attachment, suggesting that the scale may be more effective at measuring strong rather than weak attachment to companion animals (Johnson, Garrity, \& Stallones, 1992). Thus, it is possible that the full spectrum of pet attachment present in our samples (and thus related effects on well-being) was not comprehensively captured by our main predictor variable; if this is the case, our results would be less applicable to individuals who experience weaker emotional ties to their pets. Relatedly, pet attachment scores in the present research were observed to deviate from a normal distribution, displaying negative skewness. The statistical tests employed in our analyses are generally robust to non-normality, and thus this observed deviation was considered unlikely to contribute significantly to Type I error.

\section{Future Implications}

Notwithstanding these limitations, our findings do provide some insight into human-animal interaction and pet ownership. While we found little support for our hypotheses that pet attachment would promote positive well-being outcomes depending on levels of social connectedness with humans or oxytocin-related genotype, our analyses did suggest that emotional bonds with pets varied significantly across groups and depending on individuals' health status. Thus, pet ownership may be experienced differently based on owner characteristics. Future research could build on these findings 
by employing a stratified and/or longitudinal approach to data collection and analysis, increasing sample size, and exploring other potential moderators of human bonds with companion animals.

It is uncertain from the results of our investigations whether emotional bonds with pets directly impact human well-being, whether distress and poor health promote stronger attachment to pets, or whether there is a reciprocal relation between these factors over time or circumstance. Regardless, it seems clear that relationships with companion animals are viewed as highly significant and impactful to many pet owners, including and perhaps especially those considered to be vulnerable. If health-related stressors and experiences of marginalization lead to relationships with pets becoming more significant, interventions with these kinds of populations could potentially capitalize on existing pet-owner bonds. In concordance with previous research with marginalized groups, many individuals with health and social challenges are motivated to care for and keep their pets, and report that this experience brings them joy and meaning in life. Given this, programs and interventions in which the interconnectedness of human and animal well-being is taken into account, and bonds with pets are integrated into service delivery, may be particularly effective for improving engagement, and by extension, health outcomes especially among vulnerable, hard-to-reach groups (Lem et al., 2013 \& 2016). 


\section{References}

Adams, C. L., Bonnett, B. N., \& Meek, A. H. (2000). Predictors of owner response to companion animal death in 177 clients from 14 practices in Ontario. Journal of the American Veterinary Medical Association, 217(9), 1303-1309.

Andresen, E. M., (1994) Screening for depression in well older adults: Evaluation of a short form of the CES-D. American Journal of Preventive Medicine 10(2): 77.

Antonacopoulos, N. M. D., \& Pychyl, T. A. (2008). An examination of the relations between social support, anthropomorphism and stress among dog owners. Anthrozoös, 21(2), 139-152.

Antonacopoulos, N. M. D., \& Pychyl, T. A. (2010). An examination of the potential role of pet ownership, human social support and pet attachment in the psychological health of individuals living alone. Anthrozoös, 23(1), 37-54.

Amiot, C. E., \& Bastian, B. (2015). Toward a psychology of human-animal relations. Psychological Bulletin, 141(1), 6-47.

Amiot, C., Bastian, B., \& Martens, P. (2016). People and companion animals: It takes two to tango. Bioscience, 66(7), 552-560.

Bartz, J. A., Zaki, J., Bolger, N., \& Ochsner, K. N. (2011). Social effects of oxytocin in humans: Context and person matter. Trends in Cognitive Sciences, 15(7), 301-309.

Beetz, A., Uvnäs-Moberg, K., Julius, H., \& Kotrschal, K. (2012). Psychosocial and psychophysiological effects of human-animal interactions: The possible role of oxytocin. Frontiers in Psychology, 3(234). 
Beetz, A. M. (2017). Theories and possible processes of action in animal assisted interventions. Applied Developmental Science, 21(2), 139-149.

Black, K. (2012). The relationship between companion animals and loneliness among rural adolescents. Journal of Pediatric Nursing, 27(2), 103-112.

Brooks, H., Rushton, K., Walker, S., Lovell, K., \& Rogers, A. (2016). Ontological security and connectivity provided by pets: A study in the self-management of the everyday lives of people diagnosed with a long-term mental health condition. BMC Psychiatry, 16(1), 409.

Brooks, H. L., Rushton, K., Lovell, K., Bee, P., Walker, L., Grant, L., \& Rogers, A. (2018). The power of support from companion animals for people living with mental health problems: A systematic review and narrative synthesis of the evidence. BMC Psychiatry, 18(1), 31.

Brown, C. A., B.A., Cardoso, C., Ph.D., \& Ellenbogen, M. A., Ph.D. (2016). A meta-analytic review of the correlation between peripheral oxytocin and cortisol concentrations. Frontiers in Neuroendocrinology, 43, 19-27.

Brüne, M. (2012). Does the oxytocin receptor (OXTR) polymorphism (rs2254298) confer 'vulnerability' for psychopathology or 'differential susceptibility'? insights from evolution. BMC Medicine, 10(1), 38-38.

Campbell-Sills, L., \& Stein, M. B. (2007). Psychometric analysis and refinement of the ConnorDavidson resilience scale (CD-RISC): Validation of a 10-item measure of resilience. Journal of Traumatic Stress, 20(6), 1019-1028.

Chen, F. S., Kumsta, R., Dawans, B. v., Monakhov, M., Ebstein, R. P., \& Heinrichs, M. (2011). Common oxytocin receptor gene (OXTR) polymorphism and social support interact to 
reduce stress in humans. Proceedings of the National Academy of Sciences of the United States of America, 108(50), 19937-19942.

Cheung, C., \& Kam, P. K. (2017). Conditions for pets to prevent depression in older adults. Aging \& Mental Health, 1-7.

Cohen, S., \& Wills, T. A. (1985). Stress, social support, and the buffering hypothesis. Psychological Bulletin, 98(2), 310-357.

Connor, K. M., \& Davidson, J. R. (2003). Development of a new resilience scale: The ConnorDavidson resilience scale (CD-RISC). Depression and anxiety,18(2), 76-82.

Connor, M., Lawrence, A. B., \& Brown, S. M. (2018). Associations between oxytocin Receptor gene polymorphisms, empathy towards animals and implicit associations towards animals. Animals: An Open Access Journal from MDPI, 8(8), 140.

Crawford, E. K., Worsham, N. L., \& Swinehart, E. R. (2006). Benefits derived from companion animals, and the use of the term "attachment". Anthrozoös, 19(2), 98-112.

Daly, B., \& Morton, L. L. (2006). An investigation of human-animal interactions and empathy as related to pet preference, ownership, attachment, and attitudes in children. Anthrozoös, 19(2), 113-127.

Fall, T., Kuja-Halkola, R., Dobney, K., Westgarth, C., \& Magnusson, P. (2019). Evidence of large genetic influences on dog ownership in the Swedish twin registry has implications for understanding domestication and health associations. Scientific Reports, 9(1), 7554-7.

Feder, A., Charney, D. S., \& Nestler, E. J. (2009). Psychobiology and molecular genetics of resilience. Nature Reviews Neuroscience, 10(6), 446-457. 
Field, N., Orsini, L., Gavish, R., \& Packman, W. (2009). Role of attachment in response to pet loss. Death Studies, 33(4), 334-355.

Garrity, T. F., Stallones, L., Marx, M. B., \& Johnson, T. P. (1989). Pet ownership and attachment as supportive factors in the health of the elderly. Anthrozoos, 3(1), 35-44.

George, R. S., Jones, B., Spicer, J., \& Budge, R. C. (1998). Health correlates of compatibility and attachment in human-companion animal relationships. Society \& Animals, 6(3), 219-234.

Germain, S. M., Wilkie, K. D., Milbourne, V. M. K., \& Theule, J. (2018). Animal-assisted psychotherapy and trauma: A meta-analysis. Anthrozoös, 31(2), 141-164.

Grewen, K. M., Girdler, S. S., Amico, J., \& Light, K. C. (2005). Effects of partner support on resting oxytocin, cortisol, norepinephrine, and blood pressure before and after warm partner contact. Psychosomatic Medicine, 67(4), 531-538.

Handlin, L., Hydbring-Sandberg, E., Nilsson, A., Ejdebäck, M., Jansson, A., Uvnäs-Moberg, K., . . . Institutionen för biovetenskap. (2011). Short-term interaction between dogs and their owners: Effects on oxytocin, cortisol, insulin and heart rate-an exploratory study. Anthrozoös, 24(3), 301-315.

Hawkins, R. D., Williams, J. M., \& the Scottish Society for the Prevention of Cruelty to Animals (Scottish SPCA). (2017). Childhood attachment to pets: Associations between pet attachment, attitudes to animals, compassion, and humane behaviour. International Journal of Environmental Research and Public Health, 14(5), 490. 
Hayden-Evans, M., Milbourn, B., \& Netto, J. (2018). 'Pets provide meaning and purpose': A qualitative study of pet ownership from the perspectives of people diagnosed with borderline personality disorder. Advances in Mental Health, 16(2), 152-162.

Hayes, A. F., \& Preacher, K. J. (2013). Conditional process modeling: Using structural equation modeling to examine contingent causal processes.

Headey, B., \& Grabka, M. M. (2007). Pets and human health in Germany and Australia: National longitudinal results. Social Indicators Research, 80(2), 297-311.

Headey, B., Na, F., \& Zheng, R. (2008). Pet dogs benefit owners' health: A 'natural experiment' in China. Social Indicators Research, 87(3), 481-493.

Heinrichs, M., Baumgartner, T., Kirschbaum, C., and Ehlert, U. (2003). Social support and oxytocin interact to suppress cortisol and subjective responses to psychosocial stress. Biol. Psychiatry, 54, 1389-1398.

Hellhammer, D. H., Wüst, S., \& Kudielka, B. M. (2008;2009;). Salivary cortisol as a biomarker in stress research. Psychoneuroendocrinology, 34(2), 163-171.

Herzog, H. (2011). The impact of pets on human health and psychological well-being: Fact, fiction, or hypothesis? Current Directions in Psychological Science, 20(4), 236-239.

Hu, M., Zhang, P., Leng, M., Li, C., \& Chen, L. (2018). Animal-assisted intervention for individuals with cognitive impairment: A meta-analysis of randomized controlled trials and quasirandomized controlled trials. Psychiatry Research, 260, 418-427. 
Hughes, M. E., Waite, L. J., Hawkley, L. C., \& Cacioppo, J. T. (2004). A short scale for measuring loneliness in large surveys: Results from two population-based studies. Research on Aging, 26(6), 655-672.

Holcomb, R., Williams, R. C., \& Richards, P. S. (1985). The elements of attachment: Relationship maintenance and intimacy. Journal of the Delta Society, 2(1), 28-34.

Inoue, H., Yamasue, H., Tochigi, M., Abe, O., Liu, X., Kawamura, Y., . . Kasai, K. (2010).

Association between the oxytocin receptor gene and amygdalar volume in healthy adults. Biological Psychiatry, 68(11), 1066-1072.

Irvine, L., Kahl, K. N., \& Smith, J. M. (2012). Confrontations and Donations: Encounters between homeless pet owners and the public. The Sociological Quarterly, 53(1), 25-43.

Johnson, T. P., Garrity, T. F., \& Stallones, L. (1992). Psychometric evaluation of the Lexington Attachment to Pets Scale (LAPS). Anthrozoös, 5(3), 160-175.

Kabel, A., Khosla, N., \& Teti, M. (2015). The dog narratives: Benefits of the human-animal bond for women with HIV. Journal of HIV/AIDS \& Social Services, 14(4), 405-416.

Kertes, D. A., Liu, J., Hall, N. J., Hadad, N. A., Wynne, C. D. L., \& Bhatt, S. S. (2017). Effect of pet dogs on children's perceived stress and cortisol stress response. Social Development, 26(2), 382-401.

Kim, H. S., Sherman, D. K., Sasaki, J. Y., Xu, J., Chu, T. Q., Ryu, C., . . Taylor, S. E. (2010). Culture, distress, and oxytocin receptor polymorphism (OXTR) interact to influence emotional support seeking. Proceedings of the National Academy of Sciences of the United States of America, 107(36), 15717-15721. 
Koivusilta, L. K., \& Ojanlatva, A. (2006). To have or not to have a pet for better health? PloS One, 1(1), e109.

Kovács, K., Virányi, Z., Kis, A., Turcsán, B., Hudecz, Á., Marmota, M. T., . . Topál, J. (2018). Dogowner attachment is associated with oxytocin receptor gene polymorphisms in both parties. A comparative study on Austrian and Hungarian border collies. Frontiers in Psychology, 9, 435.

Krause-Parello, C. A., \& Gulick, E. E. (2013). Situational factors related to loneliness and loss over time among older pet owners. Western Journal of Nursing Research, 35(7), 905-919.

Kurdek, L. A. (2008). Pet dogs as attachment figures. Journal of Social and Personal Relationships, 25(2), 247-266.

Kurdek, L. A. (2009). Pet dogs as attachment figures for adult owners. Journal of Family Psychology, 23(4), 439-446.

Labrecque, J., \& Walsh, C. A. (2011). Homeless women's voices on incorporating companion animals into shelter services. Anthrozoös, 24(1), 79-95.

Lee, R.M., Draper, M., Lee, S. (2001). Social connectedness, dysfunctional interpersonal behaviors, and psychological distress: Testing a mediator model. Journal of Counselling Psychology, 48, 310-318.

Lem, M., Coe, J. B., Haley, D., Stone, E., \& O'Grady, W. (2013). Effects of companion animal ownership among canadian street-involved youth: A qualitative analysis. Journal of Sociology \& Social Welfare, 40(4), 285. 
Lem, M., Coe, J. B., Haley, D. B., Stone, E., \& O'Grady, W. (2016). The protective association between pet ownership and depression among street-involved youth: A cross-sectional study. Anthrozoös, 29(1), 123-136.

Li, J., Zhao, Y., Li, R., Broster, L. S., Zhou, C., \& Yang, S. (2015). Association of oxytocin receptor gene (OXTR) rs53576 polymorphism with sociality: A meta-analysis. PloS One, 10(6).

Light, K. C., Grewen, K. M., \& Amico, J. A. (2005). More frequent partner hugs and higher oxytocin levels are linked to lower blood pressure and heart rate in premenopausal women. Biological Psychology, 69(1), 5-21.

Massey-Abernathy, A. (2017). From oxytocin to health: Exploring the relationship between OXTR rs53576, emotional stability, social support, and health. Adaptive Human Behavior and Physiology, 3(3), 212-220.

Matheson, K. \& Anisman, H. (2003). Systems of coping associated with dysphoria, anxiety, and depressive illness: A multivariate profile perspective. Stress, 6, 223-234.

McCullough, M. E., Churchland, P. S., \& Mendez, A. J. (2013). Problems with measuring peripheral oxytocin: Can the data on oxytocin and human behavior be trusted? Neuroscience and Biobehavioral Reviews, 37(8), 1485-1492.

McNicholas, J., \& Collis, G. M. (2000). Dogs as catalysts for social interactions: Robustness of the effect. British Journal of Psychology, 91(1), 61-70.

McNicholas, J., Gilbey, A., Rennie, A., Ahmedzai, S., Dono, J., \& Ormerod, E. (2005). Pet ownership and human health: A brief review of evidence and issues. Bmj, 331(7527), 1252- 1254. 
McQuaid, R., McInnis, O., Stead, J., Matheson, K., \& Anisman, H. (2014). A paradoxical association of an oxytocin receptor gene polymorphism: Early-life adversity and vulnerability to depression. Frontiers in Neuroendocrine Science, 7, 128.

McQuaid, R. J., McInnis, O. A., Matheson, K., \& Anisman, H. (2015). Distress of ostracism: Oxytocin receptor gene polymorphism confers sensitivity to social exclusion. Social Cognitive and Affective Neuroscience, 10(8), 1153-1159.

Meehan, M., Massavelli, B., \& Pachana, N. (2017). Using attachment theory and social support theory to examine and measure pets as sources of social support and attachment figures. Anthrozoös, 30(2), 273-289.

Miller, S. C., Kennedy, C. C., DeVoe, D. C., Hickey, M., Nelson, T., \& Kogan, L. (2009). An examination of changes in oxytocin levels in men and women before and after interaction with a bonded dog. Anthrozoös, 22(1), 31-42.

Miltiades, H., \& Shearer, J. (2011). Attachment to pet dogs and depression in rural older adults. Anthrozoös, 24(2), 147-154.

Monin, J. K., Goktas, S. O., Kershaw, T., \& DeWan, A. (2019). Associations between spouses' oxytocin receptor gene polymorphism, attachment security, and marital satisfaction. PloS One, 14(2), e0213083-e0213083.

Mubanga, M., Byberg, L., Nowak, C., Egenvall, A., Magnusson, P. K., Ingelsson, E., ... Institutionen för kirurgiska vetenskaper. (2017). Dog ownership and the risk of cardiovascular disease and death - a nationwide cohort study. Scientific Reports, 7(1), 19. 
Müllersdorf, M., Granström, F., Sahlqvist, L., Tillgren, P., Medicinska och farmaceutiska vetenskapsområdet, Uppsala universitet, . . . Centrum för klinisk forskning i D län (CKFD). (2010). Aspects of health, physical/leisure activities, work and socio-demographics associated with pet ownership in sweden. Scandinavian Journal of Public Health, 38(1), 53-63.

Nimer, J., \& Lundahl, B. (2007). Animal-assisted therapy: A meta-analysis. Anthrozoös, 20(3), 225- 238.

Odendaal, J. S. J., \& Meintjes, R. A. (2003). Neurophysiological correlates of affiliative behaviour between humans and dogs. The Veterinary Journal, 165(3), 296-301.

Ory, M. \& Goldberg, E. (1983). Pet possession and well-being in elderly women. Research on Aging, 5, 389-409.

Peacock, J., Chur-Hansen, A., \& Winefield, H. (2012). Mental health implications of human attachment to companion animals. Journal of Clinical Psychology, 68(3), 292-303.

Petersson, M., Uvnäs-Moberg, K., Nilsson, A., Gustafson, L., Hydbring-Sandberg, E., Handlin, L., . . . Högskolan i Skövde. (2017). Oxytocin and cortisol levels in dog owners and their dogs are associated with behavioral patterns: An exploratory study. Frontiers in Psychology, 8, 1796-1796.

Polheber, J. P., \& Matchock, R. L. (2014). The presence of a dog attenuates cortisol and heart rate in the Trier Social Stress Test compared to human friends. Journal of Behavioral Medicine, 37(5), 860-867. 
Revicki, D. A., Turner, R., Brown, R., \& Martindale, J. J. (1992). Reliability and validity of a healthrelated quality of life battery for evaluating outpatient antidepressant treatment. Quality of Life Research, 1(4), 257-266.

Rew, L. (2000). Friends and pets as companions: Strategies for coping with loneliness among homeless youth. Journal of Child and Adolescent Psychiatric Nursing, 13(3), 125-132.

Rhoades, H., Winetrobe, H., \& Rice, E. (2015). Pet ownership among homeless youth: Associations with mental health, service utilization and housing status. Child Psychiatry and Human Development, 46(2), 237-244.

Rodrigues, S. M., Saslow, L. R., Garcia, N., John, O. P., \& Keltner, D. (2009). Oxytocin receptor genetic variation relates to empathy and stress reactivity in humans. Proceedings of the National Academy of Sciences of the United States of America, 106(50), 21437-21441.

Rynearson, E. (1978). Humans and pets and attachment. The British Journal of Psychiatry, 133(6), $550-555$.

Sable, P. (1995). Pets, attachment, and well-being across the life cycle. Social Work, 40(3), 334341.

Saunders, J., Parast, L., Babey, S. H., \& Miles, J. V. (2017). Exploring the differences between pet and non-pet owners: Implications for human-animal interaction research and policy. PloS One, 12(6), e0179494.

Schanzer, B., Dominguez, B., Shrout, P. E., \& Caton, C. L. M. (2007). Homelessness, health status, and health care use. American Journal of Public Health, 97(3), 464-469. 
Stammbach, K. B., \& Turner, D. C. (1999). Understanding the Human-Cat relationship: Human social support or attachment. Anthrozoös, 12(3), 162-168.

Stanley, I. H., Conwell, Y., Bowen, C., \& Van Orden, K. A. (2014). Pet ownership may attenuate loneliness among older adult primary care patients who live alone. Aging \& Mental Health, 18(3), 394-399.

Sugawara, A., Masud, M. M., Yokoyama, A., Mizutani, W., Watanuki, S., Yanai, K., .. Tashiro, M. (2012). Effects of presence of a familiar pet dog on regional cerebral activity in healthy volunteers: A positron emission tomography study. Anthrozoös, 25(1), 25-34.

Testoni, I., De Cataldo, L., Ronconi, L., \& Zamperini, A. (2017). Pet loss and representations of death, attachment, depression, and euthanasia. Anthrozoös, 30(1), 135-148.

Turner, D. C., Rieger, G., \& Gygax, L. (2003). Spouses and cats and their effects on human mood. Anthrozoös, 16(3), 213-228.

Tops, S., Habel, U., \& Radke, S. (2018). Genetic and epigenetic regulatory mechanisms of the oxytocin receptor gene (OXTR) and the (clinical) implications for social behavior. Hormones and Behavior, doi:10.1016/j.yhbeh.2018.03.002.

Utz, R. L. (2014). Walking the dog: The effect of pet ownership on human health and health behaviors. Social Indicators Research, 116(2), 327-339.

Valstad, M., Alvares, G. A., Egknud, M., Matziorinis, A. M., Andreassen, O. A., Westlye, L. T., \& Quintana, D. S. (2017). The correlation between central and peripheral oxytocin concentrations: A systematic review and meta-analysis. Neuroscience and Biobehavioral Reviews, 78, 117-124. 
Virués-Ortega, J., Pastor-Barriuso, R., Castellote, J. M., Población, A., \& de Pedro-Cuesta, J. (2012). Effect of animal-assisted therapy on the psychological and functional status of elderly populations and patients with psychiatric disorders: A meta-analysis. Health Psychology Review, 6(2), 197-221.

Watson, J., Crawley, J., \& Kane, D. (2016). Social exclusion, health and hidden homelessness. Public Health, 139, 96-102.

Wells, D. L. (2009). The effects of animals on human health and well-being. The Journal of Social Issues, 65(3), 523-543.

Winefield, H. R., Black, A., \& Chur-Hansen, A. (2008). Health effects of ownership of and attachment to companion animals in an older population. International Journal of Behavioral Medicine, 15(4), 303-310.

Wisdom, J. P., Saedi, G. A., \& Green, C. A. (2009). Another breed of "service" animals: STARS study findings about pet ownership and recovery from serious mental illness. American Journal of Orthopsychiatry, 79(3), 430-436.

Wood, L., Giles-Corti, B., \& Bulsara, M. (2005). The pet connection: Pets as a conduit for social capital? Social Science \& Medicine, 61(6), 1159-1173.

Wood, L., Martin, K., Christian, H., Nathan, A., Lauritsen, C., Houghton, S., . . McCune, S. (2015). The pet factor-companion animals as a conduit for getting to know people, friendship formation and social support. PloS One, 10(4).

Wright, J. D., Kritz-Silverstein, D., Morton, D. J., Wingard, D. L., \& Barrett-Connor, E. (2007). Pet ownership and blood pressure in old age. Epidemiology, 18(5), 613-618. 
Wu, N., Li, Z., \& Su, Y. (2012). The association between oxytocin receptor gene polymorphism (OXTR) and trait empathy. Journal of Affective Disorders, 138(3), 468-47. 
Appendix A: Materials for Study 1

Recruitment Materials

\section{Informational Handout}

\section{Pets and Our Well-being}

What are we hoping to learn?

This study aims to investigate how our relationships with our pets and other personal factors (including genetics) may interact to produce different physical and mental health outcomes.

Who can participate?

To participate in this study, you must be:

- $18+$ years old

- A current pet owner

- Able to speak and understand English

What's involved?

You will be asked to fill out a short questionnaire and to provide a saliva sample by spitting into a tube; the estimated duration for participating is 15-20 minutes.

Participation is completely voluntary and you are free to skip any step or question that you are not comfortable with. As a thank-you for participating, you will receive a small treat package for your dog or cat!

Who is running this study?

This study is being conducted by Maria Pranschke, a graduate student in Carleton University's Neuroscience department. The research is supported by Carleton's CHAIM Centre (Canadian Health Adaptations, Innovations, \& Mobilization). The CHAIM Centre advances health research and its application to health care accessibility and programs across Canada.

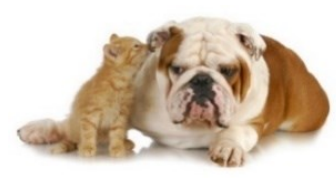

CUREB-B Clearance \#: 107984 
Pets \& Our Well-being: Recruitment Script

Hello, my name is - I am a graduate/undergraduate student at Carleton University in the Neuroscience/Psychology Department. We are conducting a research study on pet ownership and health outcomes. Are you a pet owner who is over the age of 18 ?

(If yes to both, offer the informational handout for reference and continue with script.)

If you would like to participate in this study, you will be asked to read through a consent form, fill out a series of brief questionnaires about your physical and mental well-being as well as some basic demographic information, and to provide a saliva sample by spitting into a tube; you will have the option of using a cardboard privacy screen or leaving the area to complete the sample in the washroom if you prefer. You do not need to provide your name or address to participate. Participation is completely voluntary, and you would be free to skip any question or step (such as giving the saliva sample) or stop at any time if you don't feel comfortable. The total duration of the study is about 15-20 minutes, and as a thank-you for participating, you would receive a small treat package for a dog or a cat.

We also ask that participants not eat or drink anything 30 minutes prior to providing their saliva sample. If you are interested in taking part but have had something to eat or drink within the last 30 minutes, please feel free to come back later and participate then!

Would you like to participate?

(If participant is still interested, proceed to Qualtrics and informed consent.) 


\section{A RESEARCH STUDY ON}

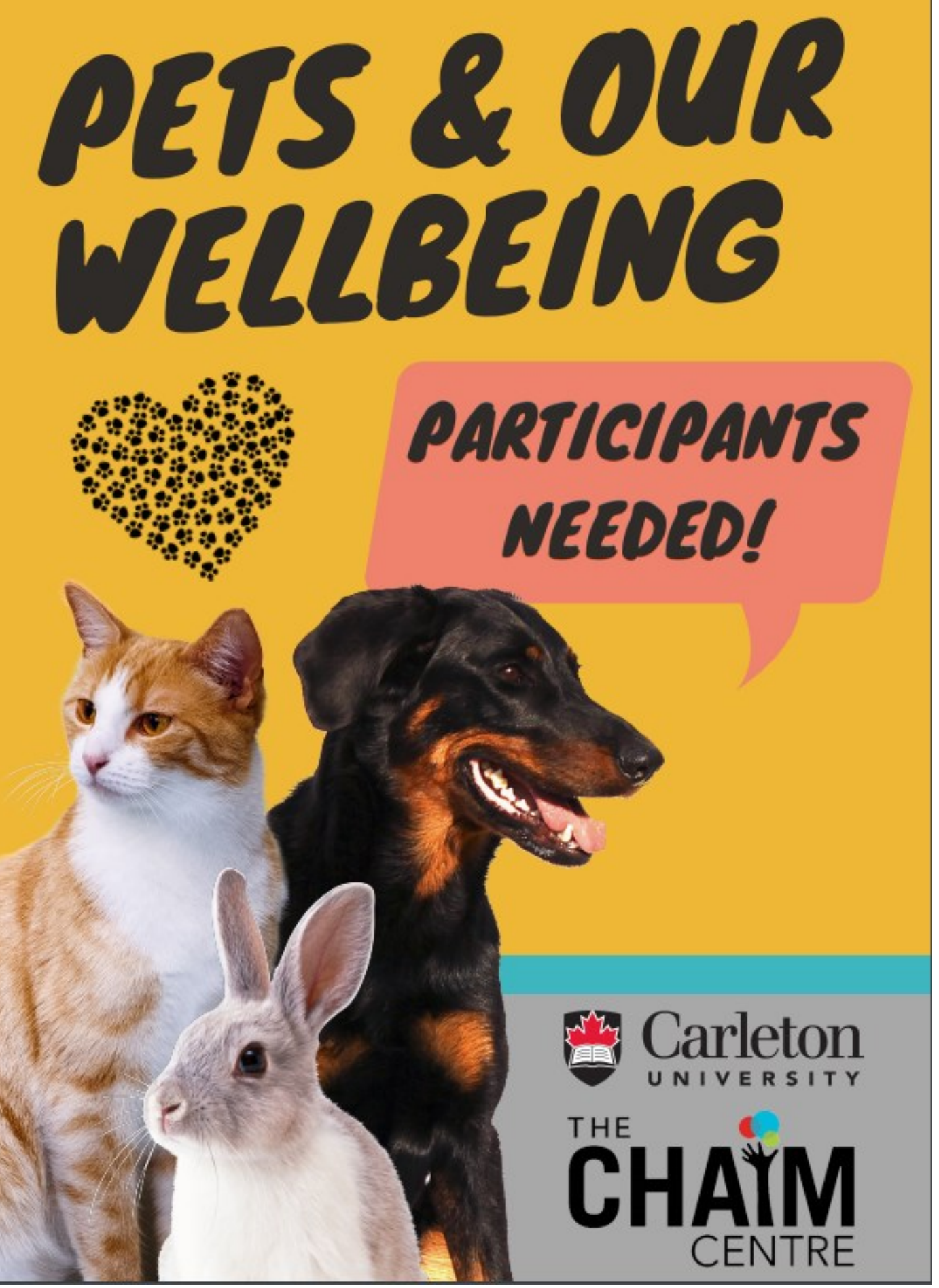


Pets \& Our Well-being: Informed Consent

Title: Pets and Our Well-being

The lead researcher for this study is Maria Pranschke in the Department of Neuroscience at Carleton University. She is working under the supervision of Dr. Kim Matheson and Dr. Hymie Anisman in the Department of Neuroscience at Carleton University.

Purpose: The purpose of this study is to investigate the relationship between pet ownership and physical and mental health outcomes. We are also interested in examining certain genetic characteristics and polymorphisms in order to determine whether these factors influence the nature of individuals' relationships with their pets.

\section{Eligibility criteria:}

To participate in this study, you must be:

- $18+$ years old

- A current pet owner

- Able to speak and understand English

\section{What are we asking you to do?}

We will be asking you to fill out a number of questionnaires relating to your background, physical and mental health, and sense of well-being, as well as your feelings towards your pet(s).

We are also asking participants to provide a DNA sample through the simple act of spitting into a tube; this process can take up to 5 minutes. You will be asked to not drink, eat, smoke or chew gum for 30 minutes before providing this sample.

This study should take approximately 15-20 minutes to complete.

For participating in this study, you will receive a small treat package for a dog or a cat.

\section{Potential risks or causes of discomfort for participants}

Some participants may feel embarrassment about spitting into a tube in a public area. There will be a cardboard divider set up to give you some privacy; alternatively, you are free to leave the booth and complete the sample in another area (e.g. the washroom) if you prefer.

\section{Anonymity and confidentiality}

All responses will be kept anonymous and confidential. All information and samples collected from you for this study will be identified with a code number, as opposed to any personal identifiers such as your name or address. Your responses may be used in future presentations or publications on the research topic; any reports on the data will use average responses only.

All research data and any notes will be encrypted and stored on a password-protected computer. Any hard copies of data (including any handwritten notes or USB keys) will be kept in a locked cabinet at Carleton University. Research data will only be accessible by the researchers and the research supervisors.

Genetic material collected will not be used for purposes other than research on the topic of human animal interaction, and genetic materials obtained will not be transferred to any other organizations or individuals for any purposes whatsoever. 
Once the project is completed, all research data will be kept for ten years and potentially used for other research projects on this same topic. At the end of ten years, all research data will be securely destroyed. Electronic data will be erased and hard copies will be shredded.

\section{Right to withdraw from this study}

Participation in this study is entirely voluntary. At any point during the study you have the right to not complete certain questions or to withdraw; you may choose to only complete the questionnaires and skip giving a saliva sample. Regardless of your choice to withdraw or to skip any step, you will still receive the treat package for a cat or dog. Please note that once you have completed the study, you will no longer be able to withdraw your data or genetic material as the research team will not be able to identify individual contributions.

The research has been cleared by Carleton University Research Ethics Board-B (CUREB-B Clearance \# 107984).

If you have any ethical concerns with the study, please contact Dr. Andy Adler, Chair, Carleton University Research Ethics Board-B and the Carleton University Research Compliance Office (phone: 613-520-2600 ext. 4085 or ethics@carleton.ca).

Should you have any other questions or concerns related to your involvement in this research, please contact:

\section{Researcher contact information:}

Maria Pranschke (Graduate Researcher)

Department of Neuroscience, Carleton University

Email: MariaPranschke@cmail.carleton.ca

Dr. Hymie Anisman

Department of Neuroscience, Carleton University

Tel: 613 520-2600 ext. 2699;

Email: hymie.anisman@carleton.ca
Dr. Kim Matheson

Department of Neuroscience,

Carleton University

Tel: 613 520-2600;

Email: kim.matheson@carleton.ca

Please indicate whether you agree to participate in this research by selecting one of the options below:

Yes, I agree to participate:

No, I do not agree to participate: 
Pets \& Our Well-being: Questionnaires

\section{Background Information}

1. What is your ethnic/racial background? Please select the one that best applies to you. Asian (e.g., Chinese, Japanese, Korean) South Asian (e.g., East Indian, Pakistani, Punjabi, Tamil, Sri Lankan) South East Asian (e.g., Cambodian, Indonesian, Laotian) Arab/West Asian (e.g., Armenian, Egyptian, Iranian, Lebanese, Moroccan) Black (e.g., African, Haitian, Jamaican, Somali) Latin American/Hispanic Indigenous (First Nations, Metis, Inuit) White/Euro-Caucasian Other (please specify):

2. What is your age? (Years)

3. What is your gender?

4. What is your current relationship status? Please select the one that best applies to you.

Single, and not seeing anyone

Going out with someone

In a serious dating relationship

Married

Separated/Divorced

Widowed

Prefer not to say

5. What is your height? (Feet/inches)

Prefer not to say 
6. What is your weight? (Pounds)

\section{Prefer not to say}

5. Do you currently have any health related (i.e., medical) illnesses or physical conditions?

NO, I don't

YES, I do

Prefer not to say

If YES, please specify disorder/condition

6. In your opinion, how would you describe your physical health?

Poor

Fair

Good

Very good

Excellent

7. Do you currently have a diagnosed mental health condition (e.g. depression, anxiety, etc.)?

NO, I don't

YES, I do

Prefer not to say

If YES, please specify condition

8. In your opinion, how would you describe your mental health?

Poor

Fair

Good

Very good

Excellent 
9. Do you currently smoke?

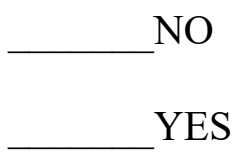

If YES, how many/day?

10. What is your estimate of your family's gross income per year? Please select the one that best applies to you.

under $\$ 15,000$

$\$ 15,000$ - $\$ 29,999$

$\$ 30,000$ - $\$ 44,999$

$\$ 45,000$ - $\$ 59,999$

Prefer not to say

$\$ 60,000-\$ 74,999$
$\$ 75,000-\$ 89,999$
$\$ 90,000-\$ 104,999$
$\$ 105,000$ or more

11. What is your employment status?

Employed Part-time

Employed Full-time

Unemployed

Retired

Other :

Prefer not to say

12. How many pets do you have?

One

Two

Three

$4+$

13. What kinds of pets do you own (check all that apply)?

Cat

Dog

Other:

14. How long have you had your oldest pet?

Years:

Months: 


\section{Lexington Attachment to Pets Scale}

Please tell us whether you agree or disagree with some very brief statements about your favorite pet. For each statement, check whether you strongly agree, somewhat agree, somewhat disagree, or strongly disagree. You may refuse to answer.

\begin{tabular}{ccccc}
$\begin{array}{c}\text { Strongly } \\
\text { Agree }\end{array}$ & $\begin{array}{c}\text { Somewhat } \\
\text { Agree }\end{array}$ & $\begin{array}{c}\text { Somewhat } \\
\text { Disagree }\end{array}$ & $\begin{array}{c}\text { Strongly } \\
\text { Disagree }\end{array}$ & $\begin{array}{c}\text { Don't know or } \\
\text { Refuse }\end{array}$ \\
\hline 1 & 2 & 3 & 4 & 5
\end{tabular}

1. My pet means more to me than any of my friends. $\quad 1 \quad 2 \quad 3 \quad 4 \quad 5$

2. Quite often I confide in my pet. $\quad \begin{array}{llllll}2 & 2 & 3 & 4 & 5\end{array}$

3. I believe that pets should have the same rights and $\begin{array}{llllll}1 & 2 & 3 & 4 & 5\end{array}$ privileges as family members.

$\begin{array}{lllllll}\text { 4. I believe my pet is my best friend. } & 1 & 2 & 3 & 4 & 5 \\ \text { 5. Quite often, my feelings toward people are } & 1 & 2 & 3 & 4 & 5\end{array}$
affected by the way they react to my pet.

6. I love my pet because he/she is more loyal to me $\quad \begin{array}{lllllll}1 & 2 & 3 & 4 & 5\end{array}$ than most of the people in my life.

7. I enjoy showing other people pictures of my pet. $\quad \begin{array}{llllll}1 & 2 & 3 & 4 & 5\end{array}$

8. I think my pet is just a pet. $\quad \begin{array}{llllll} & 1 & 2 & 3 & 4 & 5\end{array}$

9. I love my pet because it never judges me. $\quad \begin{array}{lllllll}1 & 2 & 3 & 4 & 5\end{array}$

10. My pet knows when I'm feeling bad. $\quad \begin{array}{llllll}1 & 2 & 3 & 4 & 5\end{array}$

11. I often talk to other people about my pet. $\quad \begin{array}{llllll}2 & 2 & 3 & 4 & 5\end{array}$

$\begin{array}{llllll}\text { 12. My pet understands me. } & 1 & 2 & 3 & 4 & 5 \\ \text { 13. I believe that loving my pet helps me stay healthy. } & 1 & 2 & 3 & 4 & 5\end{array}$

$\begin{array}{lllllll}\text { 14. Pets deserve as much respect as humans do. } & 1 & 2 & 3 & 4 & 5 \\ \text { 15. My pet and I have a very close relationship. } & 1 & 2 & 3 & 4 & 5\end{array}$

\begin{tabular}{|c|c|c|c|c|c|}
\hline 16. I would do almost anything to take care of my pet. & 1 & 2 & 3 & 4 & 5 \\
\hline 17. I play with my pet quite often. & 1 & 2 & 3 & 4 & 5 \\
\hline 18. I consider my pet to be a great companion. & 1 & 2 & 3 & 4 & 5 \\
\hline 19. My pet makes me feel happy. & 1 & 2 & 3 & 4 & 5 \\
\hline
\end{tabular}




\begin{tabular}{|c|c|c|c|c|c|}
\hline 20. I feel that my pet is a part of my family. & 1 & 2 & 3 & 4 & 5 \\
\hline 21. I am not very attached to my pet. & 1 & 2 & 3 & 4 & 5 \\
\hline \multicolumn{6}{|l|}{ 22. Owning a pet adds to my happiness. } \\
\hline 23. I consider my pet to be a friend. & 1 & 2 & 3 & 4 & 5 \\
\hline
\end{tabular}

\section{Quality of Life Questionnaire (QOLQ)}

For each of the following, please choose the answer that best describes how satisfied you are with that area of your life. Circle the number on the scale below that comes closest to how you feel.

1. In general, how satisfied or dissatisfied are you with your physical health as it is right now?
Completely
Dissatisfied
$\begin{array}{llllc}1 & 2 & 3 & 4 & 5 \\ \text { Neutral }\end{array}$
Completely
Satisfied

2. In general, how satisfied or dissatisfied are you with your work life as it is right now?
Completely
Dissatisfied
123
$4 \underset{\text { Neutral }}{5} 6$
$\begin{array}{llll}7 & 8 & 9 & 10\end{array}$
Completely
Satisfied

3. In general, how satisfied or dissatisfied are you with your social life as it is right now?
Completely
Dissatisfied
123
45 Neutral
Completely
Satisfied

4. In general, how satisfied or dissatisfied are you with your home life as it is right now?

Completely

Dissatisfied

$$
\begin{array}{llllc}
1 & 2 & 3 & 4 & 5 \\
\text { Neutral }
\end{array}
$$

5. In general, how satisfied or dissatisfied are you with your emotional state as it is right now?

Completely

Dissatisfied

$$
\begin{array}{llllll}
1 & 2 & 3 & 4 & 5 & 6 \\
\text { Neutral }
\end{array}
$$

7

$9 \quad 10$

Completely

Satisfied

6. In general, how satisfied or dissatisfied are you with your recreational life as it is right now?

Completely

Dissatisfied

$\begin{array}{lllll}1 & 2 & 3 & 4 & 5 \\ \text { Neutral }\end{array}$

7. In general, how satisfied or dissatisfied are you with your life as a whole right now?

Completely

Dissatisfied

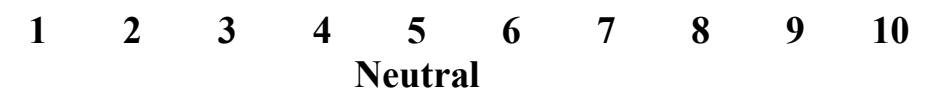




\section{Connor-Davidson Resilience Scale (CD-RISC)}

Considering your experiences over the last month, please rate how true the following statements are on a scale of 0 (rarely true) to 4 (true nearly all of the time). Please circle the appropriate number next to each question.

\begin{tabular}{ccccc}
$\begin{array}{c}\text { Not True } \\
\text { at All }\end{array}$ & $\begin{array}{c}\text { Rarely } \\
\text { True }\end{array}$ & $\begin{array}{c}\text { Sometimes } \\
\text { True }\end{array}$ & $\begin{array}{c}\text { Often } \\
\text { True }\end{array}$ & $\begin{array}{c}\text { True Nearly } \\
\text { all of the Time }\end{array}$ \\
\hline 1 & 2 & 3 & 4 & 5
\end{tabular}

Over the past month...

1. I was able to adapt to change. $\quad \begin{array}{llllll} & \mathbf{2} & \mathbf{3} & \mathbf{4} & 5\end{array}$

2. I could deal with whatever came my way. $\quad \begin{array}{llllll}2 & 2 & 3 & 4 & 5\end{array}$

3. I tried to see the humourous side of problems. $\quad \begin{array}{llllll}1 & 2 & 3 & 4 & 5\end{array}$

4. I thought that coping with stress could strengthen $\quad \begin{array}{llllll}1 & 2 & 3 & 4 & 5\end{array}$ me.

5. I tended to bounce back after illness or hardship. $\begin{array}{llllll}1 & 2 & 3 & 4 & 5\end{array}$

6. I could achieve goals despite obstacles being in my $\begin{array}{llllll}1 & 2 & 3 & 4 & 5\end{array}$ way.

7. I could stay focused under pressure. $\quad \begin{array}{llllll} & 1 & 2 & 3 & 4 & 5\end{array}$

8. I was not easily discouraged by failure. $\quad \begin{array}{llllll}1 & 2 & 3 & 4 & 5\end{array}$

9. I thought of myself as a strong person. $\quad \begin{array}{llllll}1 & 2 & 3 & 4 & 5\end{array}$

10. I could handle unpleasant feelings. $\quad \begin{array}{lllllll}1 & 2 & 3 & 4 & 5\end{array}$ 


\section{Social Connectedness Scale (SCS-15)}

The following are a number of statements that reflect various ways in which we view ourselves. Rate the degree to which you agree or disagree with each statement using the following scale $(1=$ Strongly Disagree and 6= Strongly Agree). There is no right or wrong answer. Do not spend too much time with any one statement and do not leave any unanswered.

\begin{tabular}{cccccc}
$\begin{array}{c}\text { Strongly } \\
\text { Disagree }\end{array}$ & Disagree & $\begin{array}{c}\text { Mildly } \\
\text { Disagree }\end{array}$ & $\begin{array}{c}\text { Mildly } \\
\text { Agree }\end{array}$ & Agree & $\begin{array}{c}\text { Strongly } \\
\text { Agree }\end{array}$ \\
\hline 1 & 2 & 3 & 4 & 5 & 6
\end{tabular}

1. Even among my friends, there is no sense of brother/sisterhood. 6

2. I feel close to people.

$\begin{array}{lllll}1 & 2 & 3 & 4 & 5\end{array}$

6

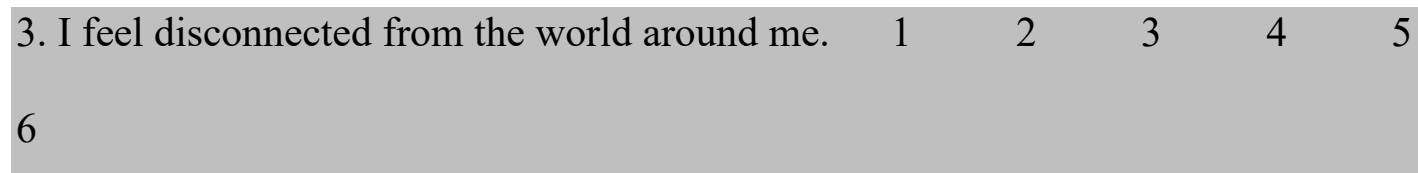

4. Even around people I know, I don't feel that I $\begin{array}{llllllll}\text { really belong. } & 1 & 2 & 3 & 4 & 5\end{array}$ 6

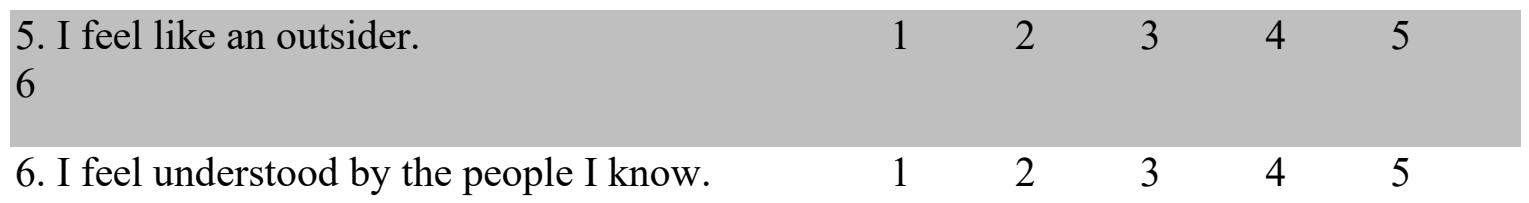
6

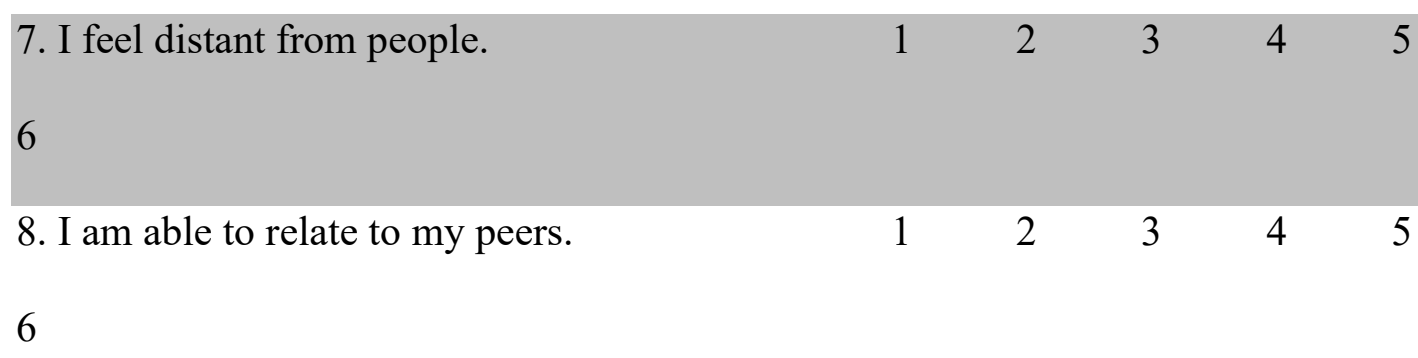

9. I have little sense of togetherness with 


\begin{tabular}{|c|c|c|c|c|c|}
\hline $\begin{array}{l}\text { my peers. } \\
6\end{array}$ & 1 & 2 & 3 & 4 & 5 \\
\hline $\begin{array}{l}\text { 10. I find myself actively involved in } \\
6 \\
\text { people's lives. }\end{array}$ & 1 & 2 & 3 & 4 & 5 \\
\hline $\begin{array}{l}\text { 11. I catch myself losing a sense of } \\
6 \\
\text { connectedness with society. }\end{array}$ & 1 & 2 & 3 & 4 & 5 \\
\hline $\begin{array}{l}\text { 12. I see myself as a loner. } \\
6\end{array}$ & 1 & 2 & 3 & 4 & 5 \\
\hline $\begin{array}{l}\text { 13. I don't feel related to most people. } \\
6\end{array}$ & 1 & 2 & 3 & 4 & 5 \\
\hline $\begin{array}{l}\text { 14. My friends feel like family. } \\
6\end{array}$ & 1 & 2 & 3 & 4 & 5 \\
\hline $\begin{array}{l}15 . \text { I don't feel I participate with anyone or } \\
6 \\
\text { any group. }\end{array}$ & 1 & 2 & 3 & 4 & 5 \\
\hline
\end{tabular}




\section{3-item Rumination Scale}

\begin{tabular}{cccc} 
Never & Sometimes & Often & Always \\
\hline 0 & 1 & 2 & 3
\end{tabular}

Ordinarily, in recent months have you:

1. Gone over your problems in your mind over and over again?

2. Thought about your problems a lot?

3. Worried about your problems a lot?

$\begin{array}{llll}\mathbf{0} & \mathbf{1} & \mathbf{2} & \mathbf{3}\end{array}$

$\begin{array}{llll}0 & 1 & 2 & 3\end{array}$

$\begin{array}{llll}0 & 1 & 2 & 3\end{array}$

\begin{tabular}{ccc}
\multicolumn{3}{c}{ 3-item Loneliness Scale } \\
$\begin{array}{c}\text { Hardly } \\
\text { Ever }\end{array}$ & $\begin{array}{c}\text { Some of the } \\
\text { Time }\end{array}$ & Often \\
\hline 1 & 2 & 3
\end{tabular}

1. How often do you feel that you lack companionship? $\quad \begin{array}{llll}2 & 2 & 3\end{array}$

2. How often do you feel left out? $\quad \begin{array}{llll}1 & 2 & 3\end{array}$

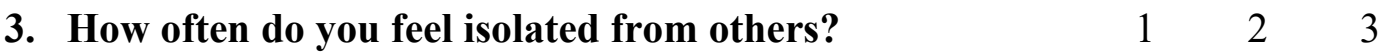


The Centre for Epidemiological Studies Depression Scale Short Form (CED-S-10)

For each statement, please indicate how often you have felt this way recently by selecting the option you most agree with.

\begin{tabular}{lccc}
$\begin{array}{l}\text { Rarely or } \\
\text { none of the } \\
\text { time }\end{array}$ & $\begin{array}{c}\text { Some or a } \\
\text { little of the } \\
\text { time }\end{array}$ & $\begin{array}{c}\text { Occasionally or } \\
\text { a moderate } \\
\text { amount of time } \\
(<1 \text { day })\end{array}$ & $\begin{array}{c}\text { All of } \\
\text { the time }\end{array}$ \\
\hline 1 & $(1-2$ days $)$ & $(5-7$ days $)$ & $\begin{array}{c}(5-7 \\
\text { days })\end{array}$ \\
\hline 1 & 2 & 3 & 4
\end{tabular}

1. I was bothered by things that don't usually bother me. $\begin{array}{lllll}1 & 2 & 3 & 4\end{array}$

2. I had trouble keeping my mind on what I was doing. $\begin{array}{lllll}1 & 2 & 3 & 4\end{array}$

3. I felt depressed. $\quad \begin{array}{lllll}1 & 2 & 3 & 4\end{array}$

4. I felt everything I did was an effort. $\quad \begin{array}{lllll}1 & 2 & 3 & 4\end{array}$

5. I felt hopeful about the future. $\quad \begin{array}{lllll}1 & 2 & 3 & 4\end{array}$

6. I felt fearful. $\quad \begin{array}{lllll}1 & 2 & 3 & 4\end{array}$

7. My sleep was restless. $\quad \begin{array}{lllll}1 & 2 & 3 & 4\end{array}$

8. I was happy. $\quad \begin{array}{llllll}1 & 2 & 3 & 4\end{array}$

9. I felt lonely. $\quad \begin{array}{lllll}1 & 2 & 3 & 4\end{array}$

10. I could not "get going". $\quad \begin{array}{lllll}1 & 2 & 3 & 4\end{array}$ 
Pets \& Our Well-being: Debriefing

\section{Study Title: Pets and Our Well-being}

\section{What are we trying to learn in this research?}

In this study, we are evaluating the effects of pet ownership on physical and mental health outcomes (e.g., depression, coping skills, health status, quality of life). In addition to the questionnaires, you were asked to provide a saliva sample. Genetic material (e.g., DNA) can be extracted from our saliva. In this case, we are interested in examining the relationships between your responses on some of the questionnaires and telomere length. Telomeres are regions at the ends of chromosomes that protect our genome from deteriorating; these regions shorten as we get older, and telomere length has been shown to be linked to psychological stress. We are also interested in assessing the impact of certain genes on pet ownership. Multiple forms of the same gene are present within the population, some of which might be related to our feelings towards pets and the degree of benefit obtained from owning them.

\section{Why is this important to scientists or the general public?}

Many pet owners view their animals as sources of companionship and support, and report beneficial health effects from interacting with them. Research on human-animal interaction and health has shown a link between owning a pet and several positive health outcomes, such as:

- Reduced stress levels

- Enhanced mood

- Lower rates of anxiety and depression

- Promotion of social interaction

- Increased exercise

- Improved cardiovascular health

In spite of this, many gaps remain in our understanding of how and why pets are beneficial to our health, especially as some of these benefits can be difficult to separate from other influences (such as income level) and challenging to measure. Investigating the factors that connect pet ownership to human health outcomes will further scientific knowledge in this area and could help provide a rationale for supporting pet ownership and human-animal interaction in general as a cost effective way of improving population health, particularly in vulnerable groups.

\section{What are our hypotheses and predictions?}

We predict that pet ownership will be associated with improved physical and mental health outcomes, and that this relationship will be moderated by the degree of 
attachment felt towards pets. We also hypothesize that pet ownership will confer resilience to stressors, and that this may be reflected in increased telomere length as a marker of general health; further, we predict that possession of certain gene alleles in combination with owning a pet will be associated with greater overall benefits to physical and mental health.

\section{Where can I learn more?}

https://www.ncbi.nlm.nih.gov/pmc/articles/PMC534658

https://www.ncbi.nlm.nih.gov/pmc/articles/PMC3408111/

Is there anything I can do if I found this experiment to be emotionally upsetting?

We do not anticipate that participants will be upset by anything in this study. However, reflecting on one's health can sometimes have an unexpected emotional impact. If you should feel upset, please feel free to contact the Distress Centre of Ottawa and Region at 613-238-3311 (http://www.dcottawa.on.ca) or the Mental Health Crisis Line at: (613) 722-6914 (http://www.crisisline.ca/).

\section{What if I have questions later?}

If you have any remaining concerns, questions, or comments about the experiment, please feel free to contact:

Maria Pranschke (Graduate Researcher)

MariaPranschke@cmail.carleton.ca

Dr. Hymie Anisman (Faculty Sponsor)

613 520-2600 ext. 2699

hymie.anisman@carleton.ca
Dr. Kim Matheson (Faculty Sponsor) $613520-2600$ ext. 2652

kim.matheson@carleton.ca

This ethics protocol for this project has been cleared by Carleton University Research Ethics Board-B (CUREB-B Clearance \# 107984).

If you have any ethical concerns with the study, please contact Dr. Andy Adler, Chair, Carleton University Research Ethics Board-B and the Carleton University Research Compliance Office (phone: 613-520-2600 ext. 4085 or ethics@carleton.ca). 


\section{Appendix B: Materials for Study 2}

Your Well-being: Recruitment Materials

\section{Informational Handout}

\section{Your Well-being}

\section{What are we hoping to learn?}

This study aims to investigate how our relationships with our pets and other personal factors (including genetics) may interact to produce different physical and mental health outcomes. We are also interested in gathering data from non-pet owners as a comparison group.

\section{Who can participate?}

To participate in this study, you must be:

- $18+$ years old

- Able to speak and understand English

\section{What's involved?}

You will be asked to fill out a short questionnaire and to provide a saliva sample by spitting into a tube; this will take about 15-20 minutes. Participation is completely voluntary and you are free to skip any step or question that you are not comfortable with. As a thank-you for participating, you will receive a chocolate bar or a treat bag for your pet.

\section{Who is running this study?}

This study is being conducted by Maria Pranschke, a graduate student in Carleton University's Neuroscience department. The research is supported by Carleton's CHAIM (Canadian Health Adaptations, Innovations, \& Mobilization) Centre. The CHAIM Centre advances health research and its application to health care accessibility and programs across Canada.

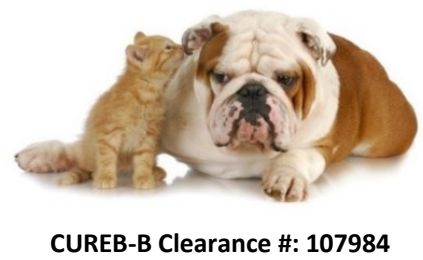




\section{Your Well-being: Recruitment Script}

Hello, my name is I am a graduate/undergraduate student at Carleton University in the Neuroscience Department. We are conducting a research study on pet ownership and health outcomes and we're interested in hearing from people who own pets as well as those who don't own pets. Are you over the age of 18 ?

(If yes to both, offer the informational handout for reference and continue with script.)

If you would like to participate in this study, you will be asked to read through a consent form, fill out a series of brief questionnaires about your physical and mental well-being as well as some basic demographic information, and to provide a saliva sample by spitting into a tube; you will have the option of using a cardboard privacy screen or leaving the area to complete the sample in the washroom if you prefer. You do not need to provide your name or address to participate. Participation is completely voluntary, and you would be free to skip any question or step (such as giving the saliva sample) or stop at any time if you don't feel comfortable. The total duration of the study is about 15-20 minutes, and as a thank-you for participating, you would receive a chocolate bar or treat bag for your pet if you have one.

We also ask that participants not eat or drink anything 30 minutes prior to providing their saliva sample. If you are interested in taking part but have had something to eat or drink within the last 30 minutes, please feel free to come back later and participate then!

Would you like to participate?

(If participant is still interested, proceed to Qualtrics and informed consent.) 
A RESEARCH STUDY ON

YOUR

WELLBENG

PARTICIPANTS

NEEDED!

CHAYM CWMTER Carleton

CUREB-B CLEARANCE: 107984

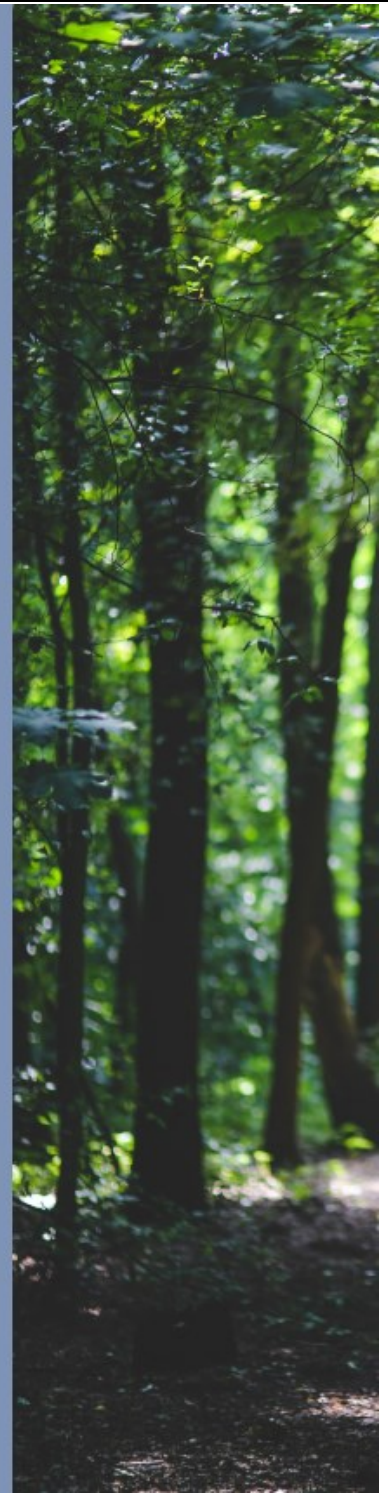


Title: Your Well-being

The lead researcher for this study is Maria Pranschke in the Department of Neuroscience at Carleton University. She is working under the supervision of Dr. Kim Matheson and Dr. Hymie Anisman in the Department of Neuroscience at Carleton University.

Purpose: The purpose of this study is to investigate the relationship between pet ownership and physical and mental health outcomes. We are interested in examining certain genetic characteristics and polymorphisms in order to determine whether these factors influence the nature of individuals' relationships with their pets. We would also like to speak to non-pet owners as a comparison group.

\section{Eligibility criteria:}

To participate in this study, you must be:

$18+$ years old

Able to speak and understand English

\section{What are we asking you to do?}

We will be asking you to fill out a number of questionnaires relating to your background, physical and mental health, and sense of well-being, as well as your feelings towards your pet if you have one.

We are also asking participants to provide a DNA sample through the simple act of spitting into a tube; this process can take up to 5 minutes. You will be asked to not drink, eat, smoke or chew gum for 30 minutes before providing this sample.

This study should take approximately 15-20 minutes to complete.

For participating in this study, you will receive a chocolate bar or treat bag for your pet.

\section{Potential risks or causes of discomfort for participants}

Some participants may feel embarrassment about spitting into a tube in a public area. There will be a cardboard divider set up to give you some privacy; alternatively, you are free to leave the booth and complete the sample in another area (e.g. the washroom) if you prefer.

\section{Anonymity and confidentiality}

All responses will be kept anonymous and confidential. All information and samples collected from you for this study will be identified with a code number, as opposed to any personal identifiers such as your name or address. Your responses may be used in future presentations or publications on the research topic; any reports on the data will use average responses only.

All research data and any notes will be encrypted and stored on a password-protected computer. Any hard copies of data (including any handwritten notes or USB keys) will be kept in a locked cabinet at Carleton University. Research data will only be accessible by the researchers and the research supervisors.

Genetic material collected will not be used for purposes other than research on the topic of human animal interaction, and genetic materials obtained will not be transferred to any other organizations or individuals for any purposes whatsoever.

Once the project is completed, all research data will be kept for ten years and potentially used for other research projects on this same topic. At the end of ten years, all research data will be securely destroyed. Electronic data will be erased and hard copies will be shredded. 


\section{Right to withdraw from this study}

Participation in this study is entirely voluntary. At any point during the study you have the right to not complete certain questions or to withdraw; you may choose to only complete the questionnaires and skip giving a saliva sample. Regardless of your choice to withdraw or to skip any step, you will still receive the chocolate bar or treat bag for your pet. Please note that once you have completed the study, you will no longer be able to withdraw your data or genetic material as the research team will not be able to identify individual contributions.

The research has been cleared by Carleton University Research Ethics Board-B (CUREB-B Clearance \# 107984).

Should you have any ethical concerns with the study, please contact Dr. Bernadette Campbell, Chair, Carleton University Research Ethics Board-B (by phone: 613-520-2600 ext. 4085 or by email: ethics@carleton.ca).

Should you have any other questions or concerns related to your involvement in this research, please contact:

\section{Researcher contact information:}

Maria Pranschke (Graduate Researcher) Department of Neuroscience,

Carleton University

Dr. Kim Matheson

Email: MariaPranschke@cmail.carleton.ca

Department of Neuroscience, Carleton University

Dr. Hymie Anisman

Tel: 613 520-2600

Email: kim.matheson@carleton.ca

Department of Neuroscience,

Carleton University

Tel: 613 520-2600 ext. 2699;

Email: hymie.anisman@carleton.ca 
Your Well-being: Questionnaires

7. background? Please select the one that best applies to you. Asian (e.g., Chinese, Japanese, Korean) South Asian (e.g., East Indian, Pakistani, Punjabi, Tamil, Sri Lankan) South East Asian (e.g., Cambodian, Indonesian, Laotian) Arab/West Asian (e.g., Armenian, Egyptian, Iranian, Lebanese, Moroccan) Black (e.g., African, Haitian, Jamaican, Somali) Latin American/Hispanic Indigenous (First Nations, Metis, Inuit) White/Euro-Caucasian Other (please specify):

8. What is your age? (Years)

9. What is your gender?

10. What is your current relationship status? Please select the one that best applies to you.

$\begin{array}{ll} & \text { Single } \\ & \text { Dating someone } \\ & \text { Common-law } \\ & \text { Married } \\ & \text { Separated/Divorced } \\ & \text { Widowed } \\ & \text { Prefer not to say }\end{array}$

5. What is your current living situation?

Living alone

Living with roommates

Living with partner

Living with family 
6. Do you currently have any health related (i.e., medical) illnesses or physical conditions?

NO, I don't

YES, I do

Prefer not to say

7. In your opinion, how would you describe your physical health?

Poor

Fair

Good

Very good

Excellent

8. Do you currently have a diagnosed mental health condition (e.g. depression, anxiety, etc.)?

NO, I don't

YES, I do

Prefer not to say

9. In your opinion, how would you describe your mental health?

Poor

Fair

Good

Very good

Excellent

10. Do you currently smoke?

NO

YES

If YES, how many/day? 
11. What is your estimate of your family's gross income per year? Please select the one that best applies to you. under $\$ 15,000$ $\$ 15,000$ - $\$ 29,999$ $\$ 30,000-\$ 44,999$ $\$ 45,000$ - $\$ 59,999$

\begin{tabular}{c}
$\$ 60,000-\$ 74,999$ \\
\hline$\$ 75,000-\$ 89,999$ \\
$\$ 90,000-\$ 104,999$ \\
\hline$\$ 105,000$ or more
\end{tabular}

Prefer not to say

12. What is your employment status?

Employed Part-time

Employed Full-time

Unemployed

Retired

Other :

Prefer not to say

13. Do you currently own a pet?

Yes

No (Note to CUREB-B: selecting "no" in Qualtrics will direct the participant to the Quality of Life Questionnaire, skipping the remainder of this section and the LAPS)

14. How many pets do you have?

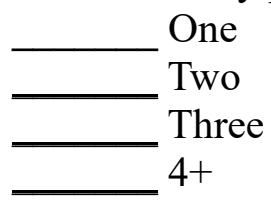

15. What kinds of pets do you own (check all that apply)?

Cat

Dog

Other:

16. When did you get your first pet of your own?

Years:

Months: 


\section{Appendix C: Materials for Study 3}

\section{The Impact of Attachment to Pets on Well-being: Recruitment Materials}

\section{Email to Caseworkers}

\section{Research Opportunity:}

Researchers from Carleton University will be on site at this clinic/event to conduct a study called "The Impact of Attachment to Pets on Well-being". Participation in this study is completely optional and voluntary, and will not affect clients' ability to receive services through CVO. The study will ask clients questions about pet ownership, demographics, mental and physical well-being, and health behaviour, and will also include a voluntary saliva sample in order to look at genetic factors. To participate, clients must be over 18 and be able to speak English; non-pet-owners will also be able to participate in a shortened version of the study. All individuals who take part in the study will receive a gift card and treat bag for their pet. For more information, please contact Maria Pranschke (lead researcher) by email at mariapranschke@cmail.carleton.ca.

\section{In-Person Script (to be used by researcher at event)}

Hi! We are researchers from Carleton University and we're doing a study about pets and well-being. Are you interested in hearing about the study?

(If yes) If you choose to participate, we would give you a questionnaire that asks you basic questions about yourself, your pet, and your health. You would choose whether to have a researcher go through the questionnaire with you, or to fill it out on your own.

Afterwards, we would ask you to provide a saliva sample by spitting into a tube (show them saliva collection kit). This would let us extract DNA and analyze small mutations in specific genes that are related to social behaviour and stress, and also to measure genetic indicators called telomeres that may be connected to stress. We would also like to audio record your answers to a few spoken questions about your pet and your health.

The whole study would take around 15-25 minutes to complete. You would be free to skip any of the steps or stop at any time if you feel uncomfortable. If you choose not to participate, it will not affect your ability to get veterinary services for your pet through CVO at any time. whether you finish the whole study or not, you will get a $15 \$$ gift card for Metro and a treat bag for your pet for participating. Would you like to participate in the study?

(If yes) Before we start, it's important that you understand what we're asking you to do. We have a document that explains the research process...(Proceed to informed consent process) 
The Impact of Attachment to Pets on Well-being: Informed Consent

The purpose of this informed consent document is to explain what the study is about and what you will be asked to do before you agree to participate. The main researcher for this study is Maria Pranschke. She is a student in the Department of Neuroscience at Carleton University. She is working with Dr. Kim Matheson and Dr. Hymie Anisman in the Department of Neuroscience at Carleton University and members of Community Veterinary Outreach (CVO). The researchers who will be speaking with you today are from Carleton University, and this study is separate from the services you get through CVO. Your choice to participate in this study will not affect your ability to receive veterinary services for your pet through CVO now or at any time in the future.

\section{What is the purpose of this study?}

We want to look at the relationship between owning a pet and your well-being. We are also interested in looking at how people's genetics may affect their relationships with their pets. We will do this by extracting DNA from saliva samples and analyzing small mutations in specific genes that are related to social behaviour and stress. We can also use this DNA to measure the length of your telomeres, which are genetic indicators that have been linked to stress.

\section{Who can participate?}

To participate, you must be over 18 and be able to speak English. If you do not own a pet, you are still welcome to participate in the $1^{\text {st }}$ and $2^{\text {nd }}$ parts of the study.

\section{What are we asking you to do?}

There are 3 parts to this study:

1. Filling out a written questionnaire with questions about your background, your health, and your feelings about your pet (if you own one). The questionnaire includes questions about drug and alcohol use, source of income,

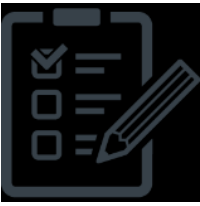
and your physical and mental health. Remember that you are free to skip any questions you don't want to answer. You can fill it out by yourself, or have a researcher go through it with you.

2. Giving a genetic sample by spitting into a tube. This can take up to 5 minutes and we will ask you not to drink, eat, smoke or chew gum for 30 minutes beforehand.

3. Answering some verbal questions about your pet(s) and your health. We will audio record your answers to these

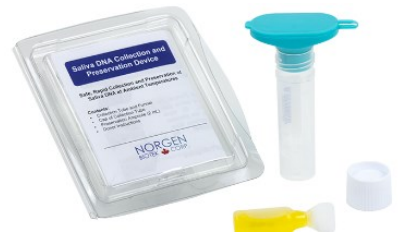


questions. If you do not own a pet, you would skip this step.

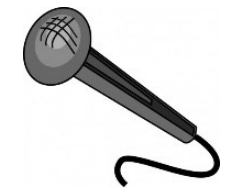

This study will take about 15-25 minutes to complete. As a thank-you for participating, you will get a $\$ 15$ gift card for the Metro grocery store and a treat bag for your pet.

\section{What are the risks?}

Some people may feel embarrassed about spitting into a tube in public. There will be a cardboard screen set up to give you some privacy. You can also leave the study area and give your sample in another room (like the washroom).

This study will ask you some sensitive questions about your mental and physical health. Thinking about your health can sometimes cause an unexpected emotional reaction. If you become upset by anything in this study, you can speak with your caseworker or with a member of the research team. Contact info for local mental health resources will also be provided at the end of the study.

\section{How will we keep your information safe and private?}

The information you give us will be labelled with a code number (not your name), so there will be no way to tell who it belongs to. It may be used in presentations or publications on the research topic. We will not include any information that could be used to identify you in any of our reports.

We will encrypt all of the information and store it on a password-protected computer. Any handwritten notes and USB keys will be kept in a locked cabinet at Carleton University. Only members of the research team will be able to access the information.

Your saliva tube will NOT be marked with your name, just a number. Your genetic material will only be used for research about people's relationships with their pets, and not for any other purpose. It will not be given to any other organizations or people for any reason.

Once the project is finished, all the research data, including saliva samples, will be kept for ten years and may be used for other research projects on the same topic. At the end of ten years, all the research data will be destroyed.

\section{What if I don't want to finish the study?}

As you go through the study, remember that you do not need to do anything you are not comfortable with. You can skip questions, decide not to give us a saliva sample, or choose to stop participating at any point. If you decide not to finish the whole study, you will still receive the gift card. Whether you decide to participate or not, you will still be able to access services for your pet through CVO. 
Once you have finished the study, you will no longer be able to take back your responses or your genetic material because the research team will not be able to tell who the individual samples and responses belong to.

The research has been cleared by Carleton University Research Ethics Board-B (CUREB-B Clearance \# 109013).

Should you have any ethical concerns with the study, please contact Dr. Bernadette Campbell, Chair, Carleton University Research Ethics Board-B (by phone: 613-520-2600 ext. 4085 or by email: ethics@carleton.ca). For all other questions about the study, please contact the researchers:

Maria Pranschke (Graduate Researcher) Department of Neuroscience, Carleton University

Email: MariaPranschke@cmail.carleton.ca

Participant name:

Researcher name:
Dr. Kim Matheson

Department of Neuroscience, Carleton University

Tel: 613 520-2600;

Email: kim.matheson@carleton.ca

Participant signature:

Researcher signature: 
The Impact of Attachment to Pets on Well-being: Questionnaires

\section{Background Information}

1. How many pets do you have?

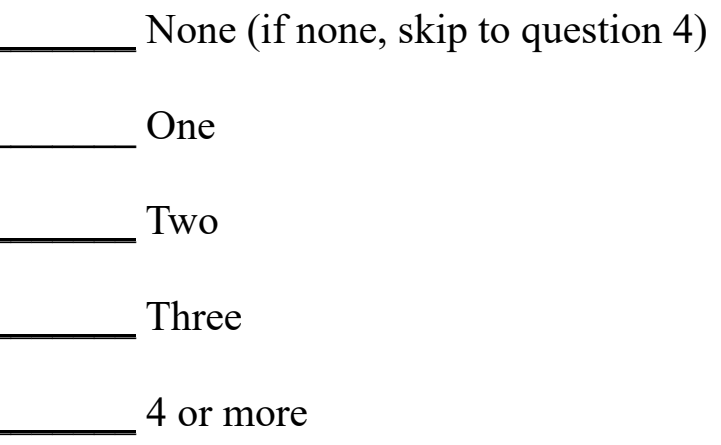

2. What kinds of pets do you own (check all that apply)?

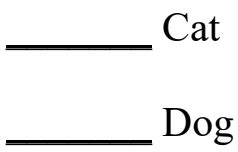

Other:

3. When did you get your first pet of your own?

Years:

Months:

4. What is your age? (Years)

5 . What is your gender? 
6. What is your ethnic/racial background? Please select the one that best applies to you. Asian (e.g., Chinese, Japanese, Korean)

South Asian (e.g., East Indian, Pakistani, Punjabi, Tamil, Sri Lankan)

South East Asian (e.g., Cambodian, Indonesian, Laotian)

Arab/West Asian (e.g., Armenian, Egyptian, Iranian, Lebanese, Moroccan)

Black (e.g., African, Haitian, Jamaican, Somali)

Latin American/Hispanic

Indigenous (First Nations, Metis, Inuit)

White/Euro-Caucasian

Other (please specify):

7. What is your current relationship status? Please select the one that best applies to you.

Single

Dating someone

Common-law

Married

Separated/Divorced

Widowed

Prefer not to say 
8. What is your current living situation?

Living in shelter or outdoors

Living alone

Living with roommates

Living with partner

Living with family

Do you currently have any physical health conditions?

NO, I don't

YES, I do

Prefer not to say

9. In your opinion, how would you describe your physical health?

Poor

Fair

Good

Very good

Excellent

10. Do you currently have any mental health conditions?

NO, I don't

YES, I do

Prefer not to say

11. In your opinion, how would you describe your mental health? 
Poor

Fair

Good

Very good

Excellent

12. What is your primary source of income?

Employed Part-time

Employed Full-time

Student

Ontario Works

Ontario Disability Support Program

Retired

CPP or private pension

Other :

Prefer not to say

13. Do you smoke tobacco regularly?

NO

YES

If YES, how many cigarettes per day?

Prefer not to say 
14. Do you drink alcohol regularly?

$\mathrm{NO}$

YES

If Yes, how many drinks per day?

Prefer not to say

15. In the past month, have you used any of the following substances recreationally (not for medical purposes)? Please check all that apply. NOTE: we will not use this information for anything other than research purposes.

Cannabis (e.g. weed, pot)

Opioids (e.g. prescription painkillers, heroin)

Cocaine (e.g. crack)

Other:

Prefer not to say 
The Impact of Attachment to Pets on Well-being: Debriefing

\section{What are we trying to learn?}

In this study, we want to find out if the way you feel about your pet affects your health. We also want to look at how genetics can affect your relationship with your pet. In large groups of people, slightly different forms of the same gene can occur because of tiny changes (or mutations) in DNA. We want to see if some of these mutations have an impact on people's health and the way they feel about their pets. Telomeres are parts of our DNA that protect our genome from breaking down, and they get shorter as we get older. Telomere length may also be related to how much stress we have in our lives. Because of this, we are interested in seeing if owning a pet and feeling close to them might affect the length of your telomeres.

\section{Why is this important?}

Many people see their pets as important sources of love and support. Research shows that owning a pet may be related to health benefits, like:

- Reduced stress

- Better mood

- More social interaction

- More exercise

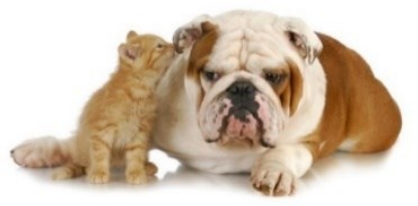

This study will help scientists understand the relationship between owning a pet and staying healthy.

\section{What are our predictions?}

- We predict that owning a pet will be related to better mental health, and that this relationship will be affected by how close people feel to their pets

- We predict that owning a pet will help people deal with stressful situations

- We predict that pet owners with different forms of certain genes will have greater health benefits

\section{Is there anything I can do if I found this study upsetting?}

We do not think that people will be upset by anything in this study. However, thinking about your health can sometimes cause an unexpected emotional reaction. If you feel upset, you may want to speak with your caseworker or contact:

- The Distress Centre of Ottawa and Region at 613-238-3311 (http://www.dcottawa.on.ca)

- The Mental Health Crisis Line at: (613) 722-6914 (http://www.crisisline.ca/)

What if I have questions later?

If you have any concerns, questions, or comments, please contact:

Maria Pranschke (Graduate Researcher)

Department of Neuroscience, Carleton University

Email: MariaPranschke@cmail.carleton.ca
Dr. Kim Matheson

Department of Neuroscience, Carleton University Tel: 613 520-2600; Email: kim.matheson@carleton.ca 


\section{Appendix D: Thematic Analysis Reflexivity Journal (MP)}

Feb. 22, 2019: First round of reading/recording themes

-Some responses difficult to understand (repeated words, interrupts/obscures meaning)

-Noticing similarities between responses \& LAPS statements...did this bias people? Should we have done this part first?

-Link between animal senses when I'm feeling bad and animal provides physical comfort (q.1)

-Given the context of CVO's events, hard not to focus on the financial issue but not everyone brings it up (q.2)

-Less repetition of themes for $q .3$

\section{Feb. 26, 2019: Second round of reading/recording themes}

-Starting with q.3 first, then q.2, then q.1

-Noticing a few different themes this time (some one-offs)

-Starting to imagine groupings (e.g. seeing them happy, taking care of them, feeling appreciated $\rightarrow$ meaning in being needed?)

-Link between watching pet and humour; also watching pet and seeing them happy (q.3)

-Owners referring to their pet as a "little dick" or an "asshole" make me laugh a bit because I call my own cats names like that sometimes (q.2)

-Lots of "no, never, not really" for q.2 but some follow up with a minor issue

-Starting to seem like most popular response to q.1 is physical comfort, while for q. 3 it's watching the pet

\section{March 8, 2019: third round of reading/recording themes}

-Starting with q.2 first, then 1, then 3

-Anxiety caused by behaviour, concerns about pet's health (q.2)

-Concerns about pet's health, running out of food tied to financial concerns (q.2)

-Funny response: one participant when asked "how" for q.1 answered "highly" 
-Responses to q.1 makes me reflect on my feelings towards my own pets; I don't feel like they can sense my emotions for example...maybe the relationships in this group are more significant?

April 24, 2019: Making master list of themes for each question (eliminating duplicate themes)

May 3, 2019: First attempt at creating superordinate themes (axial coding)

-How to weight frequency of themes?

-Some that don't fit anywhere yet but seem important-like waking up/coming home to pet for q.3. What does this mean?

May 8, 2019: Second round of axial coding (refining, checking codes for clarity by going back to data)

-Much less variation in 9.2 (relatively straightforward answers)

-Too many themes for q.3? More variation in answers, less similarity/repetition between participant responses so harder to group them 